\title{
Condensates from vapor made by impacts between metal-, silicate-rich bodies: Comparison with metal and chondrules in CB chondrites
}

${ }^{2}$ Also Enrico Fermi Institute, The University of Chicago.

31 


\section{ABSTRACT}

The impact hypothesis for the origin of $\mathrm{CB}$ chondrites was tested by performing

38 equilibrium condensation calculations in systems composed of vaporized mixtures of

39 projectile and target materials. When one of the impacting bodies is composed of the

40 metal from CR chondrites and the other is an $\mathrm{H}$ chondrite, good agreement can be found

41 between calculated and observed compositions of unzoned metal grains in CB chondrites

42 but the path of composition variation of the silicate condensate computed for the same

43 conditions that reproduce the metal grain compositions does not pass through the

44 measured compositions of barred olivine (BO) or cryptocrystalline (CC) chondrules in

45 the CBs. The discrepancy between measured chondrule compositions and those of

46 calculated silicates is not reduced when diogenite, eucrite or howardite compositions are

47 substituted for $\mathrm{H}$ chondrite as the silicate-rich impacting body. If, however, a CR

48 chondrite body is differentiated into core, a relatively $\mathrm{CaO}$-, $\mathrm{Al}_{2} \mathrm{O}_{3}$-poor mantle and a

$49 \mathrm{CaO}-, \mathrm{Al}_{2} \mathrm{O}_{3}$-rich crust, and later accretes significant amounts of water, a collision

50 between it and an identical body can produce the necessary chemical conditions for

51 condensation of $\mathrm{CB}$ chondrules. If the resulting impact plume is spatially heterogeneous

52 in its proportions of crust and mantle components, the composition paths calculated for

53 silicate condensates at the same $\mathrm{P}^{\text {tot }}, \mathrm{Ni} / \mathrm{H}$ and $\mathrm{Si} / \mathrm{H}$ ratios and water abundance that

54 produce good matches to the unzoned metal grain compositions pass through the fields of

$55 \mathrm{BO}$ and $\mathrm{CC}$ chondrules, especially if high-temperature condensates are fractionated in the

56 case of the CCs. While equilibrium evaporation of an alloy containing solar proportions

57 of siderophiles into a dense impact plume is an equally plausible hypothesis for

58 explaining the compositions of the unzoned metal grains, equilibrium evaporation can 
59 explain $\mathrm{CB}$ chondrule compositions only if an implausibly large number of starting

60 compositions is postulated. Kinetic models applied to co-condensing metal grains and

61 silicate droplets in a region of the plume with very similar composition, but with high

62 cooling rate and sharply declining $\mathrm{P}^{\text {tot }}$ during condensation, produce very good matches

63 to the zoning profiles of $\mathrm{Ir}, \mathrm{Ni}, \mathrm{Co}$ and $\mathrm{Cr}$ concentrations and $\mathrm{Fe}$ and $\mathrm{Ni}$ isotopic

64 compositions observed in the zoned metal grains in CB chondrites but produce very large

65 positive $\delta^{56} \mathrm{Fe}$ in the cogenetic silicate, which are not found in the chondrules.

\section{INTRODUCTION}

67

71 silicates, exotic chondrite clasts and an interstitial metal-silicate mixture thought to have

72 formed from a shock-produced melt. Mineral-chemical and isotopic characteristics

73 suggest that they are related to $\mathrm{CR}$ chondrites (Weisberg et al., 2001). The $\mathrm{CB}_{\mathrm{a}} \mathrm{s}$,

74 including Bencubbin, Weatherford and Gujba, contain $\sim 60$ volume $\%$ metal, $\mathrm{cm}$-sized

75 chondrules, $(\mathrm{Fe}, \mathrm{Ni})$ metal with $5-8 \% \mathrm{Ni}, \delta^{15} \mathrm{~N}$ up to $\sim 1000 \%$ and rare $\mathrm{Ca}-$, Al-rich

76 refractory inclusions (CAIs). The $\mathrm{CB}_{\mathrm{b}} \mathrm{s}$, including Hammadah al Hamra 237 (hereafter

77 HH), Queen Alexandra Range 94411 (hereafter QUE), MacAlpine Hills 02675 and

78 Isheyevo, contain $~ 70$ volume $\%$ metal, mm-sized chondrules, (Fe,Ni) metal with 4-15\%

$79 \mathrm{Ni}, \delta^{15} \mathrm{~N}$ up to $\sim 200 \%$ and minor amounts $(<1 \%)$ of CAIs. The $\mathrm{CH}$ chondrites, including

80 ALH85085, NWA470, PAT91456 and PCA91467, contain 20-40 volume \% metal, <100

$81 \mu \mathrm{m}$-sized chondrules, metal with $4-11 \% \mathrm{Ni}, \delta^{15} \mathrm{~N}$ up to $\sim 1500 \%$ and rare $(<0.1 \%)$ CAIs.

82 Most metal grains in $\mathrm{CB}_{\mathrm{a}} \mathrm{s}$ are homogeneous but, in $\mathrm{CB}_{b} \mathrm{~s}$, many metal grains with more 
83 than 7-8 wt\% Ni are chemically zoned, with contents of Ni and Co (Petaev et al., 2001)

84 and refractory PGEs (Campbell et al., 2001) decreasing, Cr increasing and Pd invariant

85 from cores to rims. These and more complex zoning profiles are found in metal grains in

86 CH chondrites (Petaev et al., 2007), but many of these show chemical (Campbell and

87 Humayun, 2004) and structural (Goldstein et al., 2007) characteristics of multi-stage

88 processing, and are not considered further in this work. Chondrules in $\mathrm{CB}_{\mathrm{a}} \mathrm{s}$ (Weisberg et

89 al., 2001) and $\mathrm{CB}_{b} \mathrm{~s}$ (Krot et al., 2001b) have barred olivine (BO) or cryptocrystalline

90 (CC) textures. Both types in $\mathrm{CB}_{b} \mathrm{~S}$ are strongly alkali-depleted and Mg-rich, with only

91 0.7-3.8 wt\% FeO in $\mathrm{CC}$ and 1.6-5.4 wt\% FeO in $\mathrm{BO}$ chondrules (Krot et al., 2001b). BO

92 chondrules have higher $\mathrm{CaO}+\mathrm{Al}_{2} \mathrm{O}_{3}$ contents than $\mathrm{CCs}, 10.5-22.8 \mathrm{wt} \%$ vs. $<0.1-7.9 \mathrm{wt} \%$.

93 From the covariation of $\mathrm{Co}$ and $\mathrm{Ni}$ among metal clasts in the Bencubbin $\mathrm{CB}_{\mathrm{a}}$,

94 Newsom and Drake (1979) argued that the metal phase condensed from a solar gas at a

95 total pressure, $\mathrm{P}^{\text {tot }}, \sim 10^{-4}$ bar. Meibom et al. (1999) and Petaev et al. (2001) showed that

96 the major element zoning of metal grains in $\mathrm{CH}$ and $\mathrm{CB}_{b}$ chondrites, respectively, could

97 have formed by equilibrium fractional condensation from a solar composition or

98 modestly dust-enriched nebular region at $\mathrm{P}^{\text {tot }}=10^{-4}$ bar. In later work, Petaev et al. (2003)

99 showed that diffusive modification of such zoning profiles would have occurred if the

100 grains condensed at a cooling rate of $10 \mathrm{~K} /$ day, the approximate cooling rates estimated

101 by Meibom et al. (1999) and Petaev et al. (2001). Campbell et al. (2001) demonstrated,

102 however, that fractional condensation was insufficient to explain gradual, core-to-rim

103 declines in the Ir contents of the grains, and adopted instead a model involving

104 supersaturation and kinetically controlled growth for the zoned grains in a gas of solar

105 composition at $\mathrm{P}^{\text {tot }} \sim 10^{-4}$ bar. Campbell et al. (2005) pointed out that the very slow 
106 diffusion rate of Ir in Fe-Ni alloys makes it unlikely that diffusion played a significant

107 role in producing the Ir profiles observed by them. Furthermore, the observation by

108 Alexander and Hewins (2004), Zipfel and Weyer (2007) and Richter et al. (2014) that the

109 chemical zonation is accompanied by iron and nickel isotopic zonation from isotopically

110 light compositions in the metal grain cores to heavier ones at their rims, is strong

111 evidence that this metal formed by rapid disequilibrium condensation.

112 Campbell et al. (2002) found that the bulk $\mathrm{Ir} / \mathrm{Fe}, \mathrm{Pd} / \mathrm{Fe}$ and $\mathrm{Ni} / \mathrm{Fe}$ ratios in the

113 unzoned metal grains in the $\mathrm{CB}_{\mathrm{a}}$ chondrites are consistent with condensation from a gas

114 whose partial pressures of siderophiles were $10^{7} \mathrm{x}$ higher than in a gas of solar

115 composition at $\mathrm{P}^{\text {tot }}=10^{-4}$ bar, and suggested that both the metal and the low-FeO, $\mathrm{BO}$ and

$116 \mathrm{CC}$ chondrules in the $\mathrm{CB}_{\mathrm{a}} \mathrm{s}$ condensed from a plume generated by a protoplanetary impact

117 between a metallic and a low-FeO silicate body. Based on metal-troilite quench textures

118 and volatile element depletions in the unzoned metal grains of the Gujba $\mathrm{CB}_{\mathrm{a}}$, Rubin et al.

119 (2003) proposed that they formed in the same plume as both the zoned metal grains and

120 silicate globules found in the $\mathrm{CB}_{\mathrm{b}} \mathrm{s}$, but in a portion of the cloud having relatively high

121 density compared to that for the $\mathrm{CB}_{\mathrm{b}} \mathrm{S}$, despite the contrastingly modest $\mathrm{P}^{\text {tot }}$ and dust

122 enrichment range previously suggested for the $\mathrm{CB}_{\mathrm{a}}$ grains (Newsom and Drake, 1979).

123 Krot et al. (2005) used ${ }^{207} \mathrm{~Pb}^{206} \mathrm{~Pb}$ dating to show that chondrules from both $\mathrm{CB}_{\mathrm{a}}$ and

$124 \mathrm{CB}_{\mathrm{b}}$ chondrites formed $\sim 5$ my after CAI condensation, and concluded that the

125 components of both types formed in a giant impact. Because this time-scale is

126 comparable to that for accretion and differentiation of solar system planetesimals

127 (Dauphas and Chaussidon, 2011), this opens up the possibility that one or more of the

128 impacting bodies was differentiated. Preferential sampling of the core of a differentiated 
129 planetesimal is a potential explanation for why CB chondrites are so metal-rich. Pierazzo

130 et al. (1997) showed that the shock pressures required for vaporization of metallic iron

131 are much greater than for dunite. Thus, in any impact involving metallic iron and

132 silicates, it is likely that complete vaporization of a larger mass of silicates will

133 accompany total vaporization of a metallic impactor. Fedkin and Grossman (2013)

134 proposed that porphyritic chondrules in ordinary chondrites formed by reaching vapor-

135 condensed phase equilibrium in impact-generated plumes.

136 Since a condensation origin is required to produce the elemental and isotopic

137 zoning of the zoned metal grains, and the Pd-Ir correlation of the unzoned metal grains

138 can be reproduced by condensation from a post-impact vapor cloud, this manuscript

139 seeks to determine if there is a combination of physico-chemical conditions and chemical

140 compositions of impacting bodies, including differentiated ones, that leads to

141 simultaneous condensation of the metal grains and chondrule-like clasts in CB chondrites

142 from the vapor produced in the impact.

\section{TECHNIQUE}

\section{2.1. Equilibrium condensation models}

145 Condensation of the unzoned metal grains was explored using equilibrium models

146 because their chemical compositions imply that they formed in a system containing very

147 high partial pressures of condensable elements (Campbell et al., 2002), conditions

148 conducive to establishment of gas-condensed phase equilibrium (e.g., Fedkin and

149 Grossman, 2013). The VAPORS program of Ebel and Grossman (2000) was used for all

150 equilibrium condensation calculations, and the same thermodynamic data were used as in

151 that work. Silicate liquids are non-ideal, and two activity-composition models are 
152 accessible in VAPORS: the CMAS model of Berman (1983); and the MELTS model of

153 Ghiorso and Sack (1995). The former is useful for modeling refractory condensate

154 liquids in reduced systems but it cannot be used when significant $\mathrm{FeO}$ contents become

155 stable. The latter is useful for liquids containing $\mathrm{FeO}$ and alkalis but it cannot be used for

156 modeling refractory liquids because it employs $\mathrm{CaSiO}_{3}$ as the calcium component. This

157 can lead to significant underestimation of the $\mathrm{CaO}$ contents of high-temperature liquids

158 because $\mathrm{SiO}_{2}$ is much less refractory than $\mathrm{CaO}$. Ebel and Grossman (2000) used the

159 CMAS model at high temperature but switched to the MELTS model at a temperature

160 where the liquids predicted by each model separately became close in composition. This

161 always occurred at a high enough temperature that the $\mathrm{FeO}$ content of the liquid was

162 negligible. Because of the bulk compositions, relatively high dust enrichments and high

163 pressures considered in the present work, however, the $\mathrm{FeO}$ content of the liquid

164 predicted by the MELTS model sometimes becomes significant at a higher temperature

165 than that where the compositions of the CMAS and MELTS liquids otherwise become

166 similar to one another. Except when otherwise noted, results reported in this work are

167 based exclusively on the MELTS model. Under circumstances where the CMAS model

168 is expected to give more accurate liquid compositions, i.e., at high temperatures where

169 the $\mathrm{FeO}$ content of the liquid is $<0.3 \mathrm{wt} \%$ and over which the $\mathrm{SiO}_{2}$ contents predicted by

170 the CMAS and MELTS models differ by more than $2 \mathrm{wt} \%$ absolute, those temperature

171 intervals are indicated on the Figures.

172 Although VAPORS computes the $\mathrm{Fe}, \mathrm{Ni}, \mathrm{Co}, \mathrm{Cr}$ and $\mathrm{Si}$ contents of the metal

173 phase at each temperature step, Pd and Ir are not included in the full equilibrium

174 calculation. The computation is begun at sufficiently low temperatures that they are 
175 present in only trace amounts in the metal phase, so their presence does not significantly

176 affect the proportions of major components calculated with VAPORS. The

177 concentrations of Pd and Ir in the alloy were calculated using their atomic abundances in

178 the plume, the ideal gas law, the total amount of condensed metal calculated by VAPORS

179 at each temperature, and the same data used in Campbell et al. (2001) for vapor pressures

180 of Pd and Ir and their activity coefficients in metallic Fe.

181 Campbell et al. (2002) suggested that the CB chondrites originated in a system

182 that resulted from a collision between a metallic body and a reduced (low-FeO) silicate

183 body, and this idea was tested in the present work. The metallic body was assumed to be

184 the core of a previously impacted planetesimal whose outer, lower-density layers were

185 lost due to tides, shock or shear (Asphaug et al., 2006). Because the oxygen isotopic

186 similarity between CB and CR chondrites suggests a genetic relationship between them

187 (Weisberg et al., 2001), and because the bulk metal in both chondrite types has

188 approximately solar relative abundances of refractory siderophiles, the composition of the

189 metallic body was assumed to be that of CR chondrite metal (Kong et al., 1999) in the

190 present work. Several candidates, both chondritic and differentiated, were considered for

191 the composition of the silicate-rich planetesimal. Low-FeO compositions investigated

192 were that of the average $\mathrm{H}$ chondrite fall from Kallemeyn et al. (1989) and Jarosewich

193 (1990), the average aubrite from Watters and Prinz (1979) and the terrestrial, "more

194 refractory peridotite" from Michael and Bonatti (1985). The compositions of the

195 Johnstown and Y75032 diogenites, the Kapoeta howardite and the Juvinas eucrite, all

196 taken from Mittlefehldt et al. (1998), were also investigated as candidates for higher-FeO,

197 differentiated bodies. Also considered were impacts between two CR chondrite bodies 
198 whose composition was based on that of Renazzo (Mason and Wiik, 1962). In the latter

199 calculations, the CR chondrite bodies were assumed to have been differentiated

200 previously into core, mantle and crust, and to have had various amounts of water added to

201 them.

202 The impact-generated plume was assumed to mix with residual nebular gas. The

203 persistence of gaseous disks around stars older than 3 my (Haisch et al., 2001; Bergin et $204 a l ., 2013)$ provides partial justification for this assumption. The extent to which nebular 205 gas can be entrained in an outward-expanding plume of vaporized rock is not known, but 206 the mixing ratio of such gas probably increases toward the edges of the plume. The 207 lithophile element composition of residual nebular gas was assumed to be complementary 208 to that of $\mathrm{H}$ chondrites in the calculations involving impactors of $\mathrm{H}$ chondrite, peridotite 209 and achondrite compositions, and complementary to that of the CR body and its water 210 content in collisions involving that object. In these cases, the relative abundance of an 211 element in the gas is simply the difference between its solar abundance and its relative 212 abundance in either $\mathrm{H}$ or $\mathrm{CR}$ composition, assuming that all of the $\mathrm{Si}$ was removed by the 213 condensate. The siderophile element content of the residual nebular gas was assumed to 214 be zero in all cases except for those involving $\mathrm{H}$ chondrite collisions, in which cases the 215 residual gas was assumed to have siderophile abundances complementary to those of $\mathrm{H}$ 216 chondrites. In all cases explored in this work, the system bulk compositions are so 217 heavily dominated by dust enrichment that these small differences in residual gas 218 composition have little effect on the calculations. The VAPORS program was used to 219 explore condensation from impact-generated plumes consisting of various combinations 220 of silicate and metal enrichments relative to the residual nebular gas. An example of a 
221 silicate- and metal-enriched plume composition used in this work is given in column 5 of

222 Table 1. When $6 \mathrm{wt} \%$ average $\mathrm{H}$ chondrite from column 2 is mixed with $5 \mathrm{wt} \%$ of its

223 complementary nebular gas from column 3 and $89 \mathrm{wt} \%$ CR chondrite metal from column

2244 , the resulting plume has $\mathrm{Ni} / \mathrm{H}$ and $\mathrm{Si} / \mathrm{H}$ ratios that are $1.4 \times 10^{4}$ and 300 times their solar

225 values, respectively.

\section{2.2. Kinetic condensation models}

227 Formation of the zoned metal grains was explored with a model of kinetically

228 controlled condensation because their chemical zoning indicates that they did not form at

229 equilibrium, and their isotopic zoning suggests that they formed by rapid condensation.

230 In an attempt to reproduce both the chemical and isotopic zoning of the metal grains and

231 to take into account the $\mathrm{Fe}$ and $\mathrm{Ni}$ that would have entered the coexisting silicate droplets

232 in the context of an impact plume model, the kinetic evaporation-recondensation model

233 of Fedkin et al. (2012) was used in the present work. To calculate equilibrium vapor

234 pressures, the model employs the Berman (1983) activity-composition model for CMAS

235 liquids and the MELTS model of Ghiorso and Sack (1995) for multicomponent silicate

236 liquids, and, for the present application, switches from the former to the latter when the

$237 \mathrm{FeO}$ concentration in the silicate liquid rises above $0.3 \mathrm{wt} \%$. The initial composition of

238 the silicate droplet is assumed to be that of the silicate condensate assemblage that would

239 have formed at equilibrium at the assumed nucleation temperature and the corresponding

$240 \mathrm{P}^{\text {tot }}$. Minor amounts of $\mathrm{Fe}, \mathrm{Ni}$ and $\mathrm{Cr}$ in this initial composition were subtracted out

241 before beginning the kinetic calculation. A $0.01 \mu \mu$-radius nucleus is used to begin the

242 metal grain calculation. The model employs the Hertz-Knudsen equation to compute the

243 flux of any element or isotope of interest across gas-condensed phase interfaces. In the 
244 metal alloy, the activity coefficients for $\mathrm{Fe}, \mathrm{Ni}$ and $\mathrm{Cr}$ were the same as those used by

245 Ebel and Grossman (2000), and those for Co, Pd and Ir were the ones used by Campbell

246 et al. (2001). The same isotopic fractionation factors and evaporation coefficients for

247 silicate liquid, and the same evaporation coefficients for metal were used as in Fedkin et

248 al. (2012). In that work, isotopic fractionations of Fe were computed by writing the

249 Hertz-Knudsen equation for each isotope, and the same procedure was adopted for both

$250 \mathrm{Fe}$ and $\mathrm{Ni}$ in the present work. Evaporation coefficients for $\mathrm{Ir}, \mathrm{Pd}, \mathrm{Co}$ and $\mathrm{Cr}$ in the metal

251 alloy were assumed to be equal to those of $\mathrm{Fe}$. The evaporation coefficient for $\mathrm{Cr}$ in the

252 silicate liquid was also assumed to be equal to that for Fe. The projectile and target

253 materials were assumed to have been heated instantaneously to a temperature high

254 enough that they evaporated completely and mixed with residual nebular gas. The

255 system was then allowed to cool at a constant rate, from 50-150K/hr. Using a linear

256 dependence of $\log \mathrm{P}^{\text {tot }}$ on $1 / \mathrm{T}, \mathrm{P}^{\text {tot }}$ was allowed to decline by $1-3 \log$ units in the $500 \mathrm{~K}$

257 interval following metal alloy nucleation. A system mass was considered that would

258 yield a single silicate droplet of $\sim 350 \mu \mathrm{m}$ radius when all lithophiles recondensed. Given

259 the system composition, the proportionate amount of metal was divided into a number of

260 grains that would each have an $\sim 200 \mu$ m radius when all siderophiles recondensed. In all

261 cases considered, metal alloy recondensation was assumed to have been delayed until

262 100-150K below the equilibrium condensation temperature of pure Ir, the most refractory

263 siderophile of those considered here. Nucleation of the silicate droplet was assumed to

264 have been independent of the metal grains and was delayed by various amounts, ranging

265 up to $175 \mathrm{~K}$ below the incoming temperature of the metal grains. The compositions of the

266 separate metal grains and silicate droplets were each dictated solely by the Hertz- 
267 Knudsen equation, and were not equilibrated with one another. As in Fedkin et al. (2012),

268 the Hertz-Knudsen equation was also used to exchange oxygen between the condensed

269 silicate droplet and the ambient gas, causing the internal $f_{\mathrm{O}_{2}}$ of the former to equilibrate

270 gradually with the $f_{\mathrm{O}_{2}}$ of the latter.

\section{RESULTS}

272 3.1. Equilibrium condensation from a plume made by impact between CR 273 chondrite metal and an $\mathbf{H}$ chondrite

274 3.1.1. Metal composition

275 For this series of calculations, the Pd content of the average $\mathrm{H}$ chondrite was

276 derived from the average $\mathrm{Ir}$ content of the $\mathrm{H}$ chondrites studied by Kallemeyn et al.

277 (1989) and the mean Pd/Ir ratio of those analysed by Horan et al. (2003). Shown in Fig.

2781 is the computed variation in composition of the metal alloy that would condense at

279 equilibrium over a range of $\mathrm{P}^{\text {tot }}$ from $10^{-2}$ to $10^{-8}$ bar from a plume whose proportions of

$280 \mathrm{CR}$ chondrite metal and $\mathrm{H}$ chondrite are such that the $\mathrm{Ni} / \mathrm{H}$ and $\mathrm{Si} / \mathrm{H}$ ratios are $1.4 \times 10^{4}$

281 and 300 times those of solar composition, respectively. Calculated trends of $\mathrm{Pd} / \mathrm{Fe}$ (Fig.

282 1a) and $\mathrm{Ir} / \mathrm{Fe}$ ratios (Fig. 1b) are plotted against $\mathrm{Ni} / \mathrm{Fe}$ ratios for condensate metal grains

283 and compared to solar ratios and to bulk compositions of unzoned metal grains from

284 Bencubbin, Weatherford and Gujba (Campbell et al., 2002) and zoned grains from QUE.

285 The QUE bulk compositions were calculated from Campbell et al.'s (2001) linear 286 traverses, assuming concentric zoning. The particular choice of plotted ratios is due to 287 the fact that Campbell et al. (2002) found that the unzoned metal grains are enriched in 288 both Pd and Ir relative to Fe compared to solar composition. They pointed out that redox 289 processes could not be responsible because of the significantly greater enrichment of Ir, 
290 and showed that, in systems uniformly enriched in siderophiles, Pd can only become

291 more refractory than $\mathrm{Fe}$ at very high partial pressures of siderophiles. At these $\mathrm{Ni} / \mathrm{H}$ and

$292 \mathrm{Si} / \mathrm{H}$ enrichments, it is seen that lowering $\mathrm{P}^{\text {tot }}$ causes the composition paths in Figs. 1a

293 and $1 \mathrm{~b}$ to flatten significantly, such that calculated $\mathrm{Pd} / \mathrm{Fe}$ and $\mathrm{Ir} / \mathrm{Fe}$ ratios are much lower

294 at the same $\mathrm{Ni} / \mathrm{Fe}$ ratio at the lowest $\mathrm{P}^{\text {tot }}$ than at the highest one. Because of this

295 flattening, model composition trajectories for a $\mathrm{P}^{\text {tot }}$ of $10^{-2}-10^{-3}$ bar match the bulk

296 compositions of most unzoned metal grains and miss many of those of the zoned grains.

297 Model composition trends calculated for a range of $\mathrm{P}^{\text {tot }}$ from $10^{-5}$ to $10^{-8}$ bar envelop the

298 bulk compositions of most of the zoned metal grains in Fig. 1a and about half of those on

299 Fig. 1b, but miss those of most of the unzoned grains. The combination of very high

300 siderophile enrichment and high $\mathrm{P}^{\mathrm{tot}}$ needed to fit the compositions of the unzoned grains

301 confirms the finding by Campbell et al. (2002) that very high partial pressures of

302 siderophiles are required.

303 The offsetting effects of $\mathrm{P}^{\text {tot }}$ and siderophile enrichment in fitting the

304 compositions of the unzoned grains are examined in Fig. 2 for a constant Si/H enrichment

305 of 300 relative to solar composition. At a $\mathrm{P}^{\text {tot }}$ of $10^{-3}$ bar in Figs. $2 \mathrm{a}$ and $\mathrm{b}$, it is seen that

306 the best fit to the unzoned grain compositions occurs for a Ni/H enrichment of $\sim 1.4 \times 10^{4}$

307 relative to solar composition, while at a $\mathrm{P}^{\text {tot }}$ of $10^{-2}$ bar in Figs. $2 \mathrm{c}$ and d, an equivalent fit

308 is obtained at a $\mathrm{Ni} / \mathrm{H}$ enrichment of $\sim 1.4 \times 10^{3}$. For a $\mathrm{P}^{\text {tot }}$ of $10^{-3}$ bar and a $\mathrm{Ni} / \mathrm{H}$

309 enrichment of $1.4 \times 10^{4}$ relative to solar composition, even a factor of ten variation in the

$310 \mathrm{Si} / \mathrm{H}$ enrichment, from 300-3000 relative to solar composition, is seen to have a

311 negligible effect on the fits to the unzoned metal grain compositions in Fig. 3. The lowest

312 observed $\mathrm{Pd} / \mathrm{Fe}$ and $\mathrm{Ir} / \mathrm{Fe}$ ratios in the unzoned metal grains are slightly below their 
313 respective solar ratios (Anders and Grevesse, 1989) and the lowest of those in the model

314 systems, which are at the limit of total condensation of all three elements.

315 3.1.2. Silicate composition

316 The compositions of $\mathrm{CC}$ and $\mathrm{BO}$ chondrules from $\mathrm{CB}_{\mathrm{b}}$ chondrites (Krot et al.,

317 2001a, b) are almost perfectly represented in the triangular diagram $\mathrm{CaO}+\mathrm{Al}_{2} \mathrm{O}_{3}-\mathrm{MgO}-$

$318 \mathrm{SiO}_{2}$ (Fig. 4) because the concentration of $\mathrm{FeO}$, the only non-CMAS major element oxide

319 they contain, never exceeds $5.4 \mathrm{wt} \%$. As shown in Fig. 4, the $\mathrm{CC}$ and $\mathrm{BO}$ compositions

320 lie within a range of $45-55 \mathrm{wt} \% \mathrm{SiO}_{2}$ along a roughly linear trend of increasing $\mathrm{CaO}+$

$321 \mathrm{Al}_{2} \mathrm{O}_{3}$ contents from CCs to BOs. Also plotted in Fig. 4, after subtraction of minor

322 components, including $\mathrm{FeO}$, and renormalization to $\mathrm{CaO}+\mathrm{Al}_{2} \mathrm{O}_{3}-\mathrm{MgO}-\mathrm{SiO}_{2}$, is the

323 calculated variation in bulk chemical composition of the bulk silicate assemblage that

324 would condense at equilibrium from a plume consisting of a mixture of CR chondrite

325 metal and $\mathrm{H}$ chondrite for various combinations of $\mathrm{P}^{\text {tot }}, \mathrm{Ni} / \mathrm{H}$ enrichment and $\mathrm{Si} / \mathrm{H}$

326 enrichment investigated above. As expected from solar nebular condensation models, the

327 bulk silicate condensate composition always begins its path at high concentrations of

328 refractory $\mathrm{CaO}+\mathrm{Al}_{2} \mathrm{O}_{3}$ at high temperature, heads toward the $\mathrm{MgO}$ corner as

329 temperature falls, and finally increases its content of $\mathrm{SiO}_{2}$, the most volatile of these 330 oxides.

331 All of the model curves in Fig. 4 completely miss the data points for BO

332 chondrules, passing to the low- $\mathrm{SiO}_{2}$ side of the composition field of the latter. At

333 constant $\mathrm{Ni} / \mathrm{H}$ and $\mathrm{Si} / \mathrm{H}$ enrichments of $1.4 \times 10^{4}$ and 300 , respectively, relative to solar

334 composition, the silicate composition paths move closer to the $\mathrm{BO}$ chondrule field as $\mathrm{P}^{\text {tot }}$

335 increases from $10^{-8}$ to $10^{-2}$ bar but are still far from it at $10^{-2}$ bar. At constant $\mathrm{P}^{\text {tot }}$ and 
$336 \mathrm{Ni} / \mathrm{H}$ enrichment of $10^{-3}$ bar and $1.4 \times 10^{4}$, respectively, increasing the $\mathrm{Si} / \mathrm{H}$ enrichment

337 from 300 to $3 \times 10^{3}$ relative to solar composition causes the silicate composition path to

338 move closer to the BO field but it is still far from it at $3 \times 10^{3}$. Similarly, at constant $\mathrm{P}^{\text {tot }}$

339 and $\mathrm{Si} / \mathrm{H}$ enrichment of $10^{-3}$ bar and 300 , respectively, increasing the $\mathrm{Ni} / \mathrm{H}$ enrichment

340 from $1.4 \times 10^{3}$ to $1.4 \times 10^{4}$ relative to solar composition moves the path no closer to the $\mathrm{BO}$

341 field and increasing it further to $1 \times 10^{5}$ moves the path further away. These paths all

342 converge when the bulk silicate reaches a $\mathrm{SiO}_{2}$ content between 45 and $50 \mathrm{wt} \%$, and

343 evolve with sharp $\mathrm{SiO}_{2}$ increases before crossing the $\mathrm{CaO}-, \mathrm{Al}_{2} \mathrm{O}_{3}$-rich end of the $\mathrm{CC}$

344 chondrule trend. Neither the BO nor most of the CC chondrule compositions can be

345 explained by equilibrium condensation from a gas made from a vaporized mixture of CR

346 chondrite metal, $\mathrm{H}$ chondrite and residual nebular gas.

347 3.1.3. Fractionation of refractory silicates

348 If, however, a fraction of the Ca-, Al-rich condensate that forms at high

349 temperature is removed from chemical communication with the vapor during continued

350 cooling, the resulting composition trajectory cuts across the $\mathrm{CC}$ array at progressively

351 lower $\mathrm{CaO}+\mathrm{Al}_{2} \mathrm{O}_{3}$ contents with increasing fraction removed. Although not shown on

352 Fig. 4, for the case of $\mathrm{Si} / \mathrm{H}$ and $\mathrm{Ni} / \mathrm{H}$ enrichments of 300 and $1.4 \times 10^{3}$, respectively, at

$353 \mathrm{P}^{\text {tot }}=10^{-2}$ bar, for example, the family of trajectories created by removing the condensate

354 that forms at $2060 \mathrm{~K}$ spans almost the entire range of CC chondrule compositions but the

355 predicted compositions are lower in $\mathrm{FeO}$ content than the latter. No amount of removal

356 of early condensate that forms at any temperature allows the subsequent trajectory of

357 condensate compositions to pass through the BO chondrule compositions on Fig. 4. Thus,

358 fractional condensation can yield the chemical compositions of neither the $\mathrm{CC}$ nor the 
359 BO chondrules during cooling of the vapor produced in an impact between an $\mathrm{H}$

360 chondrite and a CR metal body.

361 3.2. Equilibrium condensation from plumes made by impact between CR chondrite

362 metal and various differentiated rocks and meteorites

363 Shown in Fig. 5 are the composition trajectories of the bulk silicate fraction of the

364 equilibrium condensate in mixtures consisting of CR chondrite metal (Table 1), residual

365 nebular gas (Table 1) and various types of differentiated meteorites (Table 2). In all

366 cases shown, proportions of these components were selected to yield $\mathrm{Ni} / \mathrm{H}$ and $\mathrm{Si} / \mathrm{H}$ ratios

367 of $1.4 \times 10^{3}$ and 300 relative to solar composition, and a $\mathrm{P}^{\text {tot }}$ of $10^{-2}$ bar was used. The

368 conditions employed for Fig. 5 are thus very similar to those that produced good fits to

369 the unzoned metal grain compositions in Figs. 2c and 2d.

370 Once again, for the plume composition made from every differentiated silicate

371 component in Table 2, the bulk silicate composition is rich in $\mathrm{CaO}+\mathrm{Al}_{2} \mathrm{O}_{3}$ at high

372 temperature, and becomes more $\mathrm{MgO}$ - and $\mathrm{SiO}_{2}$-rich with falling temperature. For

373 plumes made from silicate components that are relatively low in $\mathrm{CaO}+\mathrm{Al}_{2} \mathrm{O}_{3}$ (e.g.,

374 average aubrite, peridotite and the Johnstown and Y75032 diogenites), the composition

375 paths pass to the low- $\mathrm{SiO}_{2}$ side of the $\mathrm{CB}_{\mathrm{b}}$ chondrule array, veer toward the $\mathrm{SiO}_{2}$ corner

376 and then intersect the $\mathrm{CB}_{\mathrm{b}}$ chondrule array. For plumes made from silicate components

377 that are relatively high in $\mathrm{CaO}+\mathrm{Al}_{2} \mathrm{O}_{3}$ (e.g., Kapoeta and Juvinas), the turn toward the

$378 \mathrm{SiO}_{2}$ corner is more gentle, and occurs at $\mathrm{CaO}+\mathrm{Al}_{2} \mathrm{O}_{3}$ contents that are higher than that

379 of the $\mathrm{CB}_{\mathrm{b}}$ chondrule with the highest $\mathrm{CaO}+\mathrm{Al}_{2} \mathrm{O}_{3}$. As a result, the latter curves do not

380 even intersect the $\mathrm{CB}_{\mathrm{b}}$ chondrule field. The array of chondrule compositions in $\mathrm{CB}_{\mathrm{b}}$

381 chondrites cannot be explained by equilibrium condensation from a vaporized mixture of 
382 CR chondrite metal, residual nebular gas and any of the differentiated silicates

383 investigated here.

384 3.3. Equilibrium condensation models in systems containing two vaporized silicate

385 components

386 It was shown above that equilibrium condensation of the vapor made by an

387 impact between CR chondrite metal and any one of many different chondritic and 388 differentiated silicate compositions does not reproduce the bulk chemical compositions of

$389 \mathrm{CB}_{\mathrm{b}}$ chondrules. In general, the array of chondrule compositions lies orthogonal to the

390 composition trajectory of the bulk silicate condensate from the vapor made from many of

391 the investigated materials. The higher the vaporized silicate is in its $\mathrm{CaO}+\mathrm{Al}_{2} \mathrm{O}_{3}$

392 contents, the higher is the total $\mathrm{CaO}+\mathrm{Al}_{2} \mathrm{O}_{3}$ at which the evolutionary path of its

393 condensate composition intersects the chondrule array. This suggests the possibility that

394 the chondrule compositions could be reproduced if two different silicate compositions

395 were vaporized in the impact, one with high and the other with low $\mathrm{CaO}+\mathrm{Al}_{2} \mathrm{O}_{3}$, as long

396 as the plume of vaporized silicates were spatially heterogeneous in composition. Perhaps

397 the metal-rich object was differentiated into a core, and a mantle and crust with different

398 silicate compositions from one another. In the previous sections, the metallic object was

399 assumed to have the composition of metal from CR chondrites because it fulfills the

400 requirement of having solar proportions of refractory siderophiles (Kong et al., 1999). If

401 it is assumed that the overall composition of each of the impacting objects was that of CR

402 chondrites, then the vaporized silicate component of the plume would be expected to

403 have the same isotopic composition as CR chondrites. This is an advantage, as the non-

404 metallic fraction of CR chondrites has similar oxygen and nitrogen isotopic compositions 
405 to the silicates in CB chondrites (Weisberg et al., 2001).

406 Accordingly, it was assumed that both of the impacting bodies were CR

407 chondrites that had become differentiated into a core, mantle and crust during the $\sim 5$ my

408 time interval between CAI condensation and formation of CB silicates (Krot et al., 2005).

409 The bulk Fe, Ni and Co contents of Renazzo (Mason and Wiik, 1962) were adjusted

410 relative to $\mathrm{Si}$ to yield the solar relative proportions of $\mathrm{Fe}, \mathrm{Ni}$ and Co typical of the average

411 CR chondrite (Kong et al., 1999), and the S content was adjusted downward to yield the

412 S/Fe ratio found by Rubin et al. (2003) for Gujba. The bulk Pd and Ir contents of

413 Renazzo were assumed to be in solar proportion to $\mathrm{Ni}$, as is the case for average $\mathrm{CR}$

414 metal (Kong et al., 1999). Water was assumed to have accreted onto the CR bodies

415 hypothesized here after they differentiated, but prior to their collision. The MELTS

416 model (Ghiorso and Sack, 1995) was applied to the resulting bulk chemical composition

417 of Renazzo (Table 3, column 2). First, to simulate core formation, the equilibrium metal

418 and silicate compositions were calculated at 1900K, high enough to ensure that metal and

419 silicate phases were liquid, and $\log f_{\mathrm{O}_{2}}=\mathrm{IW}-2.5$, chosen to yield silicates with small but

420 non-zero $\mathrm{FeO}$ contents. In addition, all of the Pd and Ir in Renazzo were assumed to go

421 into the CR core. Because the MELTS model does not compute the activity of $\mathrm{Cr}$ in the

422 metal alloy, the partitioning of $\mathrm{Cr}$ between metal and silicate was calculated as in Chabot

423 and Agee (2003). For the present purposes, the metal alloy was assumed to contain no

424 carbon and all of the inventory of S in the CR body but, because Chabot and Agee (2003)

425 define $f_{\mathrm{O}_{2}}$ differently from MELTS, the $f_{\mathrm{O}_{2}}$ was recalculated from Equation (1) of Chabot

426 and Agee (2003), using the mole fractions of $\mathrm{FeO}$ in the silicate melt and $\mathrm{Fe}$ in the liquid

427 metal taken from the MELTS calculation. This calculation resulted in $29.0 \mathrm{wt} \%$ core and 
42871.0 wt\% mantle, whose compositions are shown in columns 3 and 4 of Table 3,

429 respectively. The core contains $38 \%$ of the total $\mathrm{Cr}$ of the $\mathrm{CR}$ chondritic body.

430 MELTS was then applied to the CR mantle composition obtained from this

431 calculation at $1460 \mathrm{~K}$ and the same $f_{\mathrm{O}_{2}}$ in order to further differentiate the silicate into

432 crust and residual mantle. At this temperature, $80 \%$ of the composition is solid, which

433 was assumed to be the residual mantle (Table 3, column 6), and $20 \%$ is liquid, which was

434 assumed to form the crust (Table 3, column 5). The $\mathrm{CaO}+\mathrm{Al}_{2} \mathrm{O}_{3}$ content of the residual

435 mantle is $2.1 \mathrm{wt} \%$ and that of the crust is $23.8 \%$, making the residual mantle and crust

436 good candidates for the $\left(\mathrm{CaO}+\mathrm{Al}_{2} \mathrm{O}_{3}\right)$-poor and -rich components, respectively.

437 3.3.1. Condensation conditions for plumes made by impacts between differentiated CR

438 chondrite bodies

439 Condensation calculations identical to those in Sections 3.1 and 3.2 were

440 performed on vaporized mixtures of CR core, CR residual mantle, CR crust and residual

441 nebular gas compositions, all of whose compositions are in Table 3. The residual gas

442 composition in Table 3 differs from that in Table 1 because it is assumed to be

443 complementary to the bulk composition of the CR body (Table 3, column 2). In some

444 calculations, it was also assumed that water was present on the impacting bodies, and that

445 significant amounts of this component were also added to the impact plume. When water

446 was assumed to be present, the residual nebular gas was modified accordingly. Values of

$447 \mathrm{P}^{\text {tot }}$ and the $\mathrm{Ni} / \mathrm{H}$ and $\mathrm{Si} / \mathrm{H}$ enrichments selected for these calculations are based on the

448 results of Sections 3.1 and 3.2. In this model, the impact plume is assumed to be spatially

449 heterogeneous in composition, so the entire range of proportions of CR residual mantle to

450 CR crust was investigated. Shown in Table 3, column 8 is the bulk composition of a 
451 plume made from equal proportions of $\mathrm{CR}$ residual mantle and $\mathrm{CR}$ crust, having $\mathrm{Ni} / \mathrm{H}$

452 and $\mathrm{Si} / \mathrm{H}$ enrichments of $3 \times 10^{4}$ and 500 , respectively, relative to solar composition, and

453 containing no water. Shown in the final column is the composition of a plume with the

454 same characteristics, except that the total vaporized silicate was assumed to have

455 contained $20 \mathrm{wt} \%$ water. The relative weight proportions of the vaporized components

456 required to make these compositions are given in the footnotes to Table 3.

457 3.3.2. Metal condensate compositions from a plume made by impact between two

458 differentiated CR bodies

459 Model metal compositions computed over a wide range of $\mathrm{P}^{\text {tot }}$ for the plume

460 composition in column 8 of Table 3 are compared to bulk compositions of zoned and

461 unzoned metal grains in CB chondrites in Figs. 6a and 6b. A curve is also shown for a

462 case identical to the one at $10^{-2}$ bar except that the $\mathrm{Ni} / \mathrm{H}$ enrichment was changed to $3 \times 10^{3}$

463 relative to solar composition. Despite the different compositions of the plume

464 components from those in Fig. 1, the fits of the $\mathrm{Pd} / \mathrm{Fe}$ and $\mathrm{Ir} / \mathrm{Fe}$ vs $\mathrm{Ni} / \mathrm{Fe}$ curves for each

$465 \mathrm{P}^{\text {tot }}$ to the observed metal grain compositions are nearly identical in both Figures.

466 Although not shown, the curves for a case identical to the one at $10^{-3}$ bar, except that 20

467 wt\% water was added to the total vaporized silicate (Table 3, column 9), lie on top of

468 those for the anhydrous case. Furthermore, although also not shown, the positions of the

469 curves for each value of $\mathrm{P}^{\text {tot }}$ in Fig. 6 are nearly unchanged when the ratio of CR residual

470 mantle to CR crust varies from one extreme to the other. Once again, the compositions of

471 most of the unzoned grains are fit well by the curves at $\mathrm{P}^{\text {tot }}=10^{-2}$ and $10^{-3}$ bar, where their

472 equilibration temperatures imply that they condensed as liquids, while those of most of

473 the zoned grains, particularly their $\mathrm{Pd} / \mathrm{Fe}$ ratios in Fig. 6a, are fit well at $10^{-5}$ to $10^{-8}$ bar, 
474 where they condense in the solid state.

$475 \quad$ Predicted Cr vs Ni trends for the condensate metal phase are plotted in Fig. 7a for

476 some of the same conditions as in Fig. 6; namely, for a plume containing equal weight

477 proportions of vaporized $\mathrm{CR}$ residual mantle and $\mathrm{CR}$ crust, a $\mathrm{Si} / \mathrm{H}$ enrichment of 500

478 relative to solar composition and $\mathrm{Ni} / \mathrm{H}$ enrichments of $3 \times 10^{4}$ and $3 \times 10^{3}$ at $\mathrm{P}^{\text {tot }}=10^{-3}$ and

$47910^{-2}$ bar, respectively. The $10^{-3}$ bar case of Fig. 7a was explored over a wide range of CR

480 mantle/CR crust ratios, and the results are plotted in Fig. 7b. The same cases as in Figs.

$4817 \mathrm{a}$ and $7 \mathrm{~b}$ were run with the addition of $20 \mathrm{wt} \%$ water to the total silicate. In all cases,

482 the calculated $\mathrm{Ni}$ content of condensate metal falls with falling temperature, while the $\mathrm{Cr}$

483 content increases, first very gradually and then more steeply, and then decreases due to

484 the onset of co-condensation of Cr-rich spinel. In Fig. 7a, it is seen that the Cr vs Ni

485 trend for the $10^{-3}$ bar case is displaced to lower $\mathrm{Cr}$ contents than that at $10^{-2}$ bar. $\mathrm{The} \mathrm{Cr}$

486 vs Ni trends are insensitive to the relative proportions of CR crust and CR mantle (Fig.

487 7b). Curves for the cases with water added, though not shown, are nearly identical to the

488 anhydrous cases. Although the $\mathrm{Cr}$ content of the coexisting silicate increases by a factor

489 of 20 in the presence of water, the apparent insensitivity of the Cr concentration in the

490 metal to the water abundance is due to the very low absolute $\mathrm{Cr}$ concentration in the

491 silicate. Most $\mathrm{Cr}$ is still gaseous for $\mathrm{Ni}$ concentrations $>6.2 \mathrm{wt} \%$ in Fig. 7, as the

492 temperature is above $1600 \mathrm{~K}$ for this composition range.

493 For comparison in Fig. 7, bulk $\mathrm{Cr}$ and Ni contents are plotted only for subsets of

494 the same, unzoned and zoned metal grains as in the previous figures. For the unzoned

495 metal grains, this is because Campbell et al. (2002) measured Cr only in those from

496 Bencubbin. For the zoned grains, only those for which electron microprobe data were 
497 obtained were used for radial averaging, as those data were of significantly higher

498 precision than the LA-ICP-MS data (Campbell et al., 2001). For the unzoned grains, a

499 wide range of $\mathrm{Cr}$ contents exists for a given $\mathrm{Ni}$ content, so it is impossible for a single

500 curve to fit all the compositions. In Figs. $7 \mathrm{a}$ and $7 \mathrm{~b}$, it is seen that curves calculated for

501 conditions that produce good fits to the Pd and Ir data for unzoned grains in Figs. 6a and

5026 bield only fair fits to the $\mathrm{Cr} v s$. Ni data for both the unzoned and zoned grains.

503 3.3.3. Condensation of silicates from a plume made by impact between two differentiated

$504 \quad$ CR bodies

505 At conditions that produce good agreement between computed metal grain 506 compositions and those observed for unzoned metal grains in Fig. 6, the silicate

507 condensation sequence is relatively insensitive to $\mathrm{P}^{\text {tot }}$ and $\mathrm{Ni} / \mathrm{H}$ enrichment but does vary

508 in a significant way with the $\mathrm{Si} / \mathrm{H}$ enrichment. This is because, in hydrogen-containing

509 systems enriched in silicate dust, evaporation of condensed $\mathrm{MgO}$ and $\mathrm{SiO}_{2}$ releases free

510 oxygen, increasing the oxygen fugacity, $f_{\mathrm{O}_{2}}$, in proportion to the dust enrichment. This

511 is clearly seen in Fig. 8. In it, the $\log f_{O_{2}}$ relative to the iron-wüstite (IW) buffer is

512 plotted against temperature for enrichments of the $\mathrm{Si} / \mathrm{H}$ ratio relative to solar composition

513 of 300,500 and $1.5 \times 10^{3}$ at a $\mathrm{P}^{\text {tot }}$ of $10^{-3}$ bar and a $\mathrm{Ni} / \mathrm{H}$ enrichment of $3 \times 10^{4}$ for a plume

514 containing residual nebular gas, CR core and vaporized silicate that consists of equal

515 proportions of $\mathrm{CR}$ mantle and CR crust. Log $f_{\mathrm{O}_{2}}$ is always highest at high temperature,

516 reaching IW-2.95, IW-2.5 and IW-1.5 at Si/H enrichments of 300, 500 and 1500,

517 respectively. In each case, however, $\log f_{\mathrm{O}_{2}}$ decreases sharply with falling temperature

518 as free oxygen is consumed by recombination with gaseous $\mathrm{Mg}$ and $\mathrm{SiO}$ during

519 recondensation of magnesium silicates. Also shown on Fig. 8 are the $f_{\mathrm{O}_{2}}$ variations for 
520 cases identical to those shown for $\mathrm{Si} / \mathrm{H}$ enrichments of 300 and 500, except that 15 and

$52120 \mathrm{wt} \%$ water, respectively, was added to the silicates. Note that, compared to their

522 respective anhydrous cases, water addition not only increases the maximum $f_{\mathrm{O}_{2}}$ at $2100 \mathrm{~K}$

523 by $\sim 0.5 \log$ unit, but also significantly diminishes the rate of decline of $f_{\mathrm{O}_{2}}$ with

524 decreasing temperature. At $1500 \mathrm{~K}$, for example, addition of these amounts of water

525 increases the $f_{\mathrm{O}_{2}}$ by 1.1 and $1.7 \log$ units for the 300 and $500 \mathrm{Si} / \mathrm{H}$ enrichment cases,

526 respectively. Thus, impact plumes to which significant amounts of water have been

527 added remain more oxidizing during cooling than anhydrous plumes because a smaller

528 fraction of the oxidizing agent becomes sequestered in condensates.

529 3.3.4. Composition of silicate condensates from a plume made by impact between two

530 differentiated CR bodies

531 A. Models for BO Chondrule Compositions. Shown in Fig. 9a is the variation in

532 bulk chemical composition of the bulk silicate assemblage that would condense at

533 equilibrium from plume regions consisting of mixtures of CR core, CR residual mantle,

534 CR crust and residual nebular gas in which the relative contributions of CR mantle and

535 CR crust to the total silicate are varied. Conditions selected are those that give good fits

536 to the unzoned grain compositions shown in Fig. 6; namely, $\mathrm{P}^{\text {tot }}$ of $10^{-3}$ bar and constant

537 enrichments of $\mathrm{Ni} / \mathrm{H}$ and $\mathrm{Si} / \mathrm{H}$ of $3 \times 10^{4}$ and 500 , respectively, relative to solar

538 composition. For some mixtures, curves are also shown for identical cases except that 20

539 wt\% water was added to the total vaporized silicate, yielding a mass ratio of

540 water/silicate of 0.25 . As the relative contributions of CR crust and residual CR mantle

541 to the total $\mathrm{Si} / \mathrm{H}$ enrichment vary, it is seen that a family of condensation paths is

542 generated. As usual, all begin at high concentrations of $\mathrm{CaO}+\mathrm{Al}_{2} \mathrm{O}_{3}$ at high temperature, 
543 head toward the $\mathrm{MgO}$ corner as temperature falls, and finally increase their $\mathrm{SiO}_{2}$ content

544 sharply. As the CR mantle/total silicate ratio increases in the plume, however, the

545 condensation paths begin their sharp increases in $\mathrm{SiO}_{2}$ at progressively higher $\mathrm{MgO} /(\mathrm{CaO}$

$546+\mathrm{Al}_{2} \mathrm{O}_{3}$ ) ratios, causing them to intersect the band of chondrule compositions at

547 progressively lower $\mathrm{CaO}+\mathrm{Al}_{2} \mathrm{O}_{3}$ contents. As a result, $\mathrm{BO}$ chondrule compositions lie

548 along condensation paths for which the CR mantle contribution to the total silicate is

549 40-70\%, while many CC chondrule compositions lie along paths where the CR mantle

550 contribution is $75-100 \%$. Equilibrium condensation in plume regions in which the CR

551 mantle fraction of the total vaporized silicate $<40 \%$ cannot produce droplets with the

552 compositions of chondrules in CB chondrites. It is also seen that, in the vicinity of the

553 diagram where the curves cut across the array of chondrule compositions, the presence or

554 absence of added water has little effect on the trajectories.

555 The calculated variation of the $\mathrm{FeO}$ content of the bulk silicate with its $\mathrm{SiO}_{2}$

556 content is shown in Fig. $9 \mathrm{~b}$ for some of the same plume compositions and the same $\mathrm{P}^{\text {tot }}$ as

557 in Fig. 9a, as well as for a case in which the CR mantle fraction of the total silicate is only

5580.5 , the $\mathrm{Si} / \mathrm{H}$ enrichment is 1500 relative to solar composition, and there is no added

559 water. Shown for comparison are the bulk compositions of the same BO and CC

560 chondrules as in Fig. 9a. The plotted error bars are the maximum analytical errors cited

561 by Krot et al. (2001b) for their defocussed electron beam analyses; those for BO

562 chondrules are much larger than for CC chondrules.

563 Note that, when the $\mathrm{Si} / \mathrm{H}$ enrichment is 500 , the $\mathrm{CR}$ mantle fraction of the total

564 silicate is 0.5 and there is no added water, i.e. one of the cases that passes very close to

565 the main cluster of $\mathrm{BO}$ chondrule compositions in Fig. 9a, the bulk $\mathrm{FeO}$ content of the 
566 chondrule rises slightly, reaches a broad maximum of $\sim 0.7 \mathrm{wt} \%$ and then gradually

567 declines with progressively greater $\mathrm{SiO}_{2}$ content. As a result, the curve misses not only

568 the $\mathrm{FeO}$ contents of the $\mathrm{BO}$ chondrules to the low side in Fig. 9b but also the even lower

$569 \mathrm{FeO}$ contents of the $\mathrm{CC}$ chondrules. When a higher $\mathrm{Si} / \mathrm{H}$ enrichment, 1500 relative to

570 solar composition, is used to increase the $f_{\mathrm{O}_{2}}$ without adding water to the mix, the FeO

571 content of the bulk silicate increases sharply, reaches a maximum of $5 \mathrm{wt} \%$ and then

572 declines with increasing $\mathrm{SiO}_{2}$ content, passing through the composition field of the $\mathrm{BO}$

573 chondrules and ultimately entering the $\mathrm{CC}$ chondrule field as it does so. Agreement

574 between the model predictions for these conditions and the chondrule compositions is an

575 illusion, however. The decrease in $\mathrm{FeO}$ content from its peak level is not solely due to

576 dilution by condensing $\mathrm{SiO}_{2}$. In fact, $85 \%$ of the $\mathrm{FeO}$ that was present in the droplet at 40

$577 \mathrm{wt} \% \mathrm{SiO}_{2}$ undergoes reduction to metallic iron with falling temperature due to the

578 aforementioned tendency of dust-enriched systems to become much more reducing with

579 falling temperature. This process would have led to formation of several wt\% metallic

580 iron beads within these partially molten droplets. Such beads have never been observed

581 inside the chondrules of $\mathrm{CB}_{\mathrm{b}}$ chondrites.

582 As discussed in relation to Fig. 8 in Section 3.3.3, however, this process is

583 overcome by addition of water to the plume in an amount that is large in comparison to

584 the amount of oxygen released by evaporation of the silicates. In Fig. 9b, for example,

585 results are shown for three cases spanning the range of CR mantle/total silicate ratios that

586 pass through the cluster of BO chondrule compositions in Fig. 9a for a $\mathrm{Si} / \mathrm{H}$ enrichment

587 of 500 relative to solar composition and for which $20 \mathrm{wt} \%$ water was added to the total

588 vaporized silicate. The FeO content of the bulk silicate rises to $\sim 3.7 \mathrm{wt} \%$ with increasing 
$589 \mathrm{SiO}_{2}$ concentration and passes through the field of $\mathrm{BO}$ chondrule compositions without

590 any reduction of $\mathrm{FeO}$ with falling temperature.

591 Fractionation of an early, high-temperature condensate was investigated under

592 these conditions for a plume in which the CR mantle fraction of the total silicate is 0.4.

593 In this case, removal from further chemical communication with the vapor of $0-100 \%$ of

594 the Ca-, Al-rich condensate that forms at 2040K yields a family of condensation

595 trajectories that passes through the entire range of chondrule compositions on Fig. 10a

596 and also matches the compositions of the $\mathrm{BO}$ chondrules on the $\mathrm{FeO}-\mathrm{SiO}_{2}$ plot, Fig. 10b.

597 It is important to note that the agreement between predicted and observed $\mathrm{FeO}$ contents

598 on Fig. 10b occurs in the absence of $\mathrm{FeO}$ reduction and in the same temperature range,

599 1800-1850K, as the match between predicted and observed compositions on Fig. 10a.

600 Note that removal of high-temperature condensates from any plume region for which the

$601 \mathrm{CR}$ mantle fraction of the total silicate $\leq 0.4$ will produce good matches to $\mathrm{BO}$ chondrule

602 compositions but, for any mantle fraction $>0.4$, this mechanism can account only for

603 those chondrules whose $\mathrm{CaO}+\mathrm{Al}_{2} \mathrm{O}_{3}$ contents lie below the curve for that mantle fraction 604 on Fig. 9a.

605 B. Models for CC Chondrule Compositions. In Fig. 11a, curves analogous to 606 those in Fig. 9a are shown for a plume with the same components in the same proportions 607 and $\mathrm{P}^{\text {tot }}$ as in that Figure, except that the $\mathrm{Si} / \mathrm{H}$ enrichment is only 300 relative to solar 608 composition. As in Fig. 9a, it is seen that curves for cases of water addition, but in an 609 amount equal to only $15 \mathrm{wt} \%$ of the total vaporized silicates, yielding a water/silicate 610 ratio of 0.176 , are indistinguishable from analogous cases for which no water was added, 611 and that the condensation trajectories for regions of the plume in which the CR mantle 
612 fraction of the total silicate $\geq 0.75$ come closest to matching CC chondrule compositions.

613 In Fig. 11b, curves for this combination of $\mathrm{Si} / \mathrm{H}$ enrichment and water content also come

614 very close to the field of $\mathrm{CC}$ chondrules, and no reduction of $\mathrm{FeO}$ occurs along the way.

615 The only discrepancy between the model curves for these conditions and the CC

616 chondrule compositions is that the model curves are slightly low in $\mathrm{SiO}_{2}$, reaching $\sim 52$

$617 \mathrm{wt} \%$, while the chondrules range from 52 to $55 \mathrm{wt} \% \mathrm{SiO}_{2}$.

618 In Fig. 11a, for a CR mantle/total silicate ratio of 0.4, note that the BO chondrule

619 with the highest $\mathrm{CaO}+\mathrm{Al}_{2} \mathrm{O}_{3}$ lies very close to the condensation trajectory at $1750 \mathrm{~K}$. In

620 Figs. $12 \mathrm{a}$ and $12 \mathrm{~b}$, it is seen that $95-99 \%$ removal of that particular condensate

621 composition from further chemical communication with the gas generates composition

622 trajectories of lower-temperature condensates that extend to higher $\mathrm{SiO}_{2}$ contents than the

623 curves in Figs. 11a and 11b, thus passing directly through the compositions of almost all

$624 \mathrm{CC}$ chondrules in the temperature range 1710-1720K, again in the absence of reduction.

625 This is reminiscent of the scenario envisioned by Krot et al. (2001a), who proposed that

$626 \mathrm{CC}$ chondrules formed by condensation of the vapor remaining after condensation of $\mathrm{BO}$

627 chondrules, except that the high-temperature condensate that was removed contains only

$6281 \mathrm{wt} \% \mathrm{FeO}$, lower than the lowest-FeO BO chondrule.

629 Satisfactory matches to the range of chondrule compositions found in CB 630 chondrites can be attained by condensation of partially molten silicates from plume 631 regions made by impact vaporization of differentiated CR bodies. For the entire range of 632 BO chondrule compositions, the best matches found here are for $\mathrm{Si} / \mathrm{H}$ enrichments of 500 633 relative to solar composition and a mass ratio of vaporized water to vaporized silicate of 6340.25 (Fig. 9), either from regions whose CR mantle/total vaporized silicate ratios range 
635 from 0.4-0.7 or after sequestration of variable amounts of high-temperature, Ca-, Al-rich

636 condensates from an initially homogeneous region in which the CR mantle contribution

637 to the total vaporized silicate $\leq 40 \mathrm{wt} \%$. For the entire range of $\mathrm{CC}$ chondrule

638 compositions, the best matches found are for $\mathrm{Si} / \mathrm{H}$ enrichments of 300 relative to solar

639 composition and a mass ratio of water to vaporized silicate of 0.176 , following

640 sequestration of high-temperature condensates from an initially homogeneous region in

641 which the CR mantle contribution to the total vaporized silicate $\leq 40 \mathrm{wt} \%$ (Fig. 12).

642 3.4. Kinetically controlled condensation of metal grains

643 3.4.1. Elemental zoning

644 The kinetic evaporation-recondensation model of Fedkin et al. (2012) was applied

645 to a plume composition consisting of equal parts CR mantle and CR crust at various

646 combinations of $\mathrm{P}^{\text {tot }}$, cooling rate, degrees of subcooling of silicate and metal condensates,

647 and enrichments in $\mathrm{Ni} / \mathrm{H}$ and $\mathrm{Si} / \mathrm{H}$ ratios relative to solar values. Metal alloy condensate

648 compositions are relatively insensitive to the specific mixture of silicate components in

649 the impact plume, as the relative siderophile element abundances in the plume are

650 dominated by those of the CR core component. Because Ir is so much more refractory

651 than Fe, equilibrium condensate alloys will have much larger Ir enrichments in their cores

652 than are observed in the zoned metal grains. As recognized by Campbell et al. (2001),

653 the way to alleviate this problem is by supersaturation of the gas. Because these are such

654 iron-rich systems, the model silicate droplet always becomes an order of magnitude more

655 FeO-rich at relatively low $\mathrm{H}$ abundances, or metallic Fe-rich at relatively high $\mathrm{H}$

656 abundances, than chondrules in $\mathrm{CB}$ chondrites, whenever the silicate droplet is present at 
657 the temperature of appearance of the metal grains. Delaying silicate condensation to a

658 temperature well below the onset of metal condensation circumvents this problem.

659 Profiles of $\mathrm{Ir}, \mathrm{Ni}, \mathrm{Co}$ and $\mathrm{Cr}$ concentrations calculated for condensate metal grains

660 are compared to profiles of the same elements measured by Campbell et al. (2001) in

661 zoned metal grains \#1, 2 and 4 from QUE in Figs. 13a, b, c and d, respectively. The

662 geometric mid-point of each measured profile is offset from the point of highest Ir

663 concentration, so distance along the profiles was measured from the Ir peak. Because the

664 three grains differ from one another in size by $\sim 35 \%$, data are plotted against fraction of

665 the grain radius. The profiles were measured with an LA-ICP-MS spot diameter of $\sim 30$

$666 \mu \mathrm{m}$. To facilitate comparison with the analytical data, average concentrations along

667 successive $30 \mu \mathrm{m}$ segments of the continuous theoretical profiles were calculated and

668 plotted as discrete points centered $30 \mu \mathrm{m}$ apart.

669 The models illustrated in Fig. 13 are for $\mathrm{Ni} / \mathrm{H}$ and $\mathrm{Si} / \mathrm{H}$ enrichments of $2.5 \times 10^{3}$

670 and 500, respectively, relative to solar composition, and $15 \mathrm{wt} \%$ water added to the total

671 vaporized silicate. $\mathrm{P}^{\text {tot }}$ is $1.6 \times 10^{-4}$ bar at the metal nucleation temperature, but $\log \mathrm{P}^{\text {tot }}$

672 varies linearly with $1 / \mathrm{T}$ such that $\mathrm{P}^{\text {tot }}$ is either 10 times (hereafter referred to as the $\mathrm{P} / 10$

673 case) or 1000 times (the P/1000 case) lower after $500 \mathrm{~K}$ of cooling. Model parameters

674 included a cooling rate of $50 \mathrm{~K} / \mathrm{hr}$, a metal nucleation temperature of $1740 \mathrm{~K}$ and delay of

675 silicate condensation until $1665 \mathrm{~K}$. The assumed metal alloy nucleation temperature is

$676101 \mathrm{~K}$ and $146 \mathrm{~K}$ below the equilibrium condensation temperature of pure Ir (hereafter

677 referred to as $\Delta \mathrm{T}$ ) for the $\mathrm{P} / 10$ and $\mathrm{P} / 1000$ cases, respectively. It is not known whether

678 the selected rate of decline of temperature or pressure, the degree of metal supersaturation

679 or the delay of the silicate liquid nucleation temperature are appropriate for the dynamical 
680 environment of a shock-generated vapor plume expanding rapidly into a relatively low-

681 pressure ambient gas. The bulk composition of the system is seen to be close to plume

682 compositions that produce very good agreement with compositions of unzoned metal

683 grains in Fig. 6 but most of the condensation occurs at considerably lower $\mathrm{P}^{\text {tot }}$ than was

684 employed to model the unzoned grains. In the present cases, both ending at $1238 \mathrm{~K}$, it is

685 seen that both curves fit well the observed Ir and Ni profiles in Fig. 13, including the

686 sizes of the central peaks. Both cases systematically underestimate the Co concentrations,

687 but only by relatively small amounts. The P/10 case is low in Co by $12-15 \%$, and the

$688 \mathrm{P} / 1000$ case by only $<10 \%$. The models capture well the flatness that characterizes the

689 observed Cr profiles from the centers of the grains outwards to $75 \%$ of their radii, and the

690 upturn in $\mathrm{Cr}$ concentrations in the outer 25\%. The P/10 case overestimates the steepening

691 of the upturns at the edges by a large amount but the P/1000 case fits them well. The $\mathrm{Cr}$

692 concentrations at the edges are $\sim 2.7$ and $\sim 1.9$ times the central values in the P/10 and

$693 \mathrm{P} / 1000$ cases, respectively, compared to 1.6-2.1 times in the measured grains. Increasing

$694 \mathrm{P}^{\text {tot }}$ or $\mathrm{Ni} / \mathrm{H}$ enrichment by a factor of 3 or more would cause metal to nucleate above its

695 solidus, leading to homogeneous grains. Decreasing $\mathrm{P}^{\text {tot }}$ or $\mathrm{Ni} / \mathrm{H}$ enrichment would result

696 in smaller central peaks and shallower profiles for Ir, Ni and Co, as would higher cooling

697 rates and larger $\Delta \mathrm{T}$. Smaller $\Delta \mathrm{T}$ would yield higher central peaks and steeper profiles.

698 The reason for the steepening of the computed $\mathrm{Cr}$ profile at the edge of the grain

699 is that $\mathrm{Cr}$ is more volatile than $\mathrm{Fe}$, causing the $\mathrm{Cr}$ concentration to build up relative to $\mathrm{Fe}$ 700 at relatively low temperature. This steepening is much less extreme for the P/1000 case

701 than for the $\mathrm{P} / 10$ one, making the $\mathrm{P} / 1000$ case is a much better fit to the measured 702 profiles, because of the much greater rate of decline of $\mathrm{P}^{\text {tot }}$ for the $\mathrm{P} / 1000$ case. This 
703 results in a lower condensation rate at each temperature by an amount that increases with

704 falling temperature, and in less complete condensation by the time a given temperature is

705 reached than in the $\mathrm{P} / 10$ case. Because of their relative volatilities, the reduction in the

706 degree of condensation is greater for $\mathrm{Cr}$ than for Fe. At $1238 \mathrm{~K}$, for example, $99.9 \%$ of

707 the $\mathrm{Fe}$ and $99.3 \%$ of the $\mathrm{Cr}$ are condensed in the P/10 case but only $73 \%$ of the $\mathrm{Fe}$ and

$70849 \%$ of the $\mathrm{Cr}$ are condensed in the P/1000 case.

709 The evolution with temperature of the bulk chemical compositions of the zoned

710 grains was computed by integration of the compositions of their successive shells for

711 both the $\mathrm{P} / 10$ and $\mathrm{P} / 1000$ models. The resulting trajectories of $\mathrm{Pd} / \mathrm{Fe}$ and $\mathrm{Ir} / \mathrm{Fe}$ vs $\mathrm{Ni} / \mathrm{Fe}$

712 ratios are plotted on Figs. $6 a$ and $6 \mathrm{~b}$, respectively. It is seen that the composition paths

713 traverse the field of the bulk compositions of the zoned grains. At $1238 \mathrm{~K}$, the final

714 temperature of both model calculations, the bulk composition of the zoned metal grain in

715 the P/10 model reaches the point of convergence of all the plotted equilibrium curves,

716 which is the limit of total condensation of all the plotted elements. For the P/1000 model,

717 however, $\mathrm{P}^{\text {tot }}$ is so low at the end of the calculation that condensation has effectively

718 ceased before complete condensation, so the low-temperature end of the curve is the final

719 bulk composition of the grain. The bulk compositions computed for the measured grains

720 suggest that many stopped growing before total condensation of these elements.

721 3.4.2. Fe and Ni isotopic zoning

722 The kinetically produced iron and nickel isotopic zonation trends computed for

723 the model condensate metal alloy grains in Fig. 13 are shown in Figs. 14a and b, plots of

$724{ }^{56} \mathrm{Fe} /{ }^{54} \mathrm{Fe}$ and ${ }^{60} \mathrm{Ni} /{ }^{58} \mathrm{Ni}$ ratios, expressed as $\delta^{56} \mathrm{Fe}$ and $\delta^{60} \mathrm{Ni}$, respectively, vs distance

725 from the center of the grain. In this Figure, the computed, continuous isotopic profiles 
726 were discretized into $30 \mu \mathrm{m}$-sized bins by the same procedure as used above for the

727 concentration profiles. In both cases, $\delta^{56} \mathrm{Fe}$ and $\delta^{60} \mathrm{Ni}$ are -18.0 and $-16.8 \%$, respectively,

728 at the center and become progressively more positive toward the edge. Sequestration of

729 light isotopes in the interior of the grain causes $\delta^{56} \mathrm{Fe}$ and $\delta^{60} \mathrm{Ni}$ of the coexisting vapor

730 and, consequently, of the later-formed metal, to become progressively isotopically

731 heavier as the temperature falls. In the P/10 case, the grain reaches $192 \mu \mathrm{m}$ in radius,

$732 \delta^{56} \mathrm{Fe}$ and $\delta^{60} \mathrm{Ni}$ in the outermost $27 \mu \mathrm{m}$ of the grain are +20.2 and $+38.4 \%$, respectively,

733 and the bulk $\delta^{56} \mathrm{Fe}$ and $\delta^{60} \mathrm{Ni}$ of the whole grain are -1.4 and $-0.86 \%$, respectively.

734 Because less Fe condenses in the P/1000 case, the grain radius reaches only $172 \mu \mathrm{m}$,

$735 \delta^{56} \mathrm{Fe}$ and $\delta^{60} \mathrm{Ni}$ in the outermost $37 \mu \mathrm{m}$ are -4.0 and $+7.0 \%$, and the bulk $\delta^{56} \mathrm{Fe}$ and

$736 \delta^{60} \mathrm{Ni}$ of the grain are -9.4 and $-5.4 \%$, respectively. In both cases, the greater increase in

$737 \delta^{60} \mathrm{Ni}$ compared to $\delta^{56} \mathrm{Fe}$ with increasing radius is due to the fact that $\mathrm{Ni}$ is more

738 refractory than $\mathrm{Fe}$, so $\mathrm{Ni}$ is more completely condensed than $\mathrm{Fe}$ at any particular

739 temperature. Although $\mathrm{Fe}$ and $\mathrm{Ni}$ isotopic measurements are unavailable for any of the

740 grains in Fig. 13, calculated profiles have core-rim variations similar to the $\sim 16$ and

$741 \sim 15 \%$ variations in $\delta^{56} \mathrm{Fe}$ and $\delta^{60} \mathrm{Ni}$, respectively, reported by Alexander and Hewins

742 (2004) from an $\mathrm{HH}$ grain, but somewhat greater than the $\sim 10$ and $\sim 8 \%$ core-rim

743 variations in $\delta^{56} \mathrm{Fe}$ and $\delta^{60} \mathrm{Ni}$, respectively, seen by Richter et al. (2014) for grains in $\mathrm{HH}$

744 and MAC, and the 5.3\% range in $\delta^{56} \mathrm{Fe}$ found by Zipfel and Weyer (2007) in an $\mathrm{HH}$

745 grain. Richter et al. (2014) found almost no isotopic zoning in the QUE grains studied by

746 them, despite normal elemental zoning, and attributed this to condensation from a system

747 of unusually low mean molecular weight compared to that responsible for zoned metal

748 grains from the other $\mathrm{CB}_{\mathrm{b}} \mathrm{s}$ that they studied. Nevertheless, the isotopic zoning computed 
749 here for the same conditions that produced the elemental zoning in the QUE grains in Fig.

75013 is generally applicable to $\mathrm{CB}_{\mathrm{b}}$ metal grains with the same elemental zoning.

751

752

753

754 to Fe, compared to solar composition is a unique feature of metal grains in $\mathrm{CB}$ chondrites

755 (Campbell et al., 2002). It was shown above (Figs. 6, 7) that the magnitudes of these

756 enrichments, as well as the $\mathrm{Ni}$ and $\mathrm{Cr}$ contents in the unzoned grains, can be explained by

757 equilibrium condensation from a vapor with $\mathrm{P}^{\text {tot }}$ of $10^{-2}$ bar and a Ni/H enrichment

758 relative to solar composition of $3 \times 10^{3}$, or $10^{-3}$ bar and $3 \times 10^{4}$, respectively, regardless of

759 the enrichment in the $\mathrm{Si} / \mathrm{H}$ ratio or of the composition of the vaporized silicate. This

760 combination of high $\mathrm{P}^{\text {tot }}$ and solid enrichment lies clearly outside canonical solar nebular

761 conditions (Fedkin and Grossman, 2013), and led Campbell et al. (2002) to propose that

762 the unzoned metal grains and chondrules in $\mathrm{CB}_{\mathrm{a}} \mathrm{s}$ condensed from a plume of matter

763 vaporized in a protoplanetary impact. Inspection of Fig. 6 shows that, under these

764 conditions, the compositions of the most fractionated metal grains imply that they last

765 equilibrated with the gas at $\mathrm{T} \geq 1900 \mathrm{~K}$, indicating that the vapor from which they formed

766 had to reach temperatures at least this high and that the grains condensed in the molten

767 state, enhancing the likelihood that they would be homogeneous in composition. Under

768 identical physico-chemical conditions, the same metal grain compositions can result from

769 either equilibrium condensation or equilibrium evaporation. While there is evidence that

770 non-equilibrium evaporation played an important role in the evolution of CAIs

771 (Grossman et al., 2000), for example, evaporation into a hot, dense, impact-generated 
772 vapor plume like that envisioned here could have occurred under near-equilibrium

773 conditions, and just such an origin has been proposed for chondrules in ordinary

774 chondrites by Fedkin and Grossman (2013). There is little doubt that impact-generated

775 gases can reach high temperatures, high total pressures and high dust enrichments, but it

776 remains for detailed dynamical modeling to demonstrate whether the near-equilibrium

777 conditions required here could have occurred in any region within a plume of matter

778 expanding rapidly into residual nebular gas as a result of an impact between

779 planetesimals of plausible sizes, relative velocities and porosities.

780 In contrast, it was seen above that elemental and isotopic zoning profiles of the

781 zoned metal grains are best explained by rapid, non-equilibrium condensation from a

782 region of the plume whose $\mathrm{P}^{\text {tot }}$ and $\mathrm{Ni} / \mathrm{H}$ enrichment were lower than that of the region

783 where the unzoned metal grains formed, and whose $\mathrm{P}^{\text {tot }}$ fell by as much as a factor of $10^{3}$

784 over the $500 \mathrm{~K}$ interval below the nucleation temperature of the zoned grains. The

785 relatively steep drop in $\mathrm{P}^{\text {tot }}$ over this temperature range may be due to the drop in the

786 density of the gas due to $\sim 12 \%$ of its constituent atoms condensing as metal and silicate

787 over this interval, and to the consequent release of their latent heat.

$788 \quad \mathrm{Fe}$ and $\mathrm{Ni}$ isotopic zoning of the zoned metal grains, with progressively smaller

789 light isotope enrichments from cores to rims, strongly suggests that they formed by rapid

790 condensation. It was shown above that the $\mathrm{Ir}, \mathrm{Ni}, \mathrm{Co}$ and $\mathrm{Cr}$ concentration profiles and

$791 \delta^{56} \mathrm{Fe}$ and $\delta^{60} \mathrm{Ni}$ variations across the zoned metal grains are explained well by a kinetic

792 condensation model involving a vapor with a $\mathrm{Ni} / \mathrm{H}$ enrichment of $2.5 \times 10^{3}$ relative to solar

793 composition combined with a $\mathrm{P}^{\text {tot }}$ varying from $1.6 \times 10^{-4}$ bar to a factor of 10 to $10^{3}$ less

794 during metal alloy condensation. These conditions yield partial pressures of siderophile 
795 elements ranging from 400 to $4 \times 10^{5}$ times lower than those found suitable for

796 condensation of the unzoned metal grains, and result in condensation of siderophiles in

797 the solid state, a phenomenon conducive to zoning at high cooling rates. The evolution

798 of temperature with time, as well as with total pressure, is undoubtedly not the same in

799 every part of an impact plume. Thus, it is reasonable to consider that the zoned metal

800 grains could have formed in a separate, perhaps cooler and less dense, part of the plume

801 from the unzoned grains, as suggested by Rubin et al. (2003).

802 4.2. Condensation of CB silicates from an impact plume

803 Subspherical silicate inclusions are found inside some $\mathrm{CB}_{\mathrm{b}}$ metal grains

804 (Weisberg et al., 2001). Petaev et al. (2007) analysed a $30 \mu \mathrm{m}$-diameter silicate inclusion

805 inside Grain 8, a zoned metal grain from $\mathrm{HH}$. It contains an average of $0.38 \mathrm{wt} \% \mathrm{Cr}_{2} \mathrm{O}_{3}$

806 and $2.20 \mathrm{wt} \% \mathrm{FeO}$, and is enclosed between the 7.9 and $7.0 \mathrm{wt} \% \mathrm{Ni}$ contours of the host

807 metal grain. This object probably coexisted with the metal grain and was trapped within

808 it as the metal condensed. In both the P/10 and P/1000 models discussed above, silicate

809 condensation is delayed until the gas temperature is $75 \mathrm{~K}$ below the nucleation

810 temperature of metal. Over the temperature range where the metal reached the range of

811 Ni contents observed in Grain 8, 1672-1634K in the P/10 case and 1577-1408K in the

$812 \mathrm{P} / 1000$ case, the silicate droplet was $64-62 \%$ and $53-46 \%$ molten, respectively. The

$813 \mathrm{Cr}_{2} \mathrm{O}_{3}$ and $\mathrm{FeO}$ contents of the co-condensing silicate droplet are predicted to reach 0.20

814 and $2.6 \mathrm{wt} \%$, respectively, in the $\mathrm{P} / 10$ case and 0.34 and $3.8 \mathrm{wt} \%$, respectively, in the

$815 \mathrm{P} / 1000$ case. These values, especially for the P/1000 case, are in quite good agreement

816 with the measurements of Petaev et al. (2007), providing important confirmation of the 817 relevance of the model parameters. 
818 The zones of a metal grain with this range of Ni contents would be expected to

819 have $\delta^{56} \mathrm{Fe}$ of -7.5 to $+4.5 \%$, with a mean of $-2.1 \%$ in the $\mathrm{P} / 10$ case; the values for $\delta^{60} \mathrm{Ni}$

820 would be +0.12 to $+20.9 \%$, with a mean of $+9.4 \%$. In the $\mathrm{P} / 1000$ case, $\delta^{56} \mathrm{Fe}$ would

821 range from -5.4 to $+3.0 \%$, and average $-1.7 \%$; the values for $\delta^{60} \mathrm{Ni}$ would be +5.7 to

$822+17.0 \%$, and average $+11.6 \%$. Because the metal grain and silicate droplet do not

823 equilibrate with one another, they do not have the same isotopic composition. While the

824 metal grain sequesters relatively light $\mathrm{Fe}$ and $\mathrm{Ni}$ in buried shells of material, the liquid

825 droplet is assumed to homogenize its isotopic composition. Thus, while both the metal

826 grain and the coexisting silicate droplet are immersed in a common gas, the isotopic

827 composition of the grain surface differs from that of the droplet, causing differences in

828 the relative net fluxes of the isotopes. Therefore, by the time the Ni content of the metal

829 grain falls to $7 \mathrm{wt} \%, \delta^{56} \mathrm{Fe}$ of the silicate droplet is $+17.4 \%$ and $+7.6 \%$ in the $\mathrm{P} / 10$ and

$830 \mathrm{P} / 1000$ cases, respectively. Iron isotopic measurements of such silicate inclusions would

831 provide an obvious test of the model presented herein. Those objects should have highly

832 anomalous Fe isotopic compositions, distinct from those of the surrounding metal phase.

833 The bulk chemical compositions of $\mathrm{CB}$ chondrites call for their origin in

834 extremely iron-rich systems; yet, the chondrules in these meteorites are quite low in total

835 iron, containing no metallic $\mathrm{Fe}$ and only a few wt $\% \mathrm{FeO}$. The difficulty of preventing

836 buildup of large iron concentrations in silicate droplets that nucleated at temperatures

837 close to the nucleation temperature of the zoned metal grains was alluded to in Section

838 3.4.1. In such iron-rich systems as these, there is an enormous flux of iron atoms to the

839 surface of the silicate droplet, unless nucleation of the silicate occurs well below the

840 nucleation temperature of the metal grains, by which time a large fraction of the iron has 
841 become sequestered inside the latter. The problem with this mechanism is that the

842 process for sequestering iron inside the zoned metal grains causes it to have large

843 negative $\delta^{56} \mathrm{Fe}$ (e.g., Fig. 14), leading to very large positive $\delta^{56} \mathrm{Fe}$ in the residual gaseous

844 iron and thus in the iron that subsequently condenses into the silicates, as seen above.

845 Such silicates will almost always have much higher $\delta^{56} \mathrm{Fe}$ than the values reported for 846 individual Gujba chondrules, 0.01-0.90\% (Tang and Dauphas, 2012) and silicate

847 separates from Bencubbin, Gujba and Isheyevo, 0.07-0.27\%o (Zipfel and Weyer, 2007).

848 While the kinetic model presented in this work provides a reasonable explanation

849 of the chemical and isotopic composition of the zoned metal grains, the predicted $\delta^{56} \mathrm{Fe}$

850 of cogenetic silicate droplets would be quite distinct from those of the coexisting

851 chondrules in the $\mathrm{CB}$ chondrites. In conclusion, the silicate chondrules in these

852 meteorites did not form in the same region of the plume as the zoned metal grains.

853 Except for the relatively small amount of silicate that became trapped inside the zoned

854 metal, almost all silicate condensates present in the region of the plume where the zoned

855 metal grains formed became separated from the metal grains before they accreted.

856 On the other hand, it was demonstrated above that, under the conditions of 857 formation of the unzoned metal grains, partially molten silicate droplets would be

858 expected to condense with mineralogical and chemical compositions like those of CB

859 chondrules, as suggested by Campbell et al. (2002) and Rubin et al. (2003). The

860 conditions required are that the ratio of vaporized metal to vaporized silicate was $\sim 6-100$

861 times the solar ratio, that a $\mathrm{Ca}$-, Al-rich and a $\mathrm{Ca}-, \mathrm{Al}-$ poor silicate component were

862 distributed heterogeneously within this part of the impact plume, and that the weight ratio

863 of vaporized water to vaporized silicate was $\sim 0.176-0.25$. Under the same physico- 
864 chemical conditions, equilibrium evaporation would be expected to produce the same

865 silicate compositions if the droplets last equilibrated with the vapor at $\sim 1800 \mathrm{~K}$ for the BO

866 chondrules (Fig. 9) and $\sim 1600 \mathrm{~K}$ for the CCs (Fig. 11). Although such an origin in a

867 dense impact plume was proposed for chondrules in ordinary chondrites by Fedkin and

868 Grossman (2013), all chondrule compositions considered in that work could be achieved

869 by minimal evaporation of a starting material containing chondritic proportions of

870 condensables. In the case of $\mathrm{CB}$ chondrule formation by equilibrium evaporation,

871 however, a wide range of non-chondritic starting compositions would be required, lying

872 at more $\mathrm{SiO}_{2}$-rich compositions than the chondrules themselves, along extensions of the 873 condensation curves illustrated in Figs. 9 and 11.

874 Zipfel and Weyer (2007) and Tang and Dauphas (2012) measured $\delta^{56} \mathrm{Fe}$ in

875 coexisting metal and chondrule fractions separated from Bencubbin and Gujba, $\mathrm{CB}_{\mathrm{a}} \mathrm{s}$ in

876 which there are no zoned metal grains. For Bencubbin, Zipfel and Weyer (2007) found

877 that $\delta^{56} \mathrm{Fe}$ is $-0.2 \%$ and $+0.3 \%$ in metal and silicates, respectively, and in Gujba $-0.4 \%$ o

878 and $+0.1 \%$, respectively. In Gujba, Tang and Dauphas (2012) found that $\delta^{56} \mathrm{Fe}$ ranged

879 from -0.06 to $-0.17 \%$, averaging $-0.12 \%$, in three metal globules, and from $+0.01 \%$ to

$880+0.90 \%$, averaging $+0.34 \%$, in 14 silicate chondrules. $\delta^{56} \mathrm{Fe}$ is consistently negative in

881 the unzoned metal grains and consistently positive in the silicates, suggesting a

882 complementary relationship between the two phases, but the magnitudes of the mass-

883 fractionations in the unzoned metal grains are much smaller than in the zoned ones. It is

884 conceivable that, even at the relatively high partial pressures of iron envisioned for the

885 region of the impact plume where the unzoned grains formed, the speed with which the

886 metallic iron condensed could have resulted in negative $\delta^{56} \mathrm{Fe}$ excursions which were not 
887 totally erased by subsequent condensation, especially if cooling and/or accretion were

888 rapid. In the previously described models for condensation of unzoned metal grains,

889 oxidized iron in the silicates is predicted to form by direct condensation from the last

890 gaseous iron remaining after almost all of the metallic iron has condensed. If the

891 unzoned metal grains condensed with slightly negative $\delta^{56} \mathrm{Fe}$, perhaps the relatively small

892 positive values of $\delta^{56} \mathrm{Fe}$ observed in $\mathrm{CB}$ silicates are the natural result of condensation of

893 this complementary, thus slightly isotopically heavy, gaseous iron. In any event, the

894 negative $\delta^{56} \mathrm{Fe}$ of the unzoned metal grains argues against their being evaporation

895 residues.

896 4.3. Compositions of the two silicate components

897 4.3.1. Major elements

898 The advantages of assuming that the impact plume contains the vapor from two

899 contrasting silicate compositions were demonstrated in Section 3.3. When one silicate

900 component is rich and the other poor in $\mathrm{CaO}+\mathrm{Al}_{2} \mathrm{O}_{3}$, the major element compositions of

$901 \mathrm{BO}$ and $\mathrm{CC}$ chondrules can be explained by condensation from distinct regions of the

902 plume that differ in their mixing proportions of the two silicate components, as seen in

903 Figs. 9 and 11. If one silicate composition were from deep within the impacting bodies

904 and the other from shallow regions, such variation in their relative proportions within the

905 plume would be expected to result from the spatial variation of peak pressure in the

906 impact zone (Melosh, 1989).

907 While applying a one-stage equilibrium melting model to the CR chondrite body

908 may be a gross oversimplification of the complexity of small-body differentiation,

909 fractionation of the chondritic silicate portion of the body into $20 \%$ liquid and $80 \%$ 
910 residual solid at $1460 \mathrm{~K}$ does yield a relatively $\mathrm{CaO}-, \mathrm{Al}_{2} \mathrm{O}_{3}$-poor, mafic mantle,

911 consisting of olivine, orthopyroxene and spinel, and a relatively $\mathrm{CaO}-, \mathrm{Al}_{2} \mathrm{O}_{3}$-rich, felsic

912 crust, made mostly of plagioclase, clinopyroxene and silica. The computed $\mathrm{CaO} / \mathrm{Al}_{2} \mathrm{O}_{3}$

913 weight ratios of crust and residual mantle are 0.72 and 0.85 , below and above the solar

914 ratio of 0.79 , respectively. It was found in Section 3.3.4. that plume compositions that

915 yield the best matches to the compositions of CB chondrules are enriched in crust relative

916 to mantle compared to the overall CR body. For plume regions whose compositions have

917 crustal weight fractions of the total vaporized silicates of 0.3 and 0.6 , typical of those that

918 yield good matches to the compositions of $\mathrm{CC}$ and $\mathrm{BO}$ chondrules, respectively, the

$919 \mathrm{CaO} / \mathrm{Al}_{2} \mathrm{O}_{3}$ weight ratios are 0.74 and 0.73 , both below the solar ratio. Even when

920 modeling chondrule compositions by fractional removal of high-temperature condensates

921 from such regions, removal temperatures were selected such that both $\mathrm{Ca}$ and $\mathrm{Al}$ were

922 totally condensed in the refractory condensates, thus preserving these subchondritic ratios

923 in the chondrules that formed from the remaining material. Krot et al. (2001b) measured

924 bulk compositions of CB chondrules by defocused electron beam analysis. Although the

925 data are widely scattered and the uncertainties large, especially for the CC chondrules,

926 the average $\mathrm{CaO} / \mathrm{Al}_{2} \mathrm{O}_{3}$ weight ratio of the $\mathrm{BO}$ chondrules is 0.70 , in good agreement

927 with the above model value, 0.73. Because the error bar on the $\mathrm{CaO} / \mathrm{Al}_{2} \mathrm{O}_{3}$ weight ratio

928 of almost every CC chondrule overlaps the model value of 0.74 , the model is also in good

929 agreement with their compositions. Oulton et al. (2015) discussed additional chemical

930 characteristics of Gujba chondrules that indicate that the silicate component of the impact

931 plume must be from a differentiated body.

932 4.3.2. Oxygen isotopes 
933 On a graph of $\delta^{17} \mathrm{O} v s \delta^{18} \mathrm{O}$, the oxygen isotopic compositions of components of

$934 \mathrm{CR}$ chondrites plot on a unique mixing line, along which the $\delta$ increase with

935 increasing $\sigma \varepsilon \cup \lambda \alpha \varpi-$ petrographic evidence of hydrous alteration (Weisberg et al., 1993).

936 Among the analysed components, the least altered appear to be olivine and pyroxene

937 separates from Renazzo that average $\delta^{18} \mathrm{O}=-0.18$ and $\delta^{17} \mathrm{O}=-2.4 \%$. Oxygen isotopic

938 compositions of bulk CB chondrites form a linear array just below the CR mixing line

939 (Weisberg et al., 2001), and the average whole-rock analysis of four of them, $\delta^{18} \mathrm{O}=1.7$

940 and $\delta^{17} \mathrm{O}=-1.4 \%$, is only slightly displaced from the Renazzo separates. This similarity

941 in oxygen isotopic composition would be expected if the two colliding bodies envisioned

942 here were of CR chondrite composition. This is because, in the plume composition

943 shown in column 9 of Table 3, for example, 67.1 atomic $\%$ of the oxygen derives from

944 vaporized CR silicates, and $32.6 \%$ from CR water. Although 0.3 atomic $\%$ of the oxygen

945 comes from the residual nebular gas, it is difficult to assess what the oxygen isotopic

946 composition of such matter would have been five million years after CAI condensation.

947 In Section 3.3.4., it was found that one way of generating CB chondrule

948 compositions is by sequestering from further reaction with the gas early, high-

949 temperature condensates that lie along the $\mathrm{CaO}-, \mathrm{Al}_{2} \mathrm{O}_{3}$-rich parts of the condensation

950 trajectories in Figs. 10a and 11a. It is important to note that, along these paths, the $\mathrm{MgO}$

951 content remains low, $\sim 1$ wt $\%$, while the $\mathrm{SiO}_{2}$ content rises from $\sim 10$ to 30 wt $\%$.

952 Although CAIs are rare to minor constituents of CB chondrites, those analysed by Krot $e t$

953 al. (2001b) have much lower $\mathrm{SiO}_{2} / \mathrm{MgO}$ ratios than the model plume condensates. As a

954 result, none of the sequestered high-temperature condensates have major element

955 compositions like any of the CB CAIs. Furthermore, the sequestered objects would have 
956 oxygen isotopic compositions derived from those of CR chondrites, while the oxygen

957 isotopic compositions of the CB CAIs lie along the CCAM line (Krot et al., 2001b).

958 These CAIs are therefore general solar nebular material, not cogenetic with the

959 chondrules in these meteorites, whose oxygen isotopic compositions lie just below the

960 CR mixing line, resolvably above the CCAM line (Weisberg et al., 2001). Any Ca-, Al-

961 rich condensates that were removed from further interaction with plume gases at high

962 temperature were apparently not accreted into the CB chondrites.

963 4.3.3. Rare earth elements

964 Given the mineralogical contrast between CR crust and mantle, it is likely that the

965 REE would have been nearly quantitatively extracted into the liquid that formed the crust,

966 which would then have a flat, chondrite-normalized REE pattern. Thus, in a collision

967 between two differentiated CR chondrite bodies, a plume made only of vaporized CR

968 crust would be expected to have a flat REE pattern, and any addition of vaporized CR

969 residual mantle to the plume would simply dilute the abundances. In this way, the

970 absolute REE abundances in a region of the plume would have decreased with increasing

971 proportions of CR mantle therein. Because the REE are expected to have condensed

972 totally along with $\mathrm{CaO}$ and $\mathrm{Al}_{2} \mathrm{O}_{3}$ at high temperature before most of the $\mathrm{MgO}$ and $\mathrm{SiO}_{2}$,

973 chondrules that condensed from the plume would be expected to have flat REE patterns

974 with enrichments that correlate with their contents of $\mathrm{CaO}+\mathrm{Al}_{2} \mathrm{O}_{3}$. This is in agreement

975 with REE measurements of CC and BO chondrules (Krot et al., 2001b).

\section{4.4. Relative Proportions of Vaporized Components}

977 The requirement that significant water be present in the impact plume was

978 discussed in Section 3.3.4. In Fig. 9b, it was shown that, if a plume is enriched in 
979 vaporized, anhydrous $\mathrm{CR}$ silicates to a $\mathrm{Si} / \mathrm{H}$ ratio of 1500 relative to solar composition,

980 the $\mathrm{FeO}$ content of the silicate droplets that condense from it at high temperature is

981 comparable to the highest $\mathrm{FeO}, 5.4 \mathrm{wt} \%$, seen in $\mathrm{CB}$ chondrules. It was also shown that,

982 upon cooling, much of that $\mathrm{FeO}$ undergoes reduction to metallic Fe, beads of which have

983 never been observed within CB chondrules. For a plume with the same $\mathrm{Si} / \mathrm{H}$ enrichment,

984 however, if the silicates contain sufficient water to prevent reduction of $\mathrm{FeO}$, the $\mathrm{FeO}$

985 content of the droplets would be much higher than found in CB chondrules. Calculations

986 like those used for Fig. 9b, but for many combinations of $\mathrm{Si} / \mathrm{H}$ enrichments and water

987 contents, were used to constrain the range of possible $\mathrm{Si} / \mathrm{H}$ enrichments that would

988 reproduce the $\mathrm{FeO}$ contents of $\mathrm{CB}$ chondrules. It was found by trial and error that, to

989 constrain the $\mathrm{FeO}$ content of the condensing silicate droplet to $\leq 5.4 \mathrm{wt} \%$, the maximum

$990 \mathrm{Si} / \mathrm{H}$ enrichment is 600 relative to solar composition for any plume with sufficient water

991 in it to prevent subsequent reduction of the FeO. The highest bulk water content reported

992 by Weisberg et al. (1993) for CR chondrites is equivalent to $10 \mathrm{wt} \%$ of the silicate

993 fraction. At the maximum $\mathrm{Si} / \mathrm{H}$ enrichment needed to match the highest $\mathrm{FeO}$ content of

994 CB chondrules, the water content of the vaporized silicates needed to prevent reduction is

$99520 \mathrm{wt} \%$, within a factor of two of this amount. Due to its much greater volatility than the

996 other vaporized components, water may have been evaporated from a much greater

997 volume of the matter heated by the impact, leading to enhancement of the water

998 abundance in the plume from which the CB chondrites condensed. If $20 \mathrm{wt} \%$ is the

999 maximum water content considered reasonable for the vaporized silicate, the minimum

$1000 \mathrm{Si} / \mathrm{H}$ enrichment that allows a match to the lowest $\mathrm{FeO}$ contents, $\sim 0.7 \mathrm{wt} \%$, of $\mathrm{CB}$

1001 chondrules in the absence of $\mathrm{FeO}$ reduction is 300 relative to solar composition. 
Unless some residual nebular gas mixes with the vaporized silicate, results of the

1003 present calculations would be very similar to the infinite dust enrichment cases of Fedkin

1004 and Grossman (2013). Plume condensates from vaporized anhydrous silicates and

1005 vaporized silicates containing $20 \mathrm{wt} \%$ water would resemble those from vaporized $\mathrm{H}^{\prime}$

1006 and CI dust, respectively, in that work. At high temperature, such condensate droplets

1007 would contain $\sim 15$ and $\sim 35 \mathrm{wt} \% \mathrm{FeO}$, respectively. In the case of anhydrous dust, a very

1008 large fraction of the initial $\mathrm{FeO}$ would undergo reduction with falling temperature. In the

1009 case of the water-containing dust, the $\mathrm{FeO}$ content would remain very high. In neither

1010 case would the resulting droplets resemble CB chondrules.

1011 The tradeoff between $\mathrm{P}^{\mathrm{tot}}$ and $\mathrm{Ni} / \mathrm{H}$ enrichment was discussed in Section 3.1.1. in

1012 the context of fitting the $\mathrm{Pd} / \mathrm{Fe}$ and $\mathrm{Ir} / \mathrm{Fe} v s \mathrm{Ni} / \mathrm{Fe}$ data for the unzoned metal grains. In

1013 Figs. 6a and 6b, equivalent fits to the data points are achieved for a $\mathrm{P}^{\text {tot }}$ and $\mathrm{Ni} / \mathrm{H}$

1014 enrichment of $10^{-2}$ bar and $3 \times 10^{3}$ relative to solar composition, respectively, as for the

1015 combination of $10^{-3}$ bar and $3 \times 10^{4}$. If $\mathrm{P}^{\text {tot }}$ were only $10^{-4}$ bar, a gigantic $\mathrm{Ni} / \mathrm{H}$ enrichment

1016 of $3 \times 10^{5}$ would be required and, if a more modest $\mathrm{Ni} / \mathrm{H}$ enrichment of 300 prevailed, a

1017 more substantial plume $\mathrm{P}^{\text {tot }}$ of $10^{-1}$ bar would be required for equivalent fits. Choosing an

1018 intermediate range of $\mathrm{P}^{\text {tot }}, 10^{-2}$ to $10^{-3}$ bar, as the most reasonable leads to a $\mathrm{Ni} / \mathrm{H}$

1019 enrichment in the range of $3 \times 10^{3}$ to $3 \times 10^{4}$ relative to solar composition.

1020 The $\mathrm{Si} / \mathrm{H}$ enrichments derived above for $\mathrm{CB}$ chondrule formation, 300-600

1021 relative to solar composition, could have coexisted in the same plume region with the

1022 optimum Ni/H enrichments needed to account for the compositions of the unzoned metal

1023 grains. Total condensation of a plume region with $\mathrm{Ni} / \mathrm{H}$ enrichments of $3 \times 10^{3}$ and $3 \times 10^{4}$

1024 would lead to end products containing 64-78 and 94-97 wt\% metal, respectively. It is 
1025 interesting that independent assessments of the $\mathrm{Si} / \mathrm{H}$ and $\mathrm{Ni} / \mathrm{H}$ enrichments, if

1026 characteristic of the same plume region, lead to condensation products with metal

1027 contents so similar to the 81 to $87 \mathrm{wt} \%$ estimates derived from literature reports of the

1028 volume $\%$ of metal in the $\mathrm{CB}_{\mathrm{a}}$ and $\mathrm{CB}_{\mathrm{b}}$ chondrites, respectively. This suggests that the

1029 unzoned metal grains and chondrules condensed from a common region of the plume.

1030 When differentiated, the model CR bodies considered in this work consist of 29.0

$1031 \mathrm{wt} \%$ core and $71.0 \mathrm{wt} \%$ silicate. The latter, in turn, is differentiated into $80.0 \mathrm{wt} \%$

1032 residual mantle and $20.0 \mathrm{wt} \%$ crust. The relative proportions of core and silicate are

1033 quite distinct from those found here for co-condensation of unzoned metal grains and

1034 chondrules, i.e., a very large oversampling of core relative to silicate occurred. While the

1035 best matches to $\mathrm{CC}$ chondrule compositions are for CR mantle fractions of the total

1036 silicate as high as 0.75 , similar to the mantle fraction of the total silicate in the CR body,

1037 some BO chondrule compositions require mantle fractions at least as low as 0.40 , which

1038 represents a significant enrichment of the plume in crust relative to mantle.

1039 Because of the variation of impact temperatures and pressures with depth, and

1040 differences in material properties between metal and silicates, these components may not

1041 have been vaporized in the same proportions as existed in the pre-impact bodies.

1042 Furthermore, during an early solar system period of high collision frequencies among

1043 differentiated protoplanets, many of these objects may have been totally destroyed by

1044 physical disruption and vaporization, and then reconstituted by recondensation and

1045 reaccretion. Such objects would have undergone dramatic changes in their bulk

1046 compositions as a result. Asphaug et al. (2006) and Leinhardt and Stewart (2012)

1047 discussed particular mechanisms for stripping of surface layers, particularly during 
1048 grazing impacts, and Yang et al. $(2007 ; 2010)$ presented evidence from specific iron

1049 meteorite types for near-total removal of silicate mantles from planetary cores by

1050 protoplanetary collisions. Perhaps one or both of the differentiated CR bodies envisioned

1051 here underwent earlier collisions that resulted in stripping of their original silicates and

1052 reaccretion of small amounts of their original mantle and crustal material in different

1053 proportions from those originally present. Marty et al. (2010) showed that energetic

1054 impacts continued to affect Bencubbin up until $4.2 \mathrm{Ga}$ ago, long after recondensation and

1055 reaccretion of its components.

\section{4.5. Uniqueness of Mixing Components}

1057 In this work, conditions were found that yield the chemical and isotopic

1058 compositions of $\mathrm{CB}$ metal and silicates by condensation from a plume generated by

1059 impact vaporization of two differentiated bodies of CR chondrite composition. If the

1060 oxygen and nitrogen isotopic compositions of CB chondrites are ignored, however, it is

1061 apparent that the chemical compositions of CB metal and silicates can be accounted for in

1062 plumes generated by impacts involving bodies of compositions other than CR chondrites.

1063 In particular, a metal core from any body with chondritic proportions of non-volatile

1064 siderophiles could serve as a metallic impactor, as long as core separation occurred at

1065 sufficiently low $f_{\mathrm{O}_{2}}$ that it contained several tens of $\%$ of the planetary $\mathrm{Cr}$ inventory, for

1066 plumes with Ni/H enrichments of the magnitude envisioned here. Furthermore, any body

1067 with a $\mathrm{Ca} / \mathrm{Al}$ ratio and relative proportions of REE that are nearly chondritic, and that

1068 differentiated into a mantle and a crust into which $\mathrm{Ca}, \mathrm{Al}$ and REE were nearly totally

1069 extracted, could serve as a silicate impactor. In order to satisfy the additional oxygen and

1070 nitrogen isotopic constraints, however, CR chondrite silicates were selected for the 
1071 silicate component of the plume in this study.

1072

1073

1074 mantle and $\mathrm{CaO}-, \mathrm{Al}_{2} \mathrm{O}_{3}$-rich crust, and later accretes significant amounts of water, a

1075 collision between it and an identical body can produce impact vapor with an appropriate

1076 chemical composition for condensation of $\mathrm{CB}$ metal grains and chondrules. Good 1077 matches to the compositions of the unzoned metal grains in CB chondrites are obtained

1078 by equilibrium condensation or evaporation in a region of the plume having $\mathrm{P}^{\text {tot }}$ and an 1079 enrichment in $\mathrm{Ni} / \mathrm{H}$ relative to solar composition of $10^{-2}$ bar and $3 \times 10^{3}$, respectively, or $108010^{-3}$ bar and $3 \times 10^{4}$, respectively. From this gas, good matches to the compositions of BO 1081 chondrules are obtained when the $\mathrm{Si} / \mathrm{H}$ enrichment is 500, the water abundance is $20 \mathrm{wt} \%$ 1082 and the mantle component is either $40-70 \mathrm{wt} \%$ of the total vaporized silicate or if 1083 refractory condensate fractionation occurs with a mantle fraction $\leq 40 \%$. CC chondrule 1084 compositions arise from regions where the $\mathrm{Si} / \mathrm{H}$ enrichment is 300 , the water abundance 1085 is $15 \mathrm{wt} \%$ of the total vaporized silicate and refractory condensate separation occurs 1086 where the mantle fraction of the total silicate $\leq 40 \mathrm{wt} \%$. An origin for the chondrules by 1087 equilibrium evaporation is unlikely due to the wide range of starting compositions that 1088 would be required. Kinetic models applied to co-condensing metal grains and silicate 1089 droplets in a region of the plume with very similar composition, but with high cooling 1090 rate and sharply declining $\mathrm{P}^{\text {tot }}$ during condensation, produce very good matches to the 1091 zoning profiles of $\mathrm{Ir}, \mathrm{Ni}, \mathrm{Co}$ and $\mathrm{Cr}$ concentrations and $\mathrm{Fe}$ and $\mathrm{Ni}$ isotopic compositions 1092 that are observed in the zoned metal grains in CB chondrites, but produce very large 1093 positive $\delta^{56} \mathrm{Fe}$ and $\delta^{60} \mathrm{Ni}$ in the cogenetic silicate. Because such isotopic fractionations 
1094 are not found in CB chondrules, the latter are most likely cogenetic with the unzoned

1095 metal grains. Condensation from a plume of impact vapor is a viable hypothesis for

1096 making all the metal grains and chondrules of CB chondrites, but whether the required

1097 physico-chemical conditions and their spatial variation can be attained in such a setting

1098 must be addressed by detailed dynamical modeling.

1099 Acknowledgments-We thank N. Artemieva, F. Ciesla, B. Johnson and H. J. Melosh for

1100 insight into impact processes, and A. S. Colman, N. Dauphas, and M. Weisberg for

1101 helpful discussions. Reviews by M. Petaev and an anonymous reviewer led to important

1102 improvements to the paper. This work was supported by funds from the National

1103 Aeronautics and Space Administration under grants NNX08AE06G and NNX13AE73G

1104 to LG and NNX13AI06G to MH, as well as funds from the National Science Foundation

1105 under grant EAR-1427123 to AJC.

1106

1107

\section{REFERENCES}

1108 Alexander C. M. O’D. and Hewins R. H. (2004) Mass fractionation of Fe and Ni isotopes

1109 in metal in Hammadah al Hamra 237 (abstract). Meteoritics Planet. Sci. 39, A13.

1110 Anders E. and Grevesse N. (1989) Abundances of the elements: meteoritic and solar.

1111 Geochim. Cosmochim. Acta 53, 197-214.

1112 Asphaug E., Agnor C. B., and Williams Q. (2006) Hit-and-run planetary collisions.

1113 Nature, 439, 155-160.

1114 Bergin E. A., Cleeves L. I., Gorti U., Zhang K., Blake G. A., Green J. D., Andrews S. M.,

1115 Evans II N. J., Henning T., Öberg K., Pontoppidan K., Qi C., Salyk C., van Dishoeck E.

1116 F. (2013) An old disk still capable of forming a planetary system. Nature, 493, 644-646.

1117 Berman R. G. (1983) A Thermodynamic Model for Multicomponent Melts, with

1118 Application to the System $\mathrm{CaO}-\mathrm{MgO}-\mathrm{Al}_{2} \mathrm{O}_{3}-\mathrm{SiO}_{2}$. Ph.D. dissertation, Univ. of British 1119 Columbia. 
1120 Campbell A. J. and Humayun M. (2004) Formation of metal in the CH chondrites ALH

112185085 and PCA 91467. Geochim. Cosmochim. Acta 68, 3409-3422

1122 Campbell A. J., Humayun M., Meibom A., Krot A. N., and Keil K. (2001) Origin of

1123 zoned metal grains in the QUE94411 chondrite. Geochim. Cosmochim. Acta 65, 163-

1124180.

1125 Campbell A. J., Humayun M. and Weisberg M.K. (2002) Siderophile element constraints 1126 on the formation of metal in the metal-rich chondrites Bencubbin, Weatherford, and

1127 Gujba. Geochim. Cosmochim. Acta, 66, 647-660.

1128 Campbell A. J., Humayun M. and Weisberg M. K. (2005) Compositions of unzoned and

1129 zoned metal in the $\mathrm{CB}_{\mathrm{b}}$ chondrites Hammadah al Hamra 237 and Queen Alexandra

1130 Range 94627. Meteoritics Planet. Sci. 40, 1131-1148.

1131 Chabot N. L. and Agee C. B. (2003) Core formation in the Earth and Moon: New

1132 experimental constraints from V, Cr, and Mn. Geochim. Cosmochim. Acta, 67, 207711332091.

1134 Dauphas N. and Chaussidon M. (2011) A perspective from extinct radionuclides on a 1135 young stellar object: The sun and its accretion disk. Ann. Rev. Earth Planet. Sci., 39, 1136 351-386.

1137 Ebel D. S. and Grossman L. (2000) Condensation in dust-enriched systems. Geochim. 1138 Cosmochim. Acta 64, 339-366.

1139 Fedkin A. V. and Grossman L. (2013) Vapor saturation of sodium: Key to unlocking the 1140 origin of chondrules. Geochim. Cosmochim. Acta 112, 226-250. 
1141 Fedkin A. V., Grossman L., Ciesla F. J. and Simon S. B. (2012) Mineralogical and

1142 isotopic constraints on chondrule formation from shock wave thermal histories. Geochim.

1143 Cosmochim. Acta 87, 81-116.

1144 Ghiorso M. S. and Sack R. O. (1995) Chemical mass transfer in magmatic processes IV.

1145 A revised and internally consistent thermodynamic model for the interpolation and

1146 extrapolation of liquid-solid equilibria in magmatic systems at elevated temperatures and

1147 pressures. Contrib. Mineral. Petrol. 119, 197-212.

1148 Goldstein J. I., Jones R. H., Kotula P. G. and Michael J. R. (2007) Microstructure and

1149 thermal history of metal particles in $\mathrm{CH}$ chondrites. Meteoritics Planet. Sci. 42, 913-933.

1150 Grossman L., Ebel D. S., Simon S. B., Davis A. M., Richter F. M. and Parsad N. M.

1151 (2000) Major element chemical and isotopic compositions of refractory inclusions in C3

1152 chondrites: The separate roles of condensation and evaporation. Geochim. Cosmochim.

1153 Acta 64, 2879-2894.

1154 Haisch Jr. K. E., Lada E. A. and Lada C. J. (2001) Disk frequencies and lifetimes in

1155 young clusters. Astrophys. J. 553, L153-L156.

1156 Horan M. F., Walker R. J., Morgan J. W., Grossman J. N. and Rubin A. E. (2003) Highly

1157 siderophile elements in chondrites. Chem. Geol. 196, 5-20.

1158 Jarosewich E. (1990) Chemical analyses of meteorites: A compilation of stony and iron

1159 meteorite analyses. Meteoritics 25, 323- 337.

1160 Kallemeyn G. W., Rubin A. E., Wang D. and Wasson J. T. (1989) Ordinary chondrites:

1161 Bulk compositions, classification, lithophile-element fractionations, and composition-

1162 petrographic type relationships. Geochim. Cosmochim. Acta 53, 2747-2767.

1163 Kong P., Ebihara M., and Palme H. (1999) Distribution of siderophile elements in CR 
1164 chondrites: Evidence for evaporation and recondensation during chondrule formation.

1165 Geochim. Cosmochim. Acta 63, 2637-2652.

1166 Krot A. N., Meibom A., Russel S.S., Alexander C.M.O'D, Jeffries T.E., and Keil K.

1167 (2001a). A new astrophysical setting for chondrules formation. Science, 291, 1776-1779.

1168 Krot A. N., McKeegan K. D., Russell S. S., Meibom A., Weisberg M. K., Zipfel J., Krot

1169 T. V., Fagan T. J. and Keil K. (2001b). Refractory calcium-aluminum-rich inclusions

1170 and aluminum-diopside-rich chondrules in the metal-rich chondrites Hammadah al

1171 Hamra 237 and Queen Alexandra Range 94411. Meteoritics Planet. Sci. 36, 1189-1216.

1172 Krot A. N., Amelin Yu., Cassen P. and Meibom A. (2005) Young chondrules in CB

1173 chondrites from a giant impact in the early Solar System. Nature, 436, 989-992.

1174 Leinhardt Z. M. and Stewart S. T. (2012) Collisions between gravity-dominated bodies. I.

1175 Outcome regimes and scaling laws. Astrophys. J. 745, 79-105.

1176 Marty B., Kelley S. and Turner G. (2010) Chronology and shock history of the

1177 Bencubbin meteorite: A nitrogen, noble gas, and Ar-Ar investigation of silicates, metal

1178 and fluid inclusions. Geochim. Cosmochim. Acta 74, 6636-6653.

1179 Mason B. and Wiik H. B. (1962) The Renazzo meteorite. Amer. Mus. Novitates 2106.

1180 Meibom A., Petaev M. I., Krot A. N., Wood J. A. and Keil K. (1999) Primitive FeNi

1181 metal grains in $\mathrm{CH}$ carbonaceous chondrites formed by condensation from a gas of solar

1182 composition. J. Geophys. Res. 104, 22053-22059.

1183 Melosh H. J. (1989) Impact Cratering: A Geological Process. Oxford University Press, $1184256 \mathrm{pp}$. 
1185 Michael P. J. and Bonatti E. (1985) Peridotite composition from the North Atlantic:

1186 regional and tectonic variations and implications for partial melting. Earth Planet. Sci.

1187 Lett., 73, 91-104.

1188 Mittlefehldt D. W., McCoy T. J., Goodrich C. A., Kracher A. (1998) Non-chondritic

1189 meteorites from asteroidal bodies.

1190 Newsom H. E. and Drake M. J. (1979) The origin of metal clasts in the Bencubbin

1191 meteoritic breccia. Geochim. Cosmochim. Acta 43, 689-707.

1192 Oulton J., Humayun M., Fedkin A. V. and Grossman L. (2015) Chemical evidence from

1193 Gujba for differentiation and evaporation/recondensation processes during the CB-impact

1194 event. Lunar Planet. Sci. XLVI, \#1590.

1195 Petaev M. I., Meibom A., Krot A.N., Wood J.A., and Keil K. (2001) The condensation 1196 origin of zoned metal grains in Queen Alexandra Range 94411: Implications for the 1197 formation of the Bencubbin-like chondrites. Meteoritics Planet. Sci., 36, 93-106.

1198 Petaev M. I., Wood J. A., Meibom A., Krot A. N. and Keil K. (2003) The ZONMET

1199 thermodynamic and kinetic model of metal condensation. Geochim. Cosmochim. Acta 67, $1200 \quad 1737-1751$.

1201 Petaev M. I., Ivanova M. A., Krot A. N., Meibom A. and Jacobsen S. B. (2007) Different 1202 zoning patterns in metal grains from the $\mathrm{CH}$ and $\mathrm{CB}_{\mathrm{b}}$ chondrites: evidence for a 1203 complicated cooling history of their nebular source regions. Lunar Planet. Sci. XXXVIII, $1204 \quad \# 1641$.

1205 Pierazzo E., Vickery A. M. and Melosh H. J. (1997) A reevaluation of impact melt 1206 production. Icarus 127, 408-423. 
1207 Richter F. M., Huss G. R. and Mendybaev R. A. (2014) Iron and nickel isotopic

1208 fractionation across metal grains from three $\mathrm{CB}_{\mathrm{b}}$ meteorites. Lunar Planet. Sci. XLV, $1209 \# 1346$.

1210 Rubin A. E., Kallemeyn G. W., Wasson J. T., Clayton R. N., Mayeda T. K., Grady M., 1211 Verchovsky A. B., Eugster O. and Lorenzetti S. (2003) Formation of metal and silicate 1212 globules in Gujba: a new Bencubbin-like meteorite fall. Geochim. Cosmochim. Acta 67, $1213 \quad 3283-3298$.

1214 Tang H. and Dauphas N. (2012) Abundance, distribution, and origin of ${ }^{60} \mathrm{Fe}$ in the solar 1215 protoplanetary disk. Earth Planet. Sci. Lett. 359-360, 248-263.

1216 Watters T. R. and Prinz M. (1979) Aubrites: Their origin and relationship to enstatite 1217 chondrites. In Proc. 10 $0^{\text {th }}$ Lunar Planet. Sci. Conf., Lunar Planet. Inst., Houston, TX, pp. 1218 1073-1093.

1219 Weisberg M. K., Prinz M. and Nehru C. E. (1988) Petrology of ALH85085: a chondrite 1220 with unique characteristics. Earth Planet. Sci. Lett. 91, 19-32.

1221 Weisberg M. K., Prinz M. and Nehru C. E. (1990) The Bencubbin chondrite breccia and 1222 its relationship to CR chondrites and the ALH85085 chondrite. Meteoritics 25, 269-279.

1223 Weisberg M. K., Prinz M., Clayton R. N. and Mayeda T. K. (1993) The CR (Renazzo-

1224 type) carbonaceous chondrite group and its implications. Geochim. Cosmochim. Acta 57, $1225 \quad 1567-1586$.

1226 Weisberg M. K., Prinz M., Clayton R.N., Mayeda T.K., Sugiura N., Zashu S. and Ebihara 1227 M. (2001) A new metal-rich chondrite grouplet. Meteoritics Planet. Sci. 36, 401-418.

1228 Yang J., Goldstein J.I. and Scott E.R.D. (2007) Iron meteorite evidence for early 1229 formation and catastrophic disruption of protoplanets. Nature 446, 888-891. 
1230 Yang J., Goldstein J.I., Michael J.R., Kotula P.G. and Scott E.R.D. (2010) Thermal

1231 history and origin of the IVB iron meteorites and their parent body. Geochim.

1232 Cosmochim. Acta 74, 4493-4506.

1233 Zipfel J. and Weyer St. (2007) In situ analysis of Fe isotopes in zoned metal grains of 1234 Hammadah al Hamra 237. Lunar Planet. Sci. XXXVIII, \#1927.

1236 Fig. 1. Computed variation of the bulk (a) $\mathrm{Pd} / \mathrm{Fe}$ and (b) $\mathrm{Ir} / \mathrm{Fe}$ ratio with the bulk Ni/Fe 1237 ratio for metal grains that condense at equilibrium from a vaporized mixture of $\mathrm{CR}$ 1238 chondrite metal, $\mathrm{H}$ chondrite and residual nebular gas having enrichments in $\mathrm{Ni} / \mathrm{H}$ and $1239 \mathrm{Si} / \mathrm{H}$ of $1.4 \times 10^{4}$ and 300 , respectively, relative to solar composition at a variety of total 1240 pressures. Theoretical curves are compared to bulk compositions of unzoned metal 1241 grains in Bencubbin, Gujba and Weatherford (Campbell et al., 2002) and zoned metal 1242 grains in QUE, the latter calculated from traverses across the grains (Campbell et al., 1243 2001). Numbers on the curves are temperatures in K. The star marks the composition of 1244 a metal alloy having solar proportions of Fe, Ni, Pd and Ir (Anders and Grevesse, 1989).

1245 Fig. 2. Computed variation of the bulk (a, c) Pd/Fe and (b, d) Ir/Fe ratio with the bulk $1246 \mathrm{Ni} / \mathrm{Fe}$ ratio for metal grains that condense at equilibrium from a vaporized mixture of $\mathrm{CR}$ 1247 chondrite metal, $\mathrm{H}$ chondrite and residual nebular gas with a $\mathrm{Si} / \mathrm{H}$ enrichment of 300 1248 relative to solar composition and total pressures of $(\mathrm{a}, \mathrm{b}) 10^{-3}$ bar and (c, d) $10^{-2}$ bar at a 1249 variety of $\mathrm{Ni} / \mathrm{H}$ enrichments. Theoretical curves are compared to the same measured data 1250 as in Fig. 1. Numbers and symbols as in Fig. 1.

1251 Fig. 3. Computed variation of the bulk (a) $\mathrm{Pd} / \mathrm{Fe}$ and (b) $\mathrm{Ir} / \mathrm{Fe}$ ratio with the bulk $\mathrm{Ni} / \mathrm{Fe}$ 1252 ratio for metal grains that condense at equilibrium from a vaporized mixture of $\mathrm{CR}$ 
1253 chondrite metal, $\mathrm{H}$ chondrite and residual nebular gas with a $\mathrm{Ni} / \mathrm{H}$ enrichment of $1.4 \times 10^{4}$

1254 relative to solar composition and total pressure of $10^{-3}$ bar at a variety of $\mathrm{Si} / \mathrm{H}$

1255 enrichments. Theoretical curves are compared to the same measured data as in Fig. 1.

1256 Numbers and symbols as in Fig. 1.

1257 Fig. 4. Curves showing the evolution of the calculated bulk composition (wt\%) of the

1258 silicate fraction of the condensate in a plume produced by impact between a CR metal

1259 body and an $\mathrm{H}$ chondrite body at the indicated values of $\mathrm{P}^{\text {tot }}$ and $\mathrm{Ni} / \mathrm{H}$ and $\mathrm{Si} / \mathrm{H}$

1260 enrichments relative to solar composition, compared to bulk analyses of BO and CC

1261 chondrules from $\mathrm{CB}_{\mathrm{b}}$ chondrites (Krot et al. 2001a, b). Compositions are normalized to

$1262100 \%\left(\mathrm{CaO}+\mathrm{Al}_{2} \mathrm{O}_{3}\right)+\mathrm{MgO}+\mathrm{SiO}_{2}$. Numbers on the curves are temperatures in $\mathrm{K}$.

1263 Dashed portions of the curves are for temperature intervals where the $\mathrm{SiO}_{2}$ content of the

1264 liquid calculated from the MELTS model differs from that predicted by the CMAS model

1265 by $>2 \mathrm{wt} \%$ absolute, and the $\mathrm{FeO}$ content of the liquid $<0.3 \mathrm{wt} \%$. The curve for $\mathrm{P}^{\text {tot }}=10^{-3}$

1266 bar, $\mathrm{Si} / \mathrm{H}=300 x$ solar and $\mathrm{Ni} / \mathrm{H}=1.4 \times 10^{3}$ xsolar is indistinguishable from the curve for the

1267 same $\mathrm{P}^{\text {tot }}$ and $\mathrm{Si} / \mathrm{H}$ but with $\mathrm{Ni} / \mathrm{H}=1.4 \times 10^{4}$ xsolar. Grey diamond-Renazzo bulk silicate

1268 (Mason and Wiik, 1962); star-Bencubbin host silicate (Weisberg et al., 1990).

1269 Fig. 5. Evolution of the calculated bulk composition (wt \%) of the silicate fraction of the

1270 condensate in plumes produced by impact between a CR metal body and bodies with

1271 various differentiated silicate compositions at $\mathrm{P}^{\text {tot }}=10^{-2}$ bar and $\mathrm{Ni} / \mathrm{H}$ and $\mathrm{Si} / \mathrm{H}$

1272 enrichments of $1.4 \times 10^{3}$ and 300 , respectively, relative to solar composition. There was

1273 so little $\mathrm{FeO}$ in the aubrite case that the CMAS liquid model was used in the condensation

1274 calculation that resulted in the curve shown here. Numbers on the curves, symbols and

1275 sources of chondrule analytical data as in Fig. 4. 
1276 Fig. 6. Computed variation of the bulk (a) $\mathrm{Pd} / \mathrm{Fe}$ and (b) $\mathrm{Ir} / \mathrm{Fe}$ ratio with the bulk Ni/Fe

1277 ratio for metal grains that condense at equilibrium from a vaporized mixture of CR core,

1278 residual nebular gas, and equal weight proportions of CR crust and residual CR mantle,

1279 having enrichments in $\mathrm{Ni} / \mathrm{H}$ and $\mathrm{Si} / \mathrm{H}$ of $3 \times 10^{4}$ and 500 , respectively, relative to solar

1280 composition for the total pressures shown. A second curve for $10^{-2}$ bar at a $\mathrm{Ni} / \mathrm{H}$

1281 enrichment of $3 \times 10^{3}$ is also shown. When $20 \mathrm{wt} \%$ water is added to the total vaporized

1282 silicate, the positions of these curves are nearly unchanged. Curves labeled P/10 and

$1283 \mathrm{P} / 1000$ are bulk composition variations for zoned grains that condense from a gas with

$1284 \mathrm{Ni} / \mathrm{H}$ and $\mathrm{Si} / \mathrm{H}$ enrichments of $2.5 \times 10^{3}$ and 500 , respectively, when $20 \mathrm{wt} \%$ water is

1285 added to the total vaporized silicate, calculated using a kinetic model (see Section 3.4) at

1286 two different rates of decline of $\mathrm{P}^{\text {tot }}$ with temperature, i.e., by factors of 10 and $10^{3}$ over

$1287500 \mathrm{~K}$. Theoretical curves are compared to the same measured data as in Fig. 1. Numbers

1288 and symbols as in Fig. 1.

1289 Fig. 7. Curves showing the computed variation of $\mathrm{Cr} v s \mathrm{Ni}$ contents of metal grains that

1290 condense from a vaporized mixture of CR core, CR residual mantle, CR crust, and

1291 residual nebular gas. The $\mathrm{Si} / \mathrm{H}$ enrichment is 500 relative to solar composition in all

1292 cases, and the $\mathrm{Ni} / \mathrm{H}$ enrichment is $3 \times 10^{4}$ except in the $10^{-2}$ bar case in (a), where it is

$12933 \times 10^{3}$. The weight proportions of CR crust to residual CR mantle are 1:1 in (a), but are

1294 variable in (b). Ni contents decrease with decreasing temperature. Also plotted for

1295 comparison are bulk compositions of unzoned metal grains in Bencubbin (Campbell et al.,

1296 2002) and zoned metal grains in QUE (Campbell et al., 2001).

1297 Fig. 8. Evolution of oxygen fugacity relative to the iron-wüstite buffer (IW) as a function 1298 of temperature during condensation of a vaporized mixture of residual nebular gas, CR 
1299 core and vaporized silicate that consists of equal proportions of residual CR mantle and

$1300 \mathrm{CR}$ crust at a $\mathrm{P}^{\text {tot }}$ of $10^{-3}$ bar and a Ni/H enrichment of $3 \times 10^{4}$ relative to solar composition 1301 at $\mathrm{Si} / \mathrm{H}$ enrichments of 300,500 and $1.5 \times 10^{3}$ relative to solar composition. Also shown 1302 are curves for the 300 and $500 \mathrm{Si} / \mathrm{H}$ cases when 15 and $20 \mathrm{wt} \%$ water, respectively, is 1303 added to the total vaporized silicates.

1304 Fig. 9. Curves showing evolution of the calculated bulk composition (wt\%) of the 1305 silicate fraction of the condensate in plumes produced by impact vaporization of a 1306 mixture of $\mathrm{CR}$ core, $\mathrm{CR}$ residual mantle, CR crust, residual nebular gas and, in some 1307 cases, water (a) normalized to $100 \%\left(\mathrm{CaO}+\mathrm{Al}_{2} \mathrm{O}_{3}\right)+\mathrm{MgO}+\mathrm{SiO}_{2}$, and (b) as wt\% $\mathrm{FeO}$ $1308 v s$ wt $\% \mathrm{SiO}_{2}$. All cases shown are for $\mathrm{P}^{\mathrm{tot}}=10^{-3}$ bar and $\mathrm{Si} / \mathrm{H}$ and $\mathrm{Ni} / \mathrm{H}$ enrichments of 1309500 and $3 \times 10^{4}$, respectively, relative to solar composition, except for one case in (b) at a $1310 \mathrm{Si} / \mathrm{H}$ enrichment of 1500. Curves are shown for the indicated weight ratios of vaporized 1311 mantle/total vaporized silicate. Solid curves labeled "No water" are those for plumes to 1312 which no water has been added, and broken curves labeled " $20 \%$ water" are for plume 1313 compositions to which $20 \mathrm{~g}$ of water have been added for every $80 \mathrm{~g}$ of total silicate.

1314 Note that the evolutionary paths in (a) are very close to one another for a given mantle 1315 fraction whether or not water is added to the plume, but that the FeO content of the 1316 condensate in (b) is strongly dependent on the water abundance. BO chondrule 1317 compositions are best fit on (a) and (b) in plume regions where vaporized mantle 1318 composes $40-70 \mathrm{wt} \%$ of the total vaporized silicate. Calculated compositions of CR 1319 mantle and CR crust are shown by open and filled triangles, respectively. Numbers on 1320 curves, sources of chondrule analytical data and other symbols as in Fig. 4. In (b), 1321 numbers in parentheses are mantle fractions. 
1322 Fig. 10. Curves showing the evolution of the calculated bulk composition (wt\%) of the

1323 silicate fraction of the condensate in plumes produced by impact vaporization of a

1324 mixture of CR core, CR residual mantle, CR crust, residual nebular gas and water (a)

1325 normalized to $100 \%\left(\mathrm{CaO}+\mathrm{Al}_{2} \mathrm{O}_{3}\right)+\mathrm{MgO}+\mathrm{SiO}_{2}$, and (b) as wt $\% \mathrm{FeO}$ vs wt\% $\mathrm{SiO}_{2}$,

1326 showing the effect of removal of the high-temperature condensate assemblage that forms

1327 at $2040 \mathrm{~K}$. All cases shown are for $\mathrm{P}^{\text {tot }}=10^{-3}$ bar, $\mathrm{Si} / \mathrm{H}$ and $\mathrm{Ni} / \mathrm{H}$ enrichments of 500 and

$13283 \times 10^{4}$, respectively, relative to solar composition, and CR mantle/total silicate and

1329 water/total silicate weight ratios of 0.4 and 0.25 , respectively. Curves are shown for

1330 removal of the different fractions of the early condensate indicated. Note that BO

1331 chondrule compositions are best fit on both (a) and (b) at $~ 1820 \mathrm{~K}$ after removal of $0-70 \%$

1332 of the early condensate. Numbers, sources of chondrule analytical data and symbols as in 1333 Fig. 9.

1334 Fig. 11. Curves showing the evolution of the calculated bulk composition (wt\%) of the

1335 silicate fraction of the condensate in plumes produced by impact vaporization of a

1336 mixture of CR core, CR residual mantle, CR crust, residual nebular gas and, in some

1337 cases, water (a) normalized to $100 \%\left(\mathrm{CaO}+\mathrm{Al}_{2} \mathrm{O}_{3}\right)+\mathrm{MgO}+\mathrm{SiO}_{2}$, and (b) as wt $\% \mathrm{FeO}$

$1338 v s \mathrm{wt} \% \mathrm{SiO}_{2}$. All cases shown are for $\mathrm{P}^{\text {tot }}=10^{-3}$ bar and $\mathrm{Si} / \mathrm{H}$ and $\mathrm{Ni} / \mathrm{H}$ enrichments of

1339300 and $3 \times 10^{4}$, respectively, relative to solar composition. Curves are shown for

1340 different weight ratios of vaporized mantle/total vaporized silicate. Broken curves

1341 labeled " $15 \%$ water" are for plume compositions to which $15 \mathrm{~g}$ of water have been added

1342 for every $85 \mathrm{~g}$ of total silicate. Note that the evolutionary paths for a given mantle

1343 fraction in (a) are very close to one another whether or not water is added to the plume,

1344 but the $\mathrm{FeO}$ content of the condensate is strongly dependent on the water abundance. CC 
1345 chondrule compositions are best fit on (a) in plume regions where CR mantle $\geq 75 \mathrm{wt} \%$ of

1346 the total vaporized silicate. Labels, numbers, sources of chondrule analytical data and 1347 symbols as in Fig. 9.

1348 Fig. 12. Curves showing the evolution of the calculated bulk composition (wt $\%$ ) of the

1349 silicate fraction of the condensate in plumes produced by impact vaporization of a 1350 mixture of CR core, CR residual mantle, CR crust, residual nebular gas and water ice (a) 1351 normalized to $100 \%\left(\mathrm{CaO}+\mathrm{Al}_{2} \mathrm{O}_{3}\right)+\mathrm{MgO}+\mathrm{SiO}_{2}$, and (b) as wt\% $\mathrm{FeO}$ vs wt\% $\mathrm{SiO}_{2}$,

1352 showing the effect of removal of the high-temperature condensate assemblage that forms 1353 at $1750 \mathrm{~K}$. All cases shown are for $\mathrm{P}^{\mathrm{tot}}=10^{-3}$ bar, $\mathrm{Si} / \mathrm{H}$ and $\mathrm{Ni} / \mathrm{H}$ enrichments of 300 and $13543 \times 10^{4}$, respectively, relative to solar composition, and CR mantle/total silicate and 1355 water/total silicate weight ratios of 0.4 and 0.176 , respectively. Curves are shown for 1356 removal of the indicated fractions of the early condensate. Note that an early condensate 1357 assemblage with almost the same composition as the $\mathrm{BO}$ chondrule with the highest $\mathrm{CaO}$ $1358+\mathrm{Al}_{2} \mathrm{O}_{3}$ content is predicted to form at $1750 \mathrm{~K}$, and that the compositions of almost all 1359 CC chondrule compositions are best fit on both (a) and (b) at $\sim 1710-1720 \mathrm{~K}$ after removal 1360 of $95-100 \%$ of that early condensate. Numbers, sources of chondrule analytical data and 1361 symbols as in Fig. 9.

1362 Fig. 13. Computed variation (curves with no data points) of CI chondrite-normalized (a) $1363 \mathrm{Ir} / \mathrm{Fe},(\mathrm{b}) \mathrm{Ni} / \mathrm{Fe},(\mathrm{c}) \mathrm{Co} / \mathrm{Fe}$ and (d) $\mathrm{Cr} / \mathrm{Fe}$ ratios with distance from the center (most $\mathrm{Ir}$-rich 1364 point) of a condensate metal alloy grain, compared to profiles measured by LA-ICP-MS 1365 across three metal grains in QUE (curves with data points). In the model, grain growth is 1366 controlled by the kinetic theory of gases, as expressed by the Hertz-Knudsen equation. $1367 \mathrm{P}^{\text {tot }}$ was assumed to be $1.6 \times 10^{-4}$ bar at the metal nucleation temperature, and to fall by 
1368 factors of ten $(\mathrm{P} / 10)$ and one thousand $(\mathrm{P} / 1000)$ over the next $500 \mathrm{~K}$. The gas was

1369 assumed to cool at $50 \mathrm{~K} / \mathrm{hr}$, and to be supersaturated in siderophiles until the grain

1370 nucleated $101 \mathrm{~K}(\mathrm{P} / 10)$ or $146 \mathrm{~K}(\mathrm{P} / 1000)$ below the equilibrium condensation temperature

1371 of pure Ir. Continuous profiles predicted by theory were divided into $30 \mu \mathrm{m}$ sections

1372 over which the compositions were averaged in order to match the spatial resolution of the

1373 analytical data. These averages are joined by line segments to generate the theoretical

1374 profiles on the plot.

1375 Fig. 14. Computed variation of (a) $\delta^{56} \mathrm{Fe}$ and (b) $\delta^{60} \mathrm{Ni}$ with distance from the center of

1376 the same model condensate metal grains as in Fig. 13. The temperature interval for metal

1377 condensation is the same in both models, but the condensation rates are higher for the

1378 P/10 thermal history, resulting in more complete condensation, and a larger grain with

1379 less negative bulk $\delta^{56} \mathrm{Fe}$ and $\delta^{60} \mathrm{Ni}$ than in the P/1000 case. Continuous profiles predicted

1380 by theory were divided into $30 \mu \mathrm{m}$ sections over which the compositions were averaged, 1381 as in Fig. 13. 
Table 1. Relative atomic abundances of components used in this work.

\begin{tabular}{|c|c|c|c|c|}
\hline $\begin{array}{c}1 \\
\text { Element }\end{array}$ & $\begin{array}{c}2 \\
\text { Average } \\
\text { H chondrite }^{1}\end{array}$ & $\begin{array}{c}3 \\
\text { Residual } \\
\text { nebular gas }^{2}\end{array}$ & $\begin{array}{c}4 \\
\text { CR chondrite } \\
\text { metal }^{3}\end{array}$ & $\begin{array}{c} \\
\text { Model plume } \\
\text { composition }^{4}\end{array}$ \\
\hline $\mathrm{H}$ & $8.026 \mathrm{E}+04$ & $2.790 E+10$ & - & $9.308 \mathrm{E}+07$ \\
\hline $\mathrm{He}$ & $0.000 E+00$ & $2.720 E+09$ & - & $9.067 E+06$ \\
\hline $\mathrm{C}$ & $1.503 E+04$ & $6.834 E+06$ & - & $3.781 E+04$ \\
\hline $\mathrm{N}$ & $0.000 E+00$ & $3.130 E+06$ & - & $1.043 E+04$ \\
\hline $\mathrm{O}$ & $3.455 E+06$ & $1.021 \mathrm{E}+07$ & - & $3.489 E+06$ \\
\hline $\mathrm{Na}$ & $4.470 \mathrm{E}+04$ & $1.270 \mathrm{E}+04$ & - & $4.474 \mathrm{E}+04$ \\
\hline $\mathrm{Mg}$ & $9.591 E+05$ & $1.149 \mathrm{E}+05$ & - & $9.595 E+05$ \\
\hline $\mathrm{Al}$ & $6.936 \mathrm{E}+04$ & $1.554 \mathrm{E}+04$ & - & $6.941 E+04$ \\
\hline $\mathrm{Si}$ & $1.000 E+06$ & $0.000 E+00$ & - & $1.000 E+06$ \\
\hline$P$ & $6.245 E+03$ & $4.155 E+03$ & - & $6.259 E+03$ \\
\hline S & $1.002 E+05$ & $3.456 E+05$ & - & $1.013 E+05$ \\
\hline $\mathrm{K}$ & $3.283 E+03$ & $4.866 \mathrm{E}+02$ & - & $3.285 E+03$ \\
\hline $\mathrm{Ca}$ & $5.079 E+04$ & $1.031 E+04$ & - & $5.082 E+04$ \\
\hline $\mathrm{Ti}$ & $2.466 \mathrm{E}+03$ & $0.000 E+00$ & - & $2.466 \mathrm{E}+03$ \\
\hline $\mathrm{Cr}$ & $1.159 \mathrm{E}+04$ & $1.913 E+03$ & $2.627 E+03$ & $1.324 \mathrm{E}+05$ \\
\hline $\mathrm{Mn}$ & $6.933 E+03$ & $2.617 E+03$ & - & $6.941 E+03$ \\
\hline $\mathrm{Fe}$ & $7.966 \mathrm{E}+05$ & $1.034 \mathrm{E}+05$ & $9.000 E+05$ & $4.219 E+07$ \\
\hline Co & $2.315 E+03$ & $0.000 E+00$ & $2.250 \mathrm{E}+03$ & $1.058 \mathrm{E}+05$ \\
\hline $\mathrm{Ni}$ & $4.558 \mathrm{E}+04$ & $3.722 E+03$ & $4.930 \mathrm{E}+04$ & $2.313 E+06$ \\
\hline $\mathrm{Pd}$ & $1.374 \mathrm{E}+00$ & $1.553 \mathrm{E}-02$ & $1.390 \mathrm{E}+00$ & $6.530 \mathrm{E}+01$ \\
\hline Ir & $6.756 \mathrm{E}-01$ & $0.000 E+00$ & $6.610 \mathrm{E}-01$ & $3.108 \mathrm{E}+01$ \\
\hline
\end{tabular}

${ }^{1} \mathrm{Si}, \mathrm{Ti}, \mathrm{C}, \mathrm{H}, \mathrm{O}, \mathrm{P}$ and $\mathrm{S}$ are from Jarosewich (1990); others from Kallemeyn et al. (1989); Pd from average $\mathrm{H}$ chondrite $\mathrm{Pd} / \mathrm{Ir}$ of Horan et al. (2003), in atoms $/ 10^{6} \mathrm{Si}$

${ }^{2}$ After removal of average $\mathrm{H}$ chondrite

${ }^{3}$ Kong et al. (1999) average CR metal but Ir/Ni and Pd/Ni were assumed to be solar (Anders and Grevesse, 1989)

${ }^{4} 89.3 \mathrm{wt} \% \mathrm{CR}$ metal $+6.0 \mathrm{wt} \% \mathrm{H}$ chondrite $+4.7 \mathrm{wt} \%$ of residual nebular gas to yield $\mathrm{Ni} / \mathrm{H}=1.4 \times 10^{4}$ and $\mathrm{Si} / \mathrm{H}=300$ times their solar values, respectively, in atoms $/ 10^{6} \mathrm{Si}$ 
Table 2. Atomic abundances of differentiated silicate components used in this work, relative to $10^{6} \mathrm{Si}$, and of plumes made from them that are enriched in $\mathrm{Ni} / \mathrm{H}$ and $\mathrm{Si} / \mathrm{H}$ by factors of $1.4 \times 10^{3}$ and 300 .

\begin{tabular}{|c|c|c|c|c|c|c|c|c|c|c|c|c|}
\hline & \multicolumn{2}{|c|}{ Average aubrite } & \multicolumn{2}{|c|}{ Juvinas } & \multicolumn{2}{|c|}{ Kapoeta } & \multicolumn{2}{|c|}{$Y 75032$} & \multicolumn{2}{|c|}{ Johnstown } & \multicolumn{2}{|c|}{ Peridotite } \\
\hline & $\begin{array}{c}\text { Pure } \\
\text { component }\end{array}$ & $\begin{array}{l}\text { Model plume } \\
\text { composition }^{1} \\
\end{array}$ & $\begin{array}{c}\text { Pure } \\
\text { component }\end{array}$ & $\begin{array}{l}\text { Model plume } \\
\text { composition }^{2} \\
\end{array}$ & $\begin{array}{c}\text { Pure } \\
\text { component }\end{array}$ & $\begin{array}{l}\text { Model plume } \\
\text { composition }^{3} \\
\end{array}$ & $\begin{array}{c}\text { Pure } \\
\text { component }\end{array}$ & $\begin{array}{l}\text { Model plume } \\
\text { composition }^{4} \\
\end{array}$ & $\begin{array}{c}\text { Pure } \\
\text { component }\end{array}$ & $\begin{array}{l}\text { Model plume } \\
\text { composition }^{5} \\
\end{array}$ & $\begin{array}{c}\text { Pure } \\
\text { component } \\
\end{array}$ & $\begin{array}{l}\begin{array}{l}\text { Model plume } \\
\text { composition }\end{array} \\
\end{array}$ \\
\hline $\mathrm{H}$ & $0.000 \mathrm{E}+00$ & $9.300 \mathrm{E}+07$ & $0.000 \mathrm{E}+00$ & $9.300 \mathrm{E}+07$ & $0.000 \mathrm{E}+00$ & $9.300 \mathrm{E}+07$ & $0.000 \mathrm{E}+00$ & $9.300 \mathrm{E}+07$ & $0.000 \mathrm{E}+00$ & $9.300 \mathrm{E}+07$ & $0.000 \mathrm{E}+00$ & $9.300 \mathrm{E}+07$ \\
\hline $\mathrm{He}$ & $0.000 E+00$ & $9.067 \mathrm{E}+06$ & $0.000 E+00$ & $9.067 \mathrm{E}+06$ & $0.000 \mathrm{E}+00$ & $9.067 \mathrm{E}+06$ & $0.000 \mathrm{E}+00$ & $9.067 E+06$ & $0.000 E+00$ & $9.067 \mathrm{E}+06$ & $0.000 \mathrm{E}+00$ & $9.067 E+06$ \\
\hline $\mathrm{C}$ & $0.000 E+00$ & $2.278 \mathrm{E}+04$ & $0.000 E+00$ & $2.278 E+04$ & $0.000 E+00$ & $2.278 \mathrm{E}+04$ & $0.000 E+00$ & $2.278 \mathrm{E}+04$ & $0.000 E+00$ & $2.278 \mathrm{E}+04$ & $0.000 E+00$ & $2.278 E+04$ \\
\hline $\mathrm{N}$ & $0.000 E+00$ & $1.043 E+04$ & $0.000 E+00$ & $1.043 E+04$ & $0.000 E+00$ & $1.043 E+04$ & $0.000 E+00$ & $1.043 E+04$ & $0.000 E+00$ & $1.043 E+04$ & $0.000 E+00$ & $1.043 E+04$ \\
\hline 0 & $3.016 \mathrm{E}+06$ & $3.050 \mathrm{E}+06$ & $3.268 \mathrm{E}+06$ & $3.302 \mathrm{E}+06$ & $3.201 \mathrm{E}+06$ & $3.235 \mathrm{E}+06$ & $3.104 E+06$ & $3.138 \mathrm{E}+06$ & $3.095 \mathrm{E}+06$ & $3.129 \mathrm{E}+06$ & $3.719 \mathrm{E}+06$ & $3.753 E+06$ \\
\hline $\mathrm{Na}$ & $6.732 \mathrm{E}+03$ & $6.774 E+03$ & $1.486 \mathrm{E}+04$ & $1.490 \mathrm{E}+04$ & $1.064 \mathrm{E}+04$ & $1.068 \mathrm{E}+04$ & $3.665 E+03$ & $3.707 E+03$ & $7.386 \mathrm{E}+02$ & $7.809 E+02$ & $2.172 \mathrm{E}+03$ & $2.214 \mathrm{E}+03$ \\
\hline $\mathrm{Mg}$ & $9.654 E+05$ & $9.658 E+05$ & $2.000 E+05$ & $2.004 E+05$ & $4.683 E+05$ & $4.687 E+05$ & $5.890 E+05$ & $5.894 E+05$ & $7.241 E+05$ & $7.245 E+05$ & $1.415 E+06$ & $1.415 E+06$ \\
\hline $\mathrm{Al}$ & $1.862 E+04$ & $1.867 \mathrm{E}+04$ & $3.114 \mathrm{E}+05$ & $3.115 E+05$ & $1.945 \mathrm{E}+05$ & $1.945 \mathrm{E}+05$ & $7.575 \mathrm{E}+04$ & $7.580 \mathrm{E}+04$ & $3.367 E+04$ & $3.373 E+04$ & $5.967 E+04$ & $5.972 E+04$ \\
\hline $\mathrm{Si}$ & $1.000 E+06$ & $1.000 \mathrm{E}+06$ & $1.000 E+06$ & $1.000 E+06$ & $1.000 \mathrm{E}+06$ & $1.000 \mathrm{E}+06$ & $1.000 \mathrm{E}+06$ & $1.000 \mathrm{E}+06$ & $1.000 \mathrm{E}+06$ & $1.000 \mathrm{E}+06$ & $1.000 \mathrm{E}+06$ & $1.000 \mathrm{E}+06$ \\
\hline $\mathrm{P}$ & $0.000 E+00$ & $1.385 E+01$ & $0.000 E+00$ & $1.385 E+01$ & $0.000 E+00$ & $1.385 \mathrm{E}+01$ & $0.000 E+00$ & $1.385 \mathrm{E}+01$ & $0.000 E+00$ & $1.385 \mathrm{E}+01$ & $0.000 E+00$ & $1.385 \mathrm{E}+01$ \\
\hline S & $1.590 E+04$ & $1.705 E+04$ & $0.000 E+00$ & $1.152 \mathrm{E}+03$ & $0.000 E+00$ & $1.152 \mathrm{E}+03$ & $0.000 E+00$ & $1.152 \mathrm{E}+03$ & $2.864 E+03$ & $9.006 E+03$ & $0.000 E+00$ & $1.152 \mathrm{E}+03$ \\
\hline $\mathrm{K}$ & $6.644 E+02$ & $6.660 \mathrm{E}+02$ & $7.000 E+02$ & $7.017 \mathrm{E}+02$ & $5.579 \mathrm{E}+02$ & $5.596 \mathrm{E}+02$ & $1.688 \mathrm{E}+02$ & $1.704 \mathrm{E}+02$ & $2.673 E+01$ & $2.835 E+01$ & $0.000 E+00$ & $1.622 \mathrm{E}+00$ \\
\hline $\mathrm{Ca}$ & $1.581 \mathrm{E}+04$ & $1.585 E+04$ & $2.395 E+05$ & $2.396 E+05$ & $1.108 \mathrm{E}+05$ & $1.108 \mathrm{E}+05$ & $7.312 E+04$ & $7.315 E+04$ & $3.735 E+04$ & $3.738 \mathrm{E}+04$ & $4.440 E+04$ & $4.444 E+04$ \\
\hline $\mathrm{Ti}$ & $6.528 \mathrm{E}+02$ & $6.528 \mathrm{E}+02$ & $9.629 E+03$ & $9.629 \mathrm{E}+03$ & $4.485 E+03$ & $4.485 E+03$ & $3.696 \mathrm{E}+03$ & $3.696 \mathrm{E}+03$ & $1.432 \mathrm{E}+03$ & $1.432 \mathrm{E}+03$ & $5.054 \mathrm{E}+02$ & $5.054 \mathrm{E}+02$ \\
\hline $\mathrm{Cr}$ & $4.118 \mathrm{E}+02$ & $1.262 \mathrm{E}+04$ & $4.901 E+03$ & $1.714 \mathrm{E}+04$ & $1.091 \mathrm{E}+04$ & $2.311 E+04$ & $1.031 \mathrm{E}+04$ & $2.246 \mathrm{E}+04$ & $1.235 \mathrm{E}+04$ & $2.460 \mathrm{E}+04$ & $8.679 E+03$ & $2.092 \mathrm{E}+04$ \\
\hline $\mathrm{Mn}$ & $5.882 \mathrm{E}+02$ & $5.969 E+02$ & $8.866 E+03$ & $8.875 E+03$ & $8.335 E+03$ & $8.344 E+03$ & $9.767 E+03$ & $9.776 \mathrm{E}+03$ & $7.809 E+03$ & $7.817 E+03$ & $0.000 E+00$ & $8.725 E+00$ \\
\hline $\mathrm{Fe}$ & $7.669 \mathrm{E}+04$ & $4.258 \mathrm{E}+06$ & $3.179 E+05$ & $4.509 \mathrm{E}+06$ & $2.910 E+05$ & $4.470 \mathrm{E}+06$ & $2.940 \mathrm{E}+05$ & $4.452 E+06$ & $2.561 E+05$ & $4.447 E+06$ & $1.549 \mathrm{E}+05$ & $4.348 \mathrm{E}+06$ \\
\hline Co & $0.000 E+00$ & $1.045 E+04$ & $0.000 \mathrm{E}+00$ & $1.048 \mathrm{E}+04$ & $0.000 E+00$ & $1.045 E+04$ & $0.000 E+00$ & $1.040 E+04$ & $0.000 E+00$ & $1.048 \mathrm{E}+04$ & $0.000 E+00$ & $1.048 \mathrm{E}+04$ \\
\hline $\mathrm{Ni}$ & $1.066 \mathrm{E}+03$ & $2.301 \mathrm{E}+05$ & $0.000 E+00$ & $2.296 \mathrm{E}+05$ & $0.000 E+00$ & $2.289 \mathrm{E}+05$ & $0.000 \mathrm{E}+00$ & $2.278 \mathrm{E}+05$ & $0.000 \mathrm{E}+00$ & $2.297 E+05$ & $0.000 \mathrm{E}+00$ & $2.297 \mathrm{E}+05$ \\
\hline $\mathrm{Pd}$ & $0.000 E+00$ & $6.457 \mathrm{E}+00$ & $0.000 E+00$ & $6.473 E+00$ & $0.000 E+00$ & $6.454 E+00$ & $0.000 E+00$ & $6.422 E+00$ & $0.000 E+00$ & $6.477 \mathrm{E}+00$ & $0.000 E+00$ & $6.475 E+00$ \\
\hline Ir & $0.000 \mathrm{E}+00$ & $3.071 \mathrm{E}+00$ & $0.000 \mathrm{E}+00$ & $3.078 \mathrm{E}+00$ & $0.000 \mathrm{E}+00$ & $5.115 \mathrm{E}+00$ & $0.000 E+00$ & $3.054 \mathrm{E}+00$ & $0.000 \mathrm{E}+00$ & $3.080 \mathrm{E}+00$ & $0.000 \mathrm{E}+00$ & $3.079 \mathrm{E}+00$ \\
\hline
\end{tabular}

$151.1 \mathrm{wt} \% \mathrm{CR}$ metal $+21.9 \mathrm{wt} \%$ average aubrite $+27 \mathrm{wt} \%$ of residual nebular gas.

${ }^{2} 49.5 w t \%$ CR metal $+24.4 w t \%$ Juvinas $+26.1 w t \%$ of residual nebular gas.

${ }^{3} 49.9 \mathrm{wt} \%$ CR metal $+23.8 \mathrm{wt} \%$ Kapoeta $+26.4 \mathrm{wt} \%$ of residual nebular gas.

${ }^{4} 50.1 \mathrm{wt} \% \mathrm{CR}$ metal $+23.3 \mathrm{wt} \%$ Y75032 $+26.6 \mathrm{wt} \%$ of residual nebular gas.

${ }^{5} 50.5 \mathrm{wt} \% \mathrm{CR}$ metal $+23 \mathrm{wt} \%$ Johnstown $+26.5 \mathrm{wt} \%$ of residual nebular gas.

${ }^{6} 48.4 \mathrm{wt} \% \mathrm{CR}$ metal $+26.1 \mathrm{wt} \%$ peridotite $+25.5 \mathrm{wt} \%$ of residual nebular gas. 
Table 3. Relative atomic abundances used in the impact vaporization model of a differentiated CR chondrite body.

\begin{tabular}{|c|c|c|c|c|c|c|c|c|}
\hline $\begin{array}{c}1 \\
\text { Element }\end{array}$ & $\begin{array}{c}2 \\
\text { Bulk composition } \\
\text { of CR body }{ }^{1}\end{array}$ & $\begin{array}{c}3 \\
\text { CR core }\end{array}$ & $\begin{array}{c}4 \\
\text { CR mantle }\end{array}$ & $\begin{array}{c}5 \\
\text { CR }_{\text {crust }}{ }^{2}\end{array}$ & $\begin{array}{c}6 \\
\text { Residual CR mantle }\end{array}$ & $\begin{array}{c}7 \\
\text { Residual } \\
\text { nebular gas }^{3}\end{array}$ & $\begin{array}{c}8 \\
\text { Model plume } \\
\text { comp. w/o water }\end{array}$ & $\begin{array}{c}9 \\
\text { Model plume } \\
\text { comp. w/ } 20 \% \text { water }^{5}\end{array}$ \\
\hline $\mathrm{H}$ & $0.000 \mathrm{E}+00$ & $0.000 E+00$ & $0.000 E+00$ & $0.000 \mathrm{E}+00$ & $0.000 E+00$ & $2.790 \mathrm{E}+10$ & $5.580 \mathrm{E}+07$ & $5.580 \mathrm{E}+07$ \\
\hline $\mathrm{He}$ & $0.000 E+00$ & $0.000 E+00$ & $0.000 E+00$ & $0.000 E+00$ & $0.000 E+00$ & $2.720 E+09$ & $5.440 E+06$ & $5.140 E+06$ \\
\hline $\mathrm{C}$ & $0.000 E+00$ & $0.000 E+00$ & $0.000 E+00$ & $0.000 E+00$ & $0.000 E+00$ & $6.636 E+06$ & $1.327 E+04$ & $1.254 \mathrm{E}+04$ \\
\hline $\mathrm{N}$ & $0.000 E+00$ & $0.000 E+00$ & $0.000 E+00$ & $0.000 E+00$ & $0.000 E+00$ & $3.122 \mathrm{E}+06$ & $6.245 E+03$ & $5.900 E+03$ \\
\hline 0 & $3.746 E+06$ & $0.000 E+00$ & $3.348 E+06$ & $3.008 \mathrm{E}+06$ & $3.444 E+06$ & $9.353 E+06$ & $3.228 \mathrm{E}+06$ & $4.769 \mathrm{E}+06$ \\
\hline $\mathrm{Na}$ & $3.168 \mathrm{E}+04$ & $0.000 E+00$ & $3.171 E+04$ & $1.427 \mathrm{E}+05$ & $5.564 E+02$ & $0.000 E+00$ & $7.707 E+04$ & $7.707 E+04$ \\
\hline $\mathrm{Mg}$ & $1.047 \mathrm{E}+06$ & $0.000 E+00$ & $1.048 \mathrm{E}+06$ & $1.910 \mathrm{E}+05$ & $1.288 \mathrm{E}+06$ & $0.000 E+00$ & $6.974 \mathrm{E}+05$ & $6.974 \mathrm{E}+05$ \\
\hline $\mathrm{Al}$ & $8.230 E+04$ & $0.000 E+00$ & $8.232 E+04$ & $2.801 E+05$ & $2.681 E+04$ & $0.000 E+00$ & $1.632 \mathrm{E}+05$ & $1.632 \mathrm{E}+05$ \\
\hline $\mathrm{Si}$ & $1.000 E+06$ & $0.000 E+00$ & $1.000 E+06$ & $1.000 E+06$ & $1.000 E+06$ & $0.000 E+00$ & $1.000 E+06$ & $1.000 E+06$ \\
\hline$P$ & $6.882 E+03$ & $0.000 E+00$ & $7.010 E+03$ & $2.567 E+04$ & $1.772 \mathrm{E}+03$ & $3.518 \mathrm{E}+03$ & $1.464 \mathrm{E}+04$ & $1.464 \mathrm{E}+04$ \\
\hline s & $1.165 E+04$ & $1.232 \mathrm{E}+04$ & $0.000 E+00$ & $0.000 E+00$ & $0.000 E+00$ & $4.341 \mathrm{E}+05$ & $7.012 \mathrm{E}+05$ & $6.993 \mathrm{E}+05$ \\
\hline $\mathrm{K}$ & $1.363 E+03$ & $0.000 E+00$ & $1.547 E+03$ & $7.018 \mathrm{E}+03$ & $1.063 E+01$ & $0.000 E+00$ & $3.783 E+03$ & $3.783 E+03$ \\
\hline $\mathrm{Ca}$ & $5.629 E+04$ & $0.000 E+00$ & $5.640 E+04$ & $1.836 \mathrm{E}+05$ & $2.067 E+04$ & $0.000 E+00$ & $1.084 \mathrm{E}+05$ & $1.084 \mathrm{E}+05$ \\
\hline $\mathrm{Ti}$ & $4.080 E+03$ & $0.000 E+00$ & $4.114 \mathrm{E}+03$ & $1.487 \mathrm{E}+04$ & $1.094 \mathrm{E}+03$ & $0.000 E+00$ & $8.512 E+03$ & $8.512 \mathrm{E}+03$ \\
\hline $\mathrm{Cr}$ & $1.298 \mathrm{E}+04$ & $4.807 E+03$ & $1.562 E+04$ & $1.646 \mathrm{E}+03$ & $1.969 E+04$ & $0.000 E+00$ & $2.833 E+05$ & $2.825 \mathrm{E}+05$ \\
\hline $\mathrm{Mn}$ & $5.820 E+03$ & $0.000 E+00$ & $6.011 E+03$ & $2.728 \mathrm{E}+04$ & $4.132 E+01$ & $0.000 E+00$ & $1.471 \mathrm{E}+04$ & $1.471 \mathrm{E}+04$ \\
\hline $\mathrm{Fe}$ & $9.000 E+05$ & $9.000 E+05$ & $4.916 E+04$ & $1.509 E+04$ & $5.872 \mathrm{E}+04$ & $0.000 E+00$ & $5.120 E+07$ & $5.107 \mathrm{E}+07$ \\
\hline Co & $3.436 \mathrm{E}+03$ & $3.636 E+03$ & $0.000 E+00$ & $0.000 E+00$ & $0.000 E+00$ & $0.000 E+00$ & $2.067 E+05$ & $2.062 E+05$ \\
\hline $\mathrm{Ni}$ & $4.929 E+04$ & $5.214 E+04$ & $0.000 E+00$ & $0.000 E+00$ & $0.000 E+00$ & $0.000 E+00$ & $2.965 E+06$ & $2.957 E+06$ \\
\hline $\mathrm{Pd}$ & $1.390 E+00$ & $1.470 E+00$ & $0.000 E+00$ & $0.000 E+00$ & $0.000 E+00$ & $0.000 E+00$ & $8.358 \mathrm{E}+01$ & $8.336 \mathrm{E}+01$ \\
\hline Ir & $6.608 \mathrm{E}-01$ & $6.991 \mathrm{E}-01$ & $0.000 E+00$ & $0.000 E+00$ & $0.000 E+00$ & $0.000 E+00$ & $3.975 \mathrm{E}+01$ & $3.964 \mathrm{E}+01$ \\
\hline
\end{tabular}

${ }^{1}$ Renazzo composition of Weisberg et al. (1993), modified as in text

${ }^{2}$ See text

${ }^{3}$ See text

${ }^{4} 94.2 \mathrm{wt} \%$ CR core $+1.7 \mathrm{wt} \%$ residual CR mantle $+1.7 \% \mathrm{wt} \% \mathrm{CR}$ crust $+2.4 \mathrm{wt} \%$ of residual nebular gas

to yield $\mathrm{Ni} / \mathrm{H}=3 \times 10^{4}$ and $\mathrm{Si} / \mathrm{H}=500$ times their solar values, respectively

${ }^{5} 93.5 \mathrm{wt} \%$ CR core $+1.68 \mathrm{wt} \%$ residual CR mantle $+1.68 \mathrm{wt} \% \mathrm{CR}$ crust $+0.84 \mathrm{wt} \%$ water $+2.3 \mathrm{wt} \%$ of residual nebular gas

to yield $\mathrm{Ni} / \mathrm{H}=3 \times 10^{4}$ and $\mathrm{Si} / \mathrm{H}=500$ times their solar values, respectively 


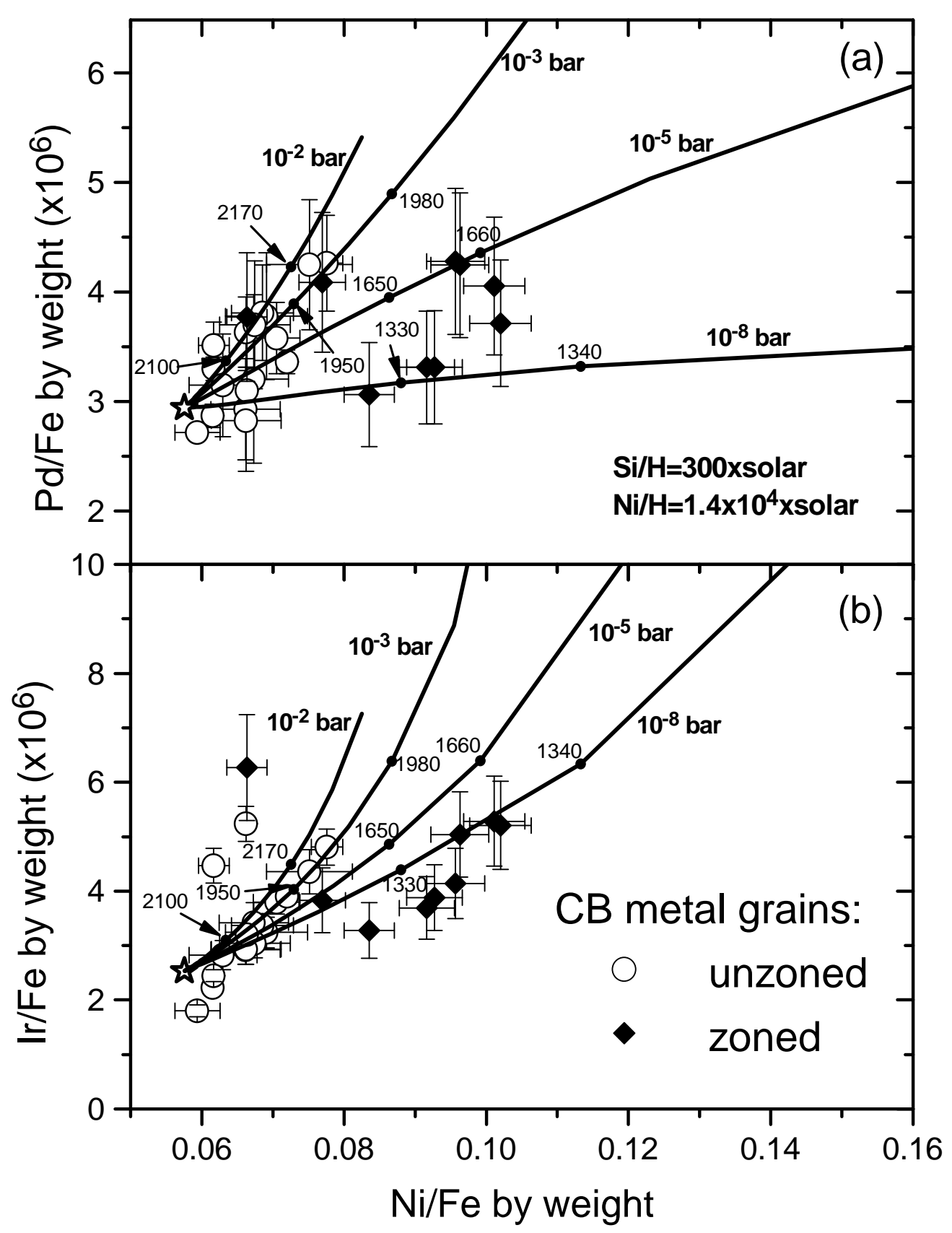

Fig. 1 


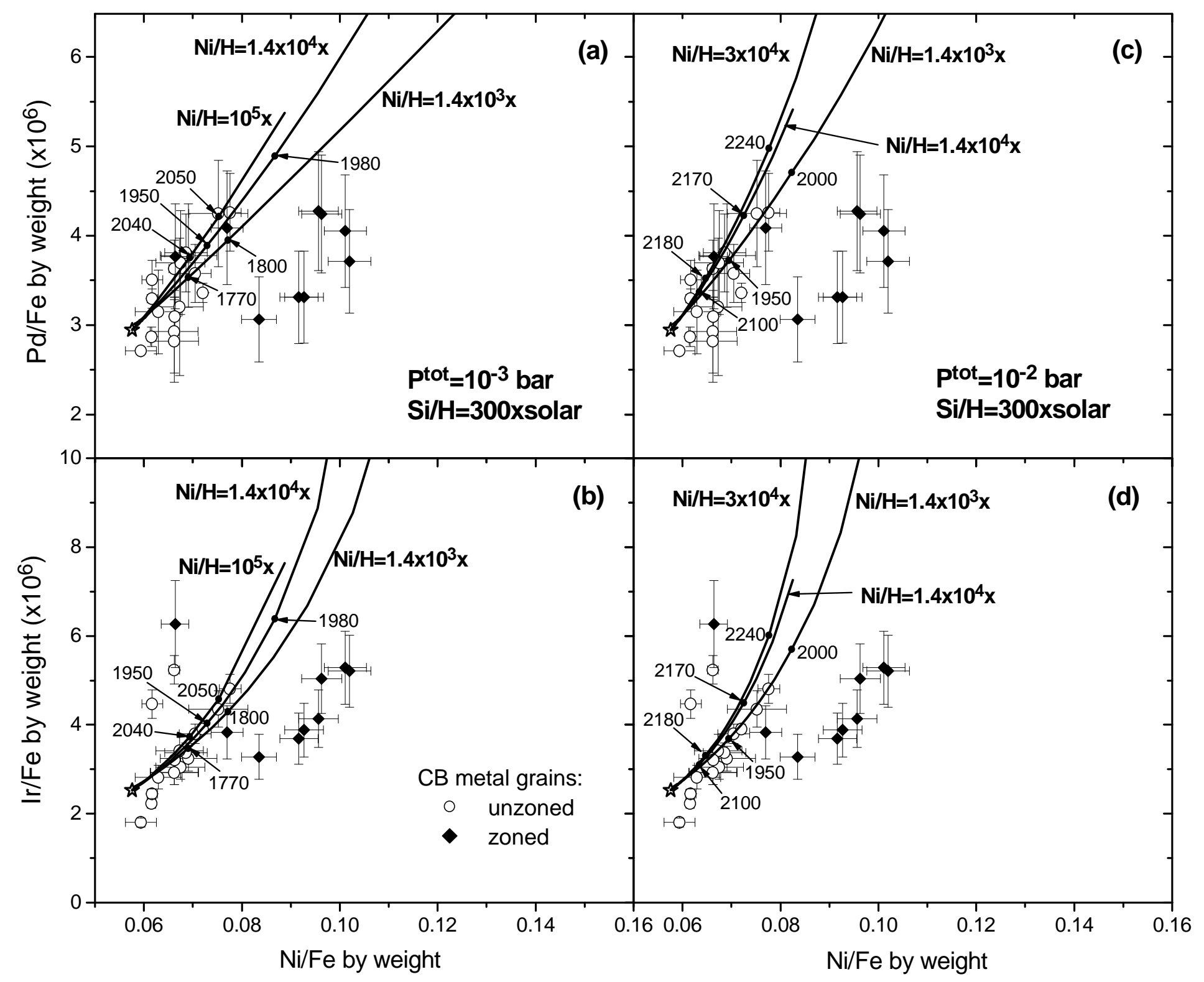

Fig. 2 


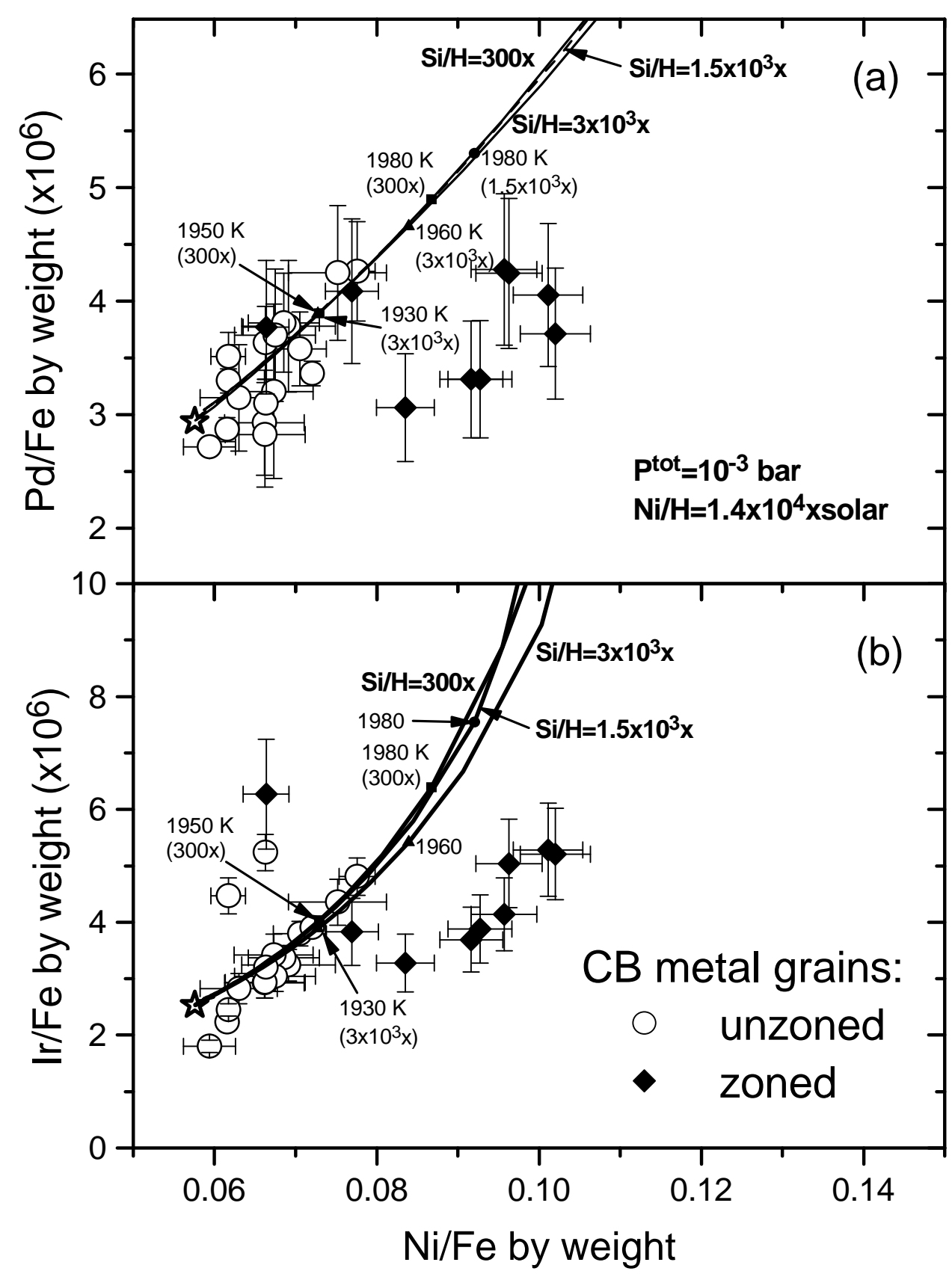

Fig. 3 


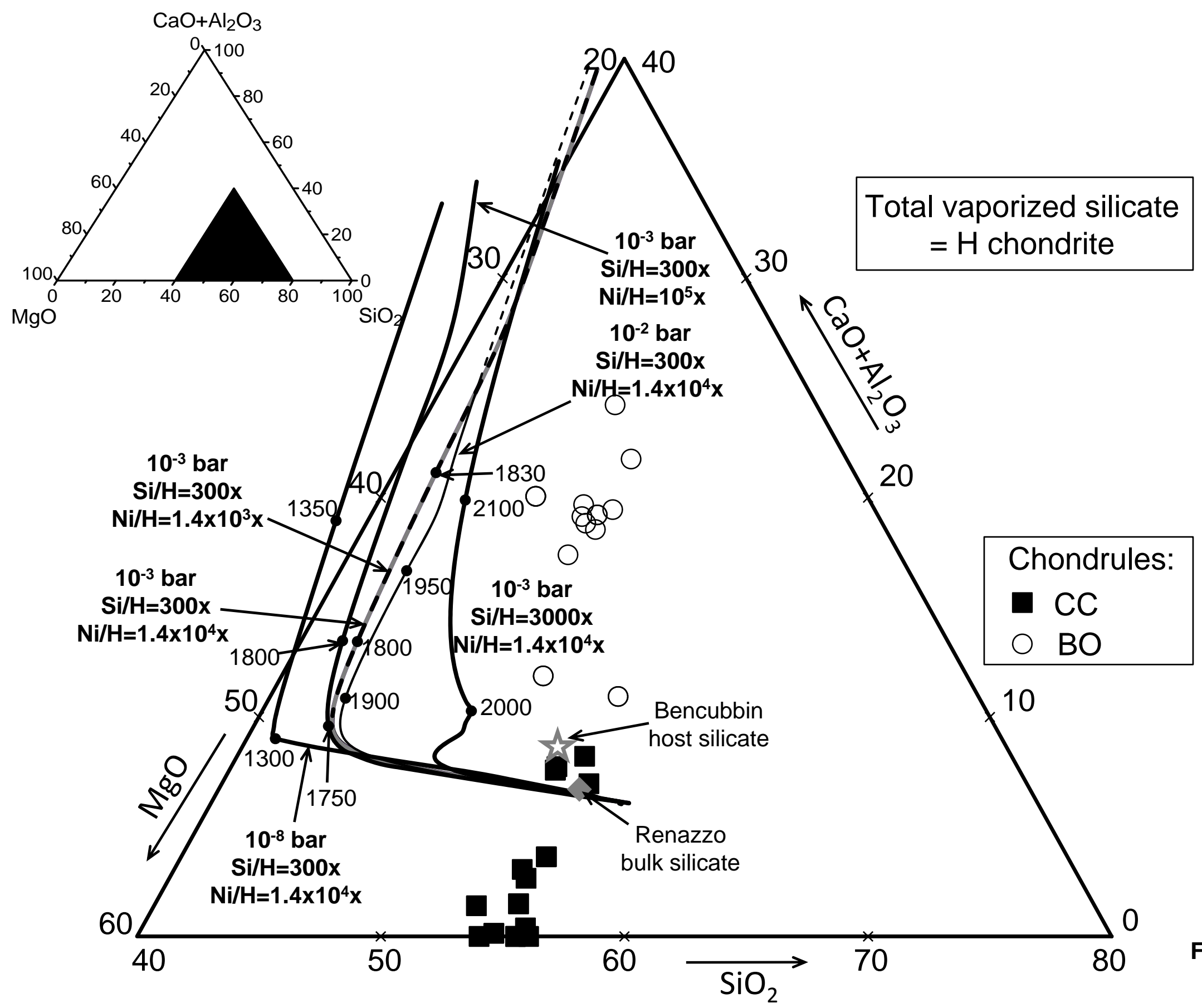

Fig. 4 


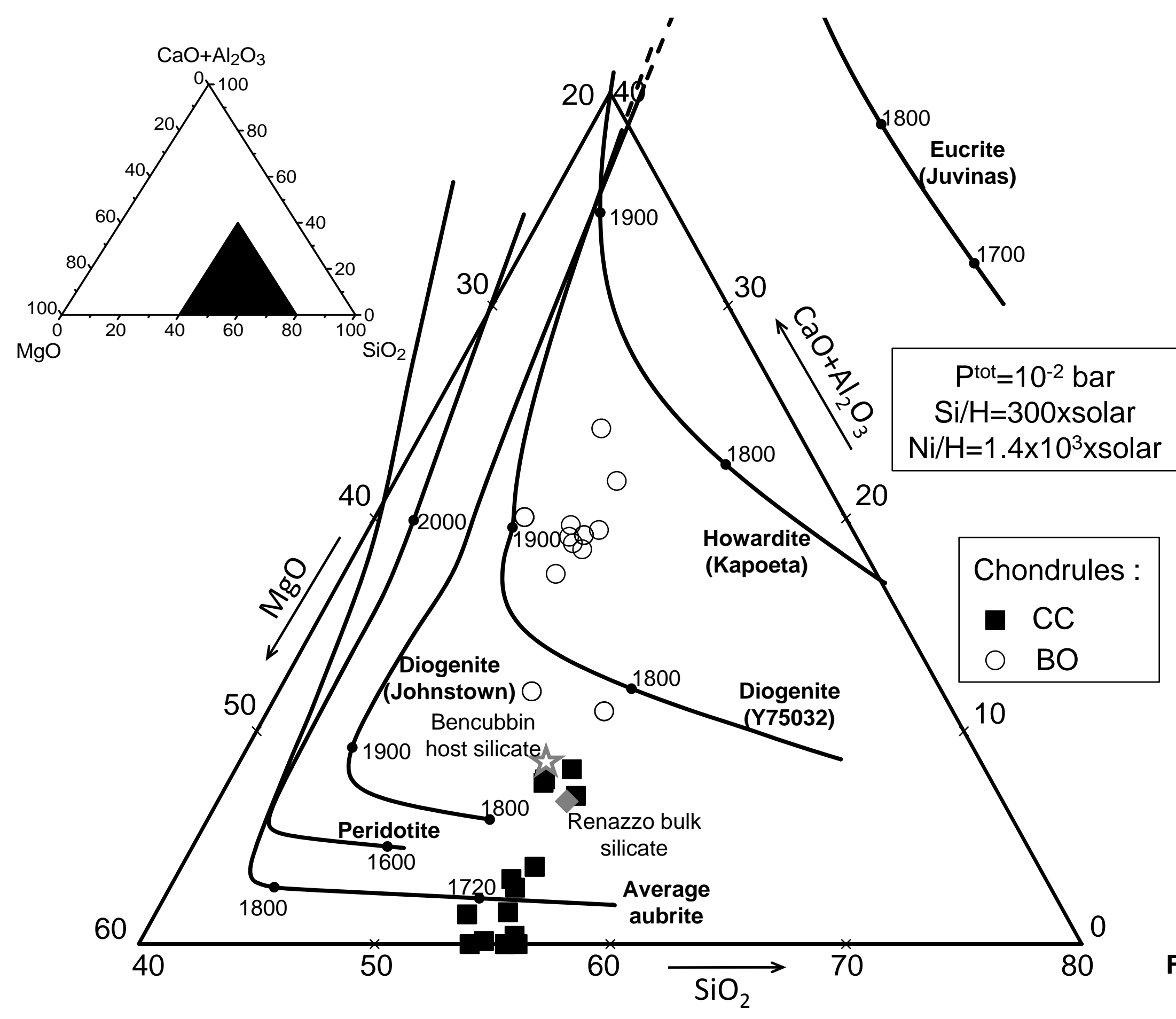

Fig. 5 


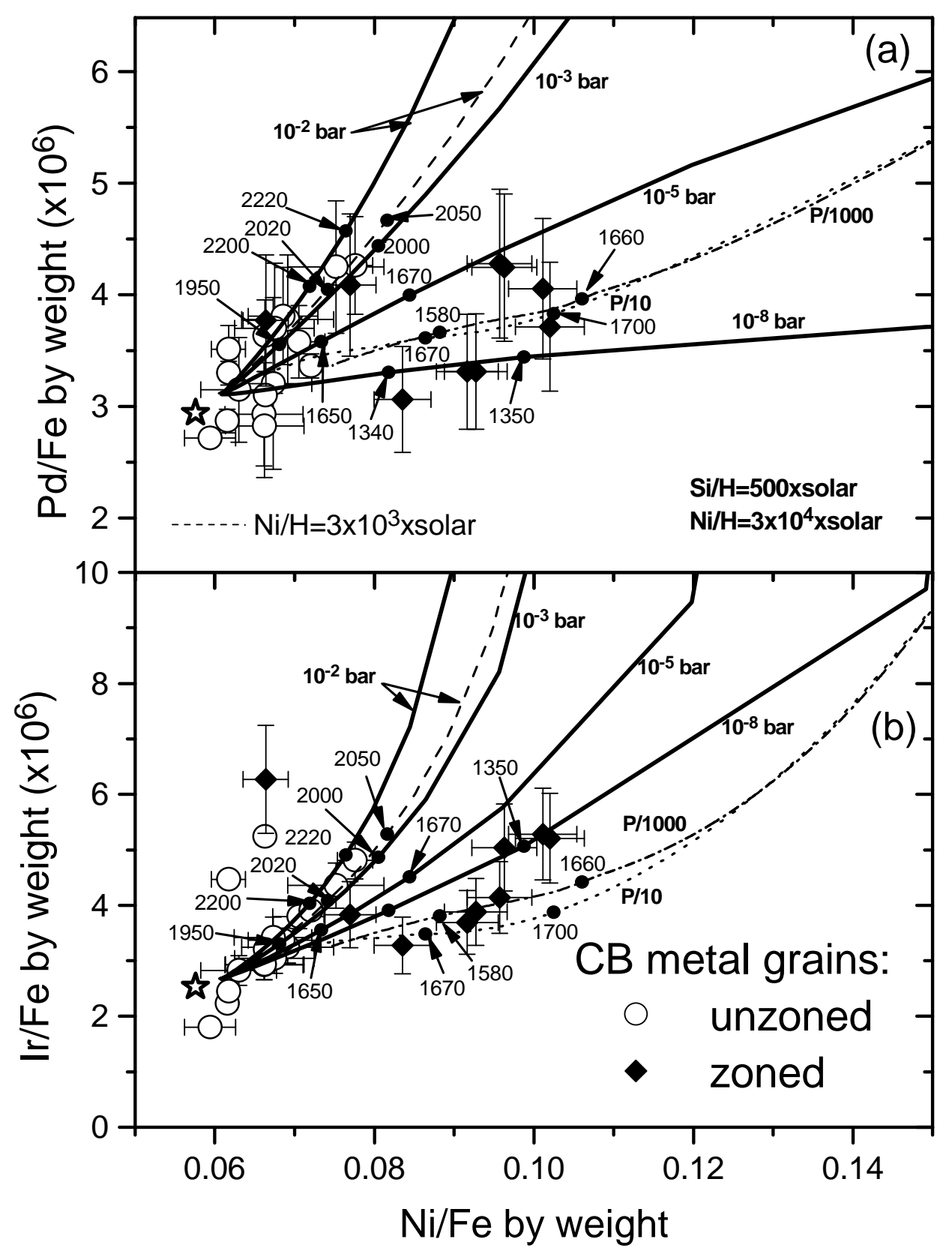

Fig.6 


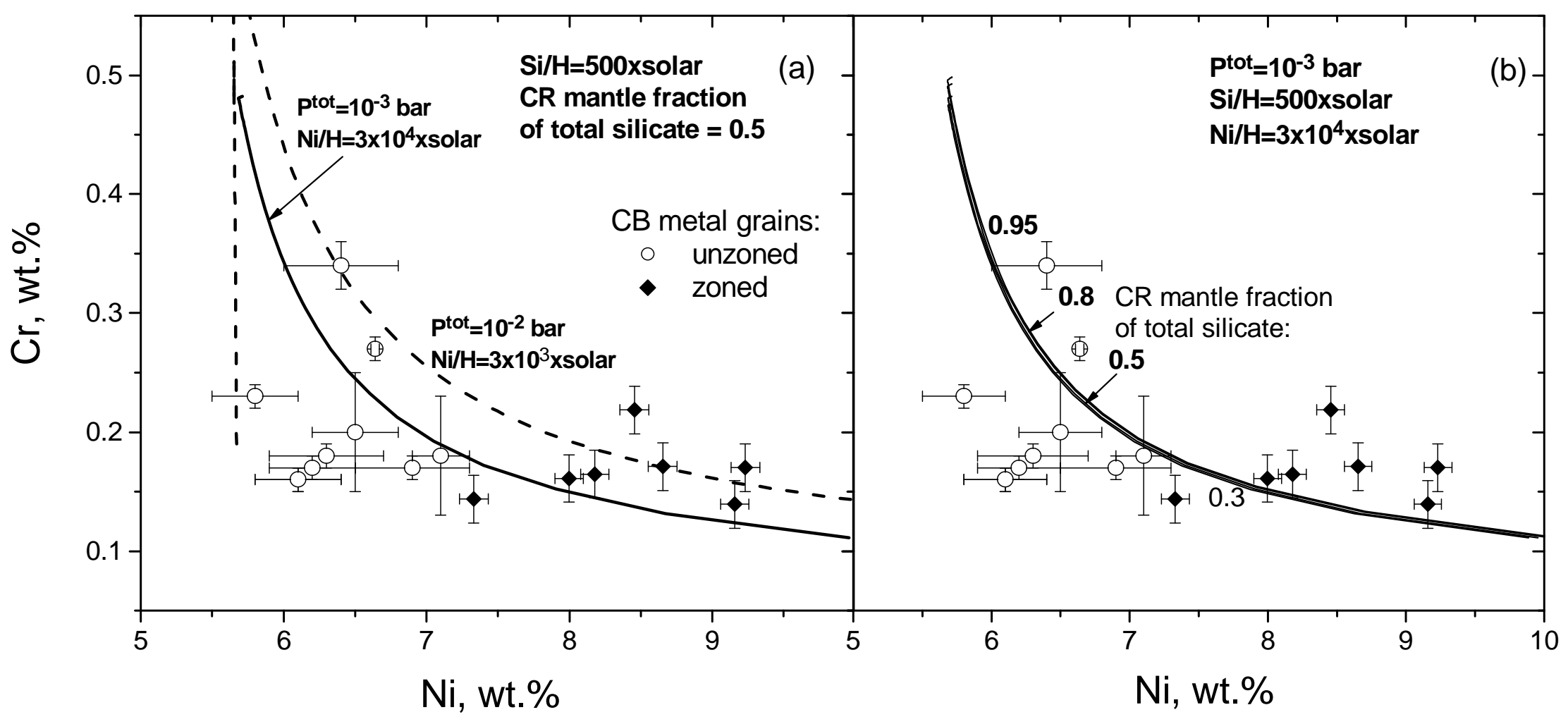

Fig. 7 


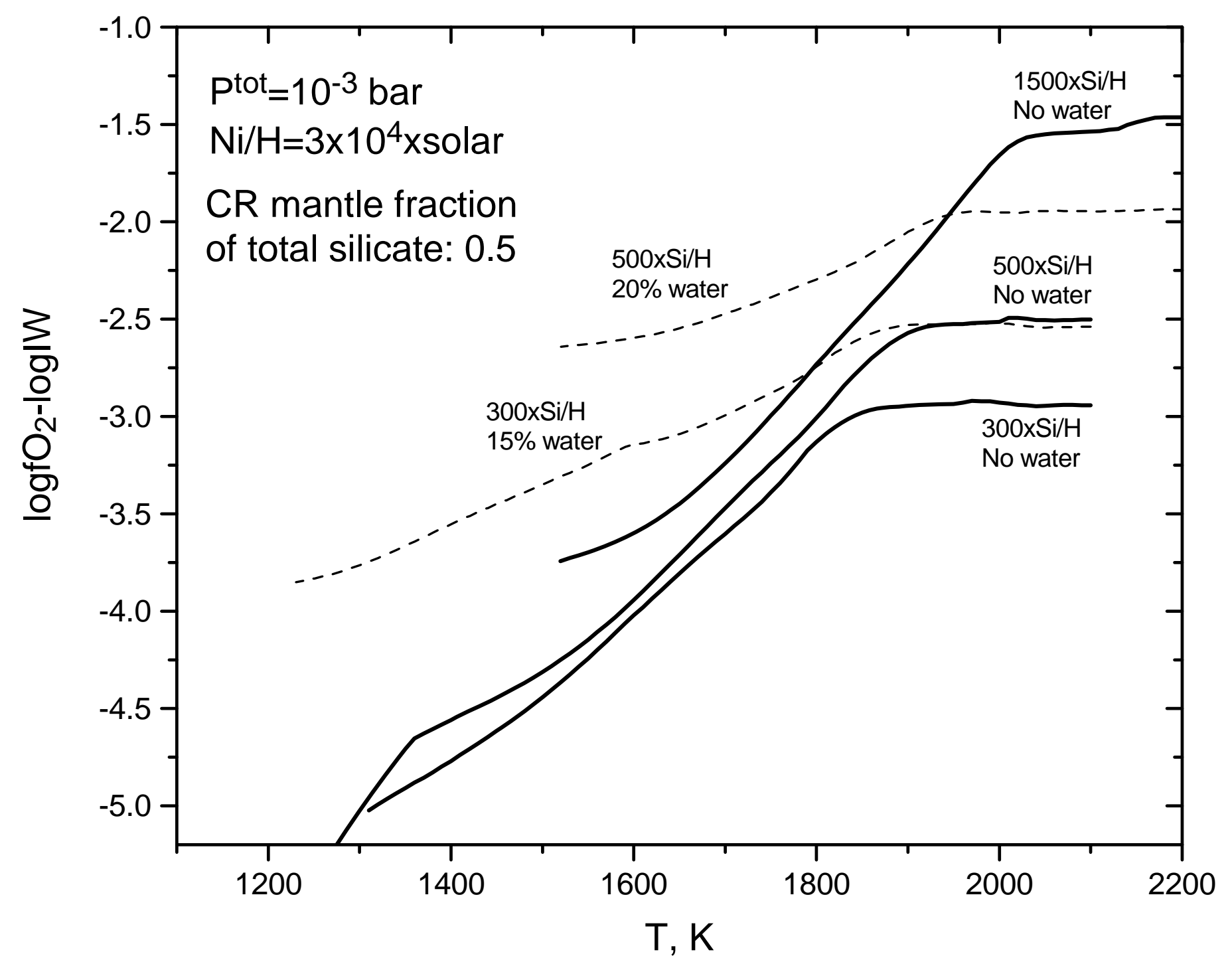

Fig. 8 


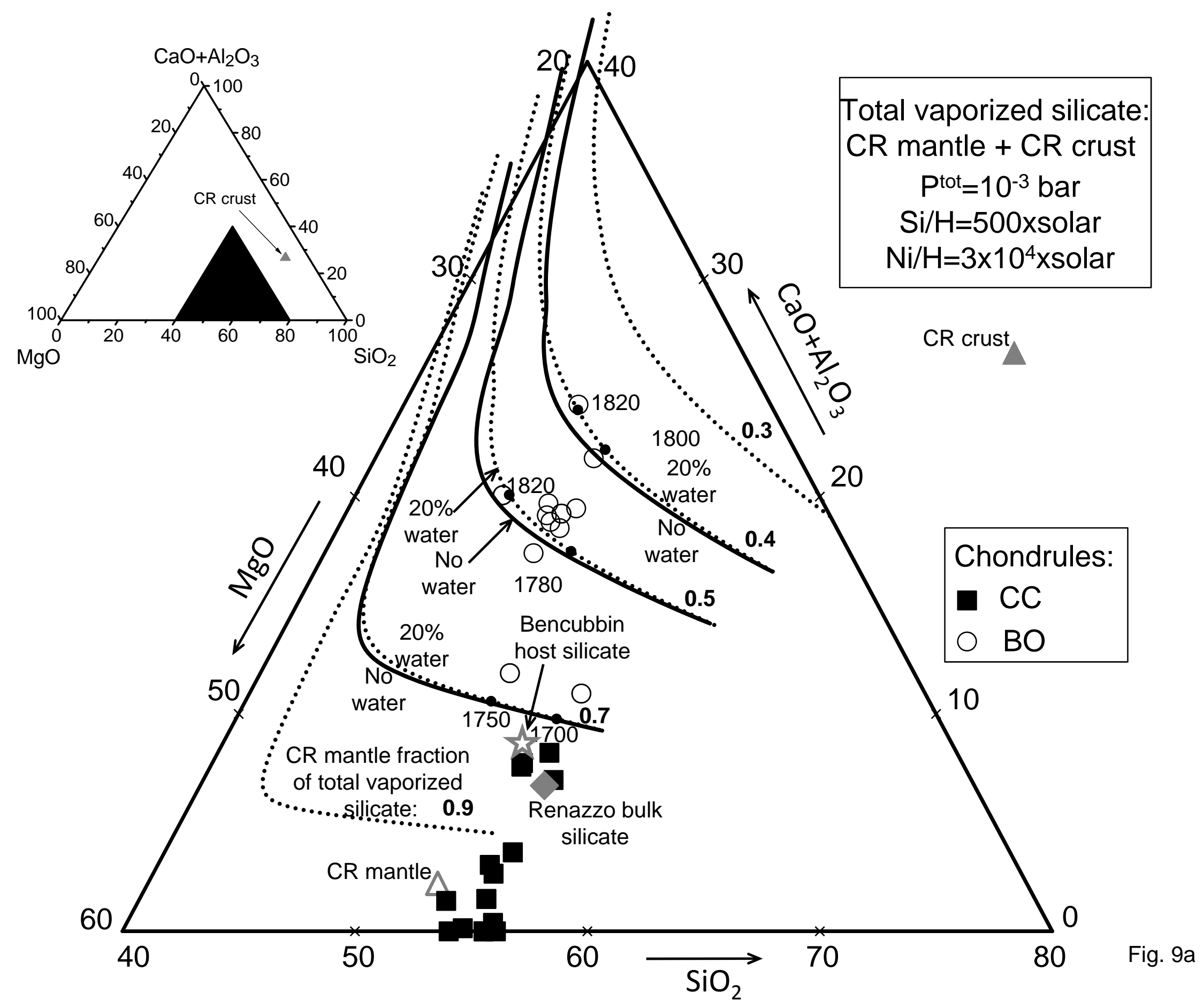




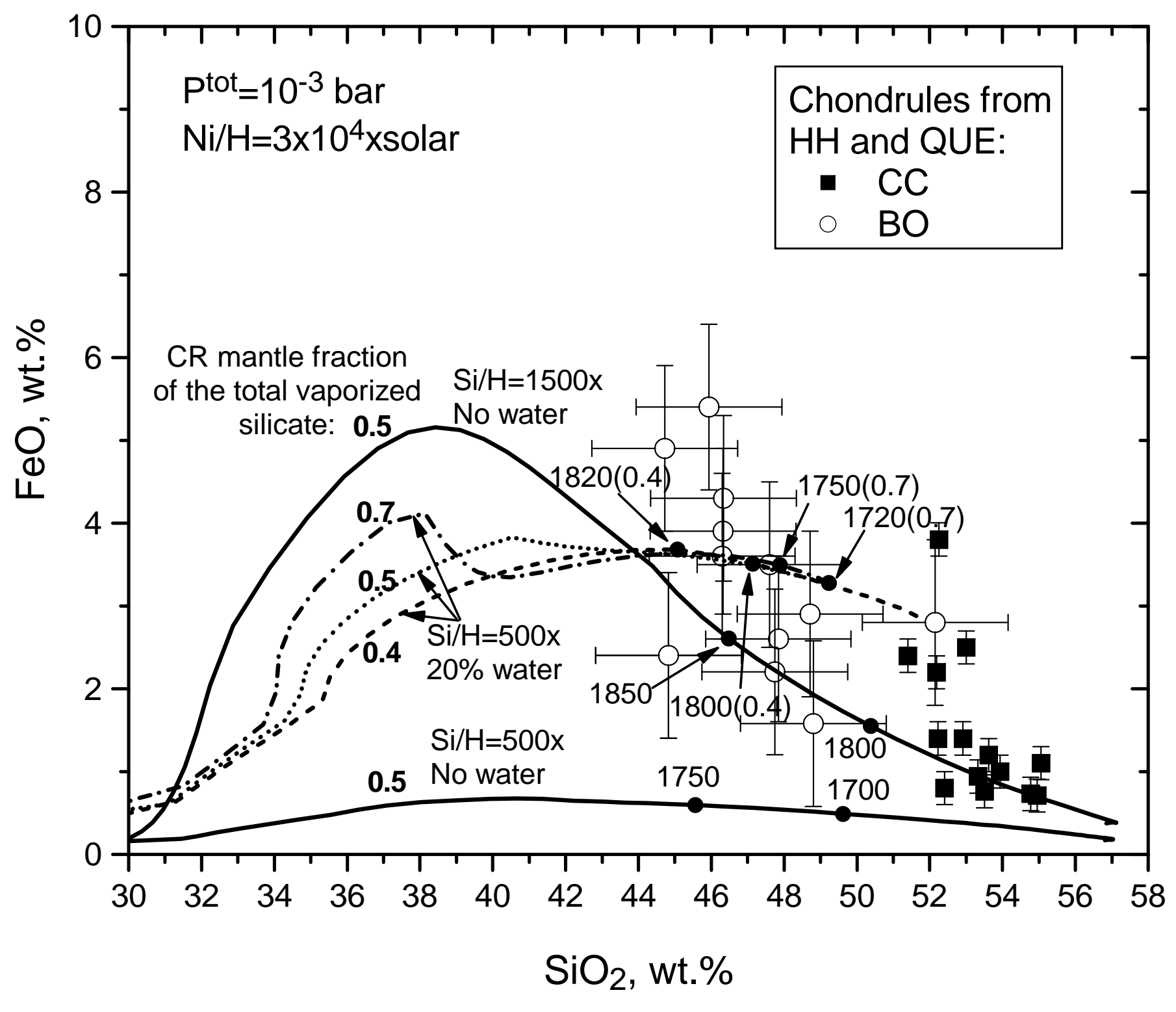

Fig. 9b 


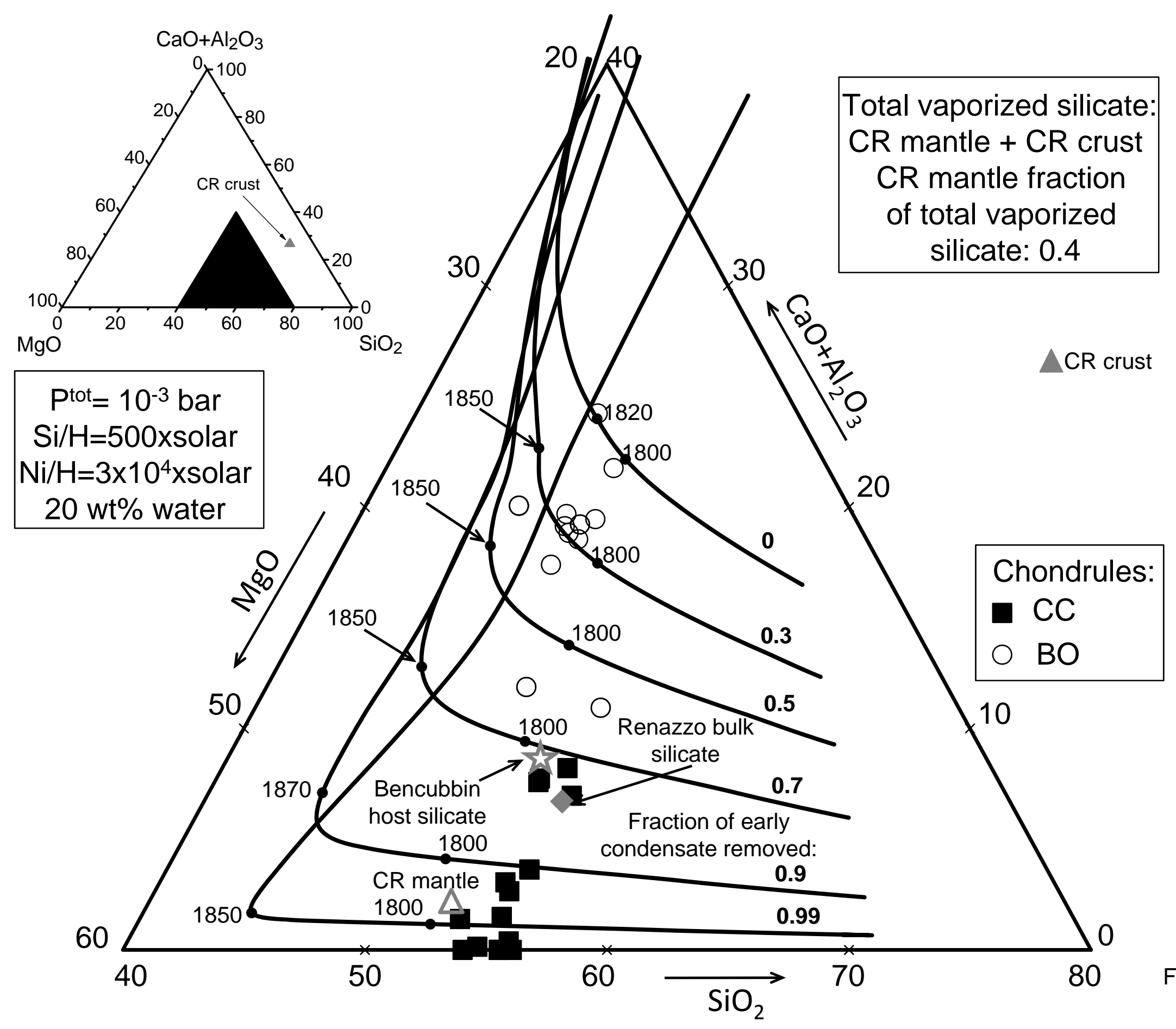

Fig. 10a 


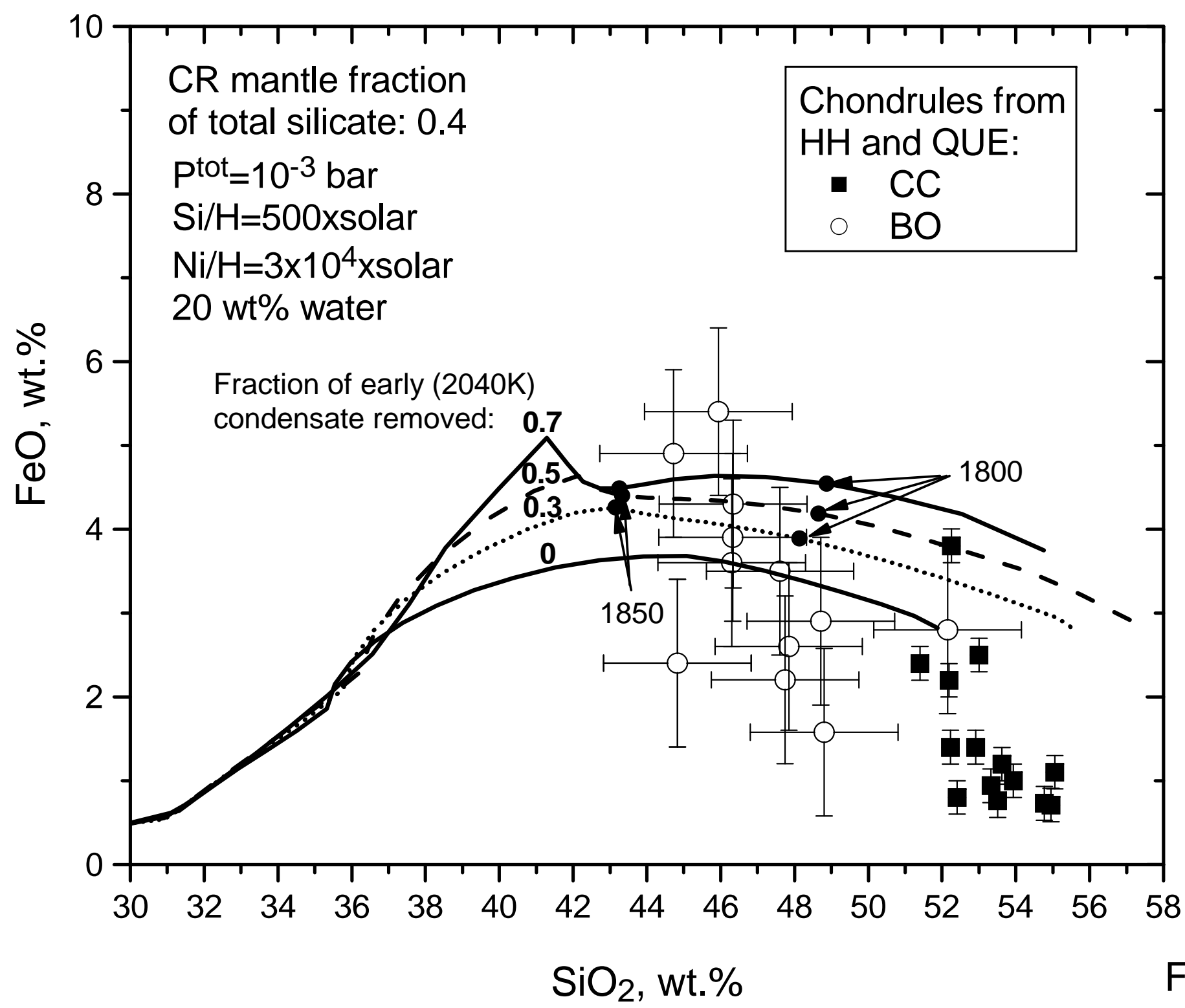

Fig. 10b 


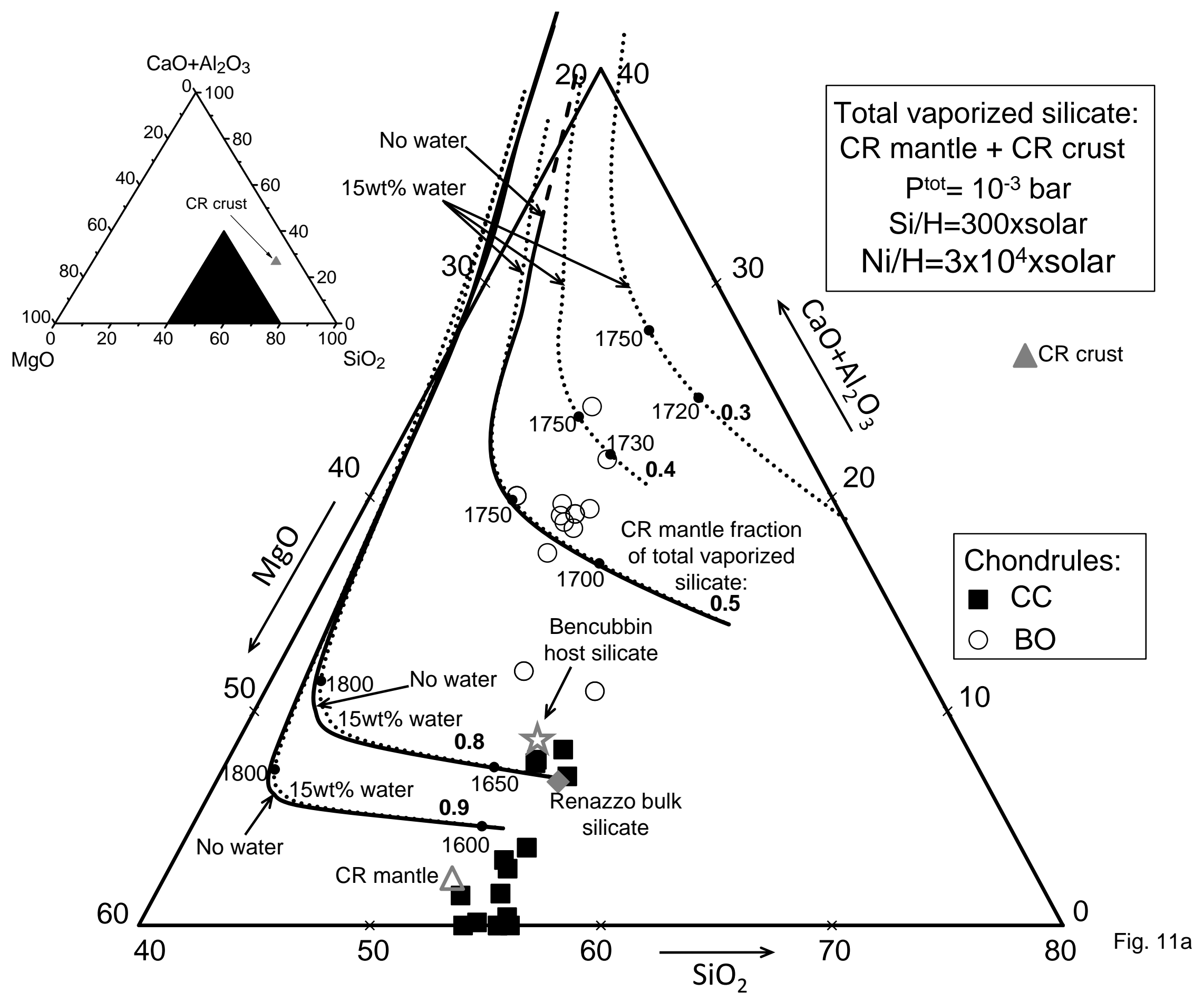




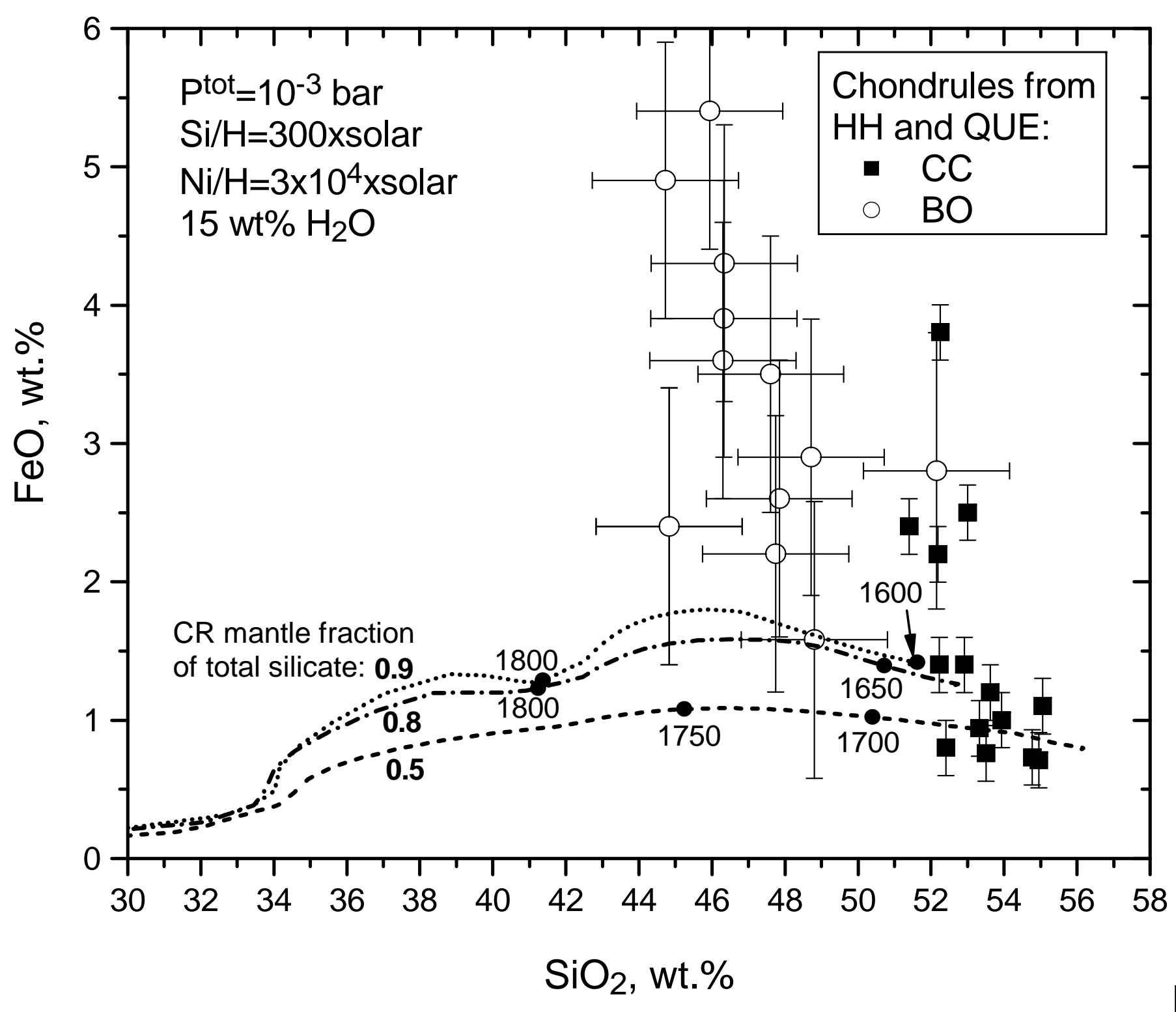

Fig. 11b 


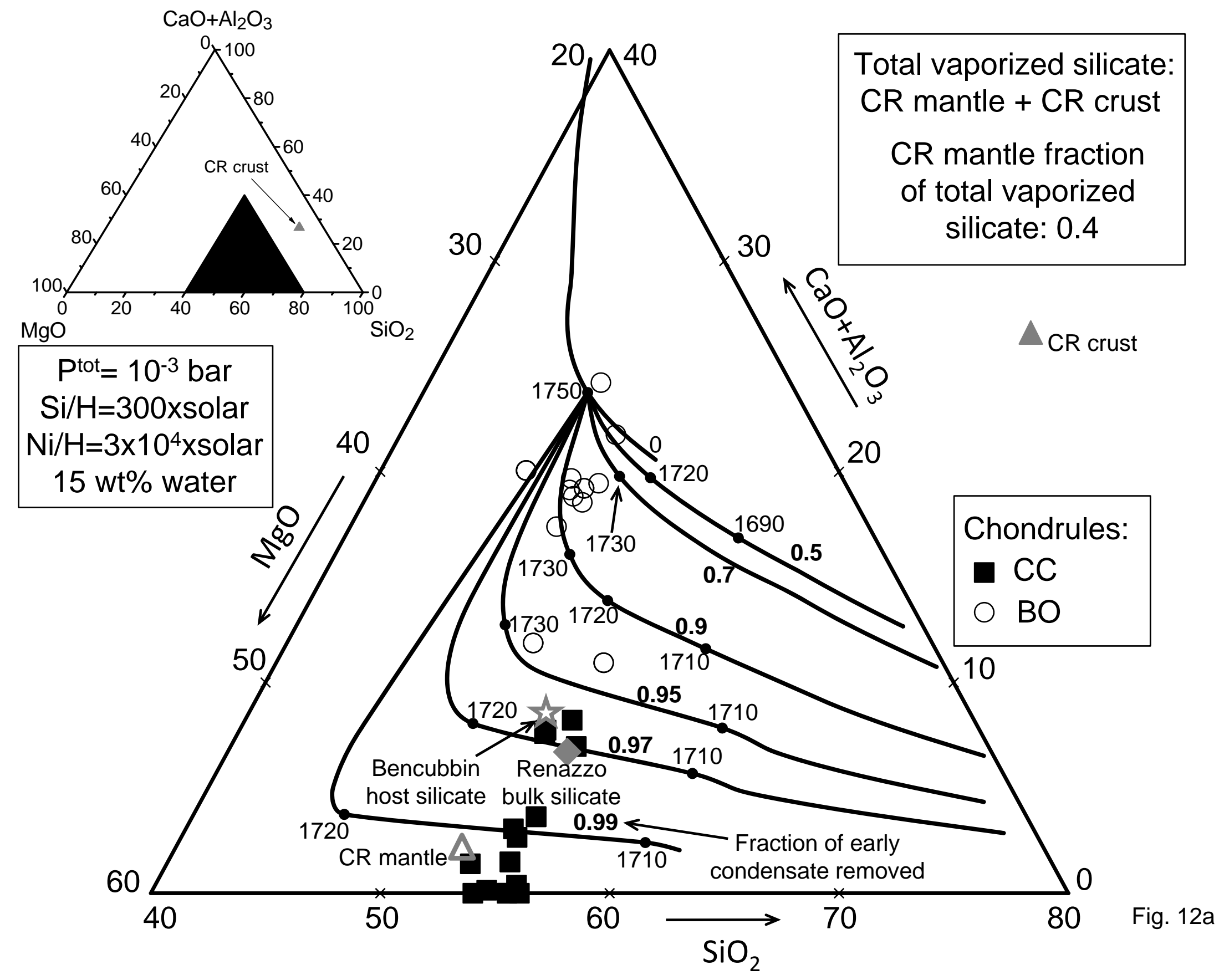




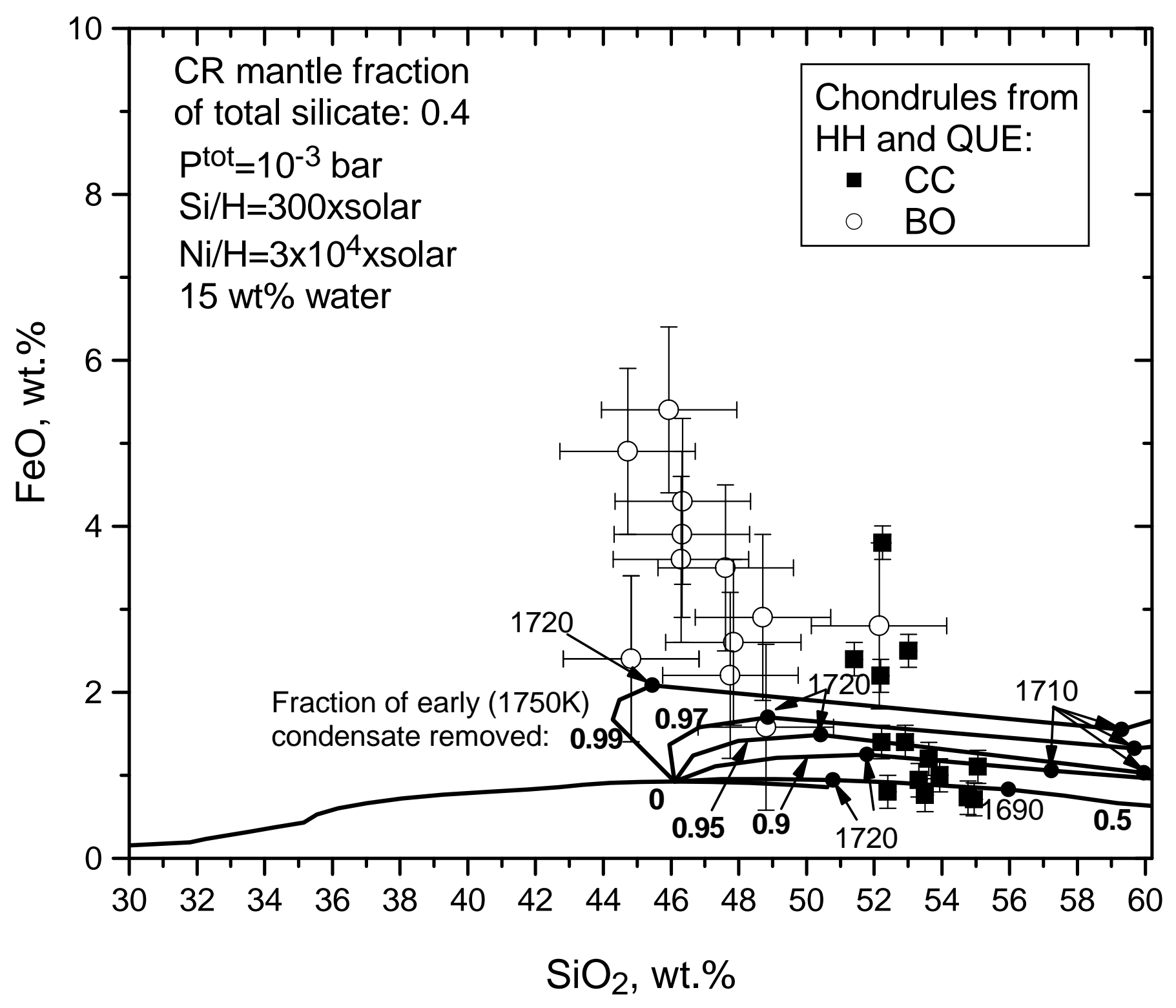

Fig. 12b 

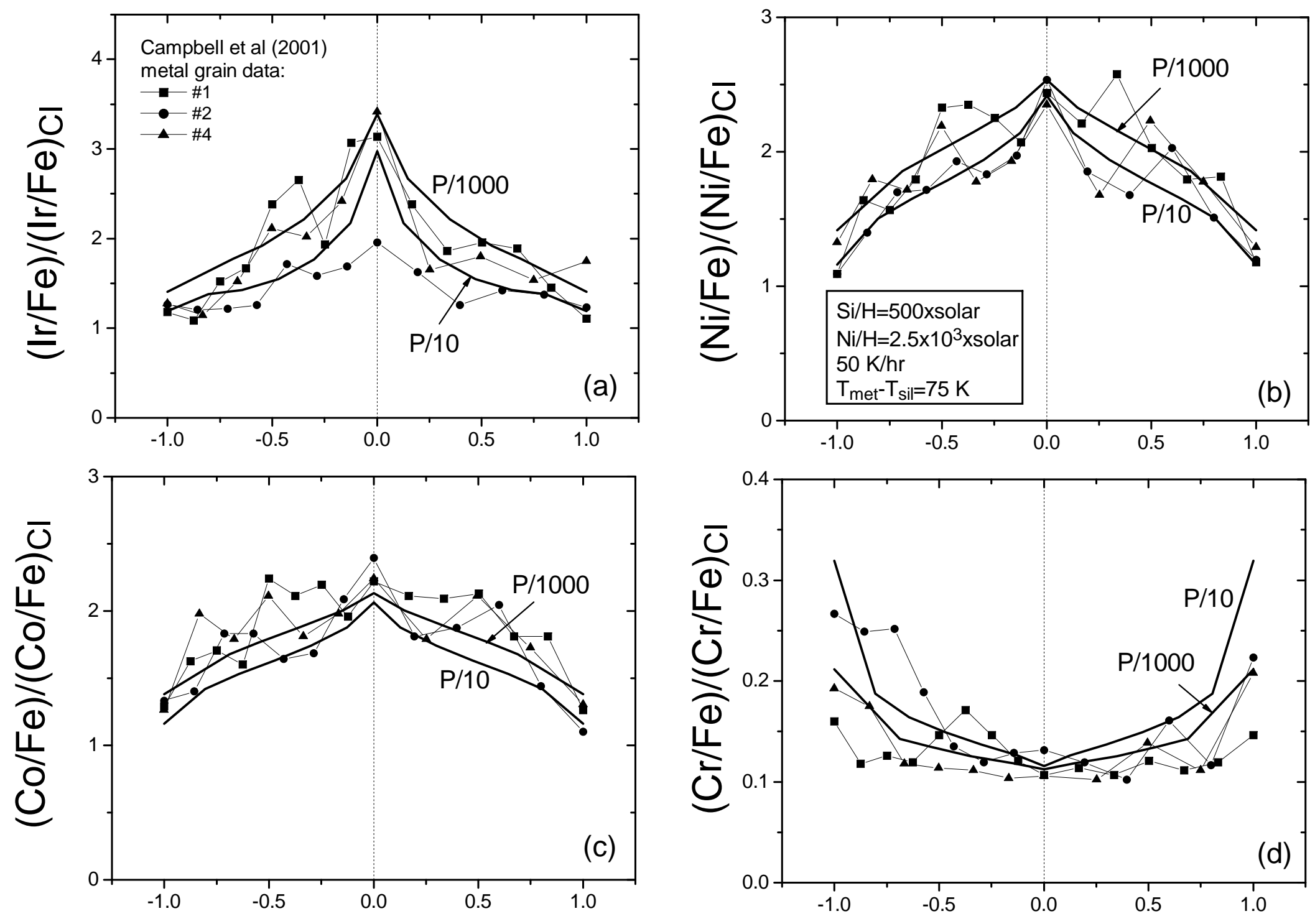

Fractional radius of the metal grain

Fig. 13 


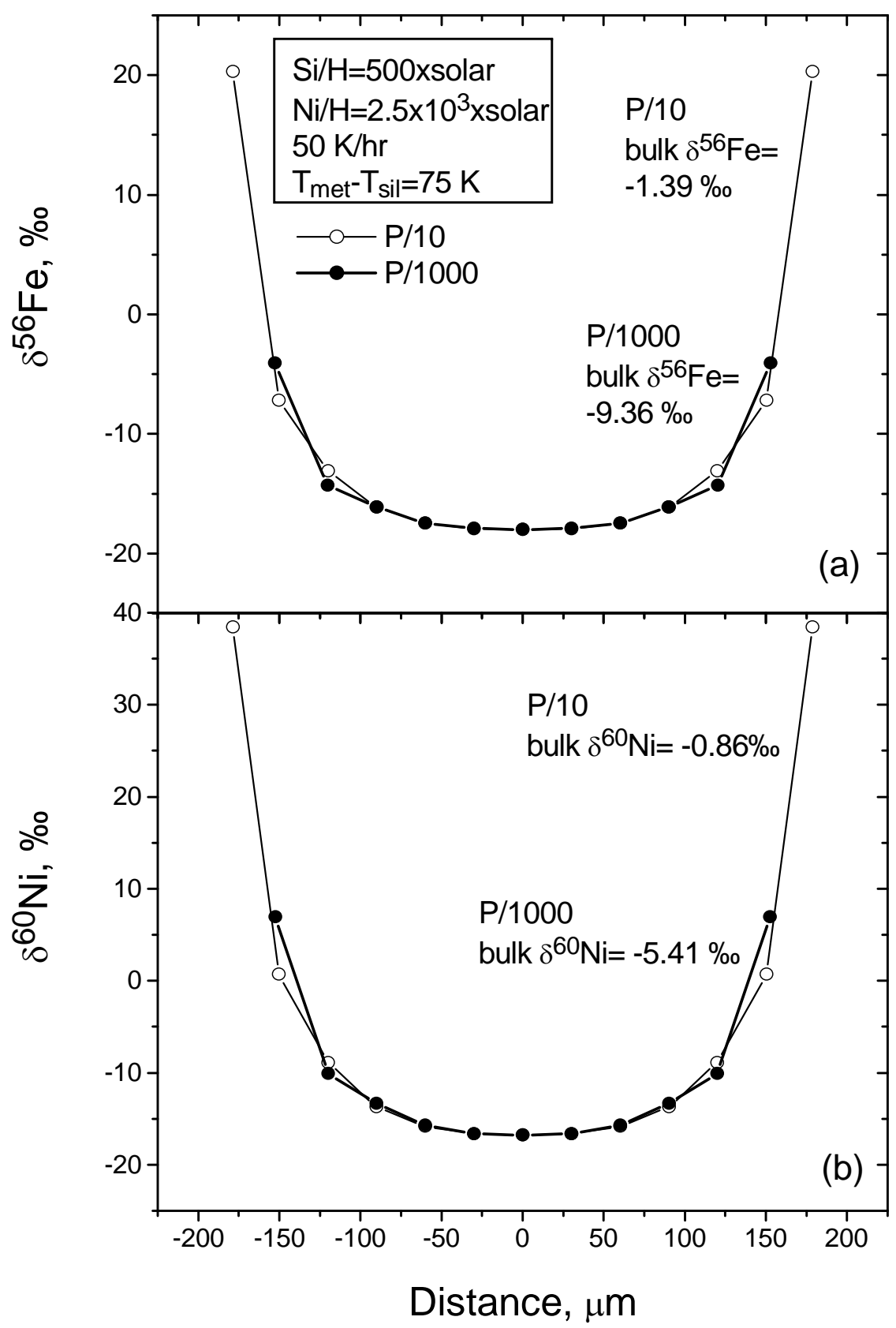

Fig. 14 